\title{
The Glenn T. Seaborg Institute for Transactinium Science 1997-1998 Activity Report
}

\author{
Louis J. Terminello
}

June 1999

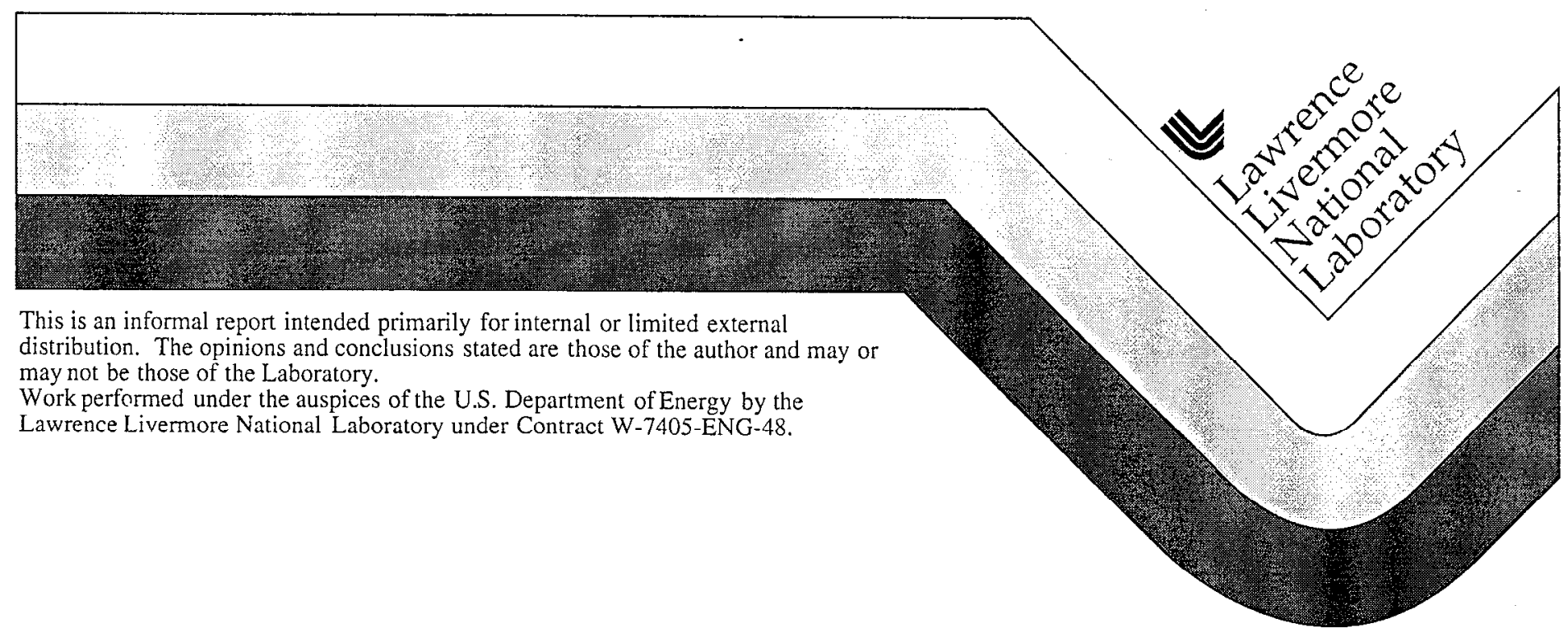




\section{DISCLAIMER}

This document was prepared as an account of work sponsored by an agency of the United States Government. Neither the United States Government nor the University of California nor any of their employees, makes any warranty, express or implied, or assumes any legal liability or responsibility for the accuracy, completeness, or usefulness of any information, apparatus, product, or process disclosed, or represents that its use would not infringe privately owned rights. Reference herein to any specific commercial product, process, or service by trade name, trademark, manufacturer, or otherwise, does not necessarily constitute or imply its endorsement, recommendation, or favoring by the United States Government or the University of California. The views and opinions of authors expressed herein do not necessarily state or reflect those of the United States Government or the University of California, and shall not be used for advertising or product endorsement purposes.

This report has been reproduced directly from the best available copy.

Available to DOE and DOE contractors from the Office of Scientific and Technical Information

P.O. Box 62, Oak Ridge, TN 37831

Prices available from (423) 576-8401

Available to the public from the National Technical Information Service

U.S. Department of Commerce 5285 Port Royal Rd. Springfield, VA 22161 


\section{ThE GLenN T. SEABorg InSTITUTE For TransaCTINIUM SCIENCE}

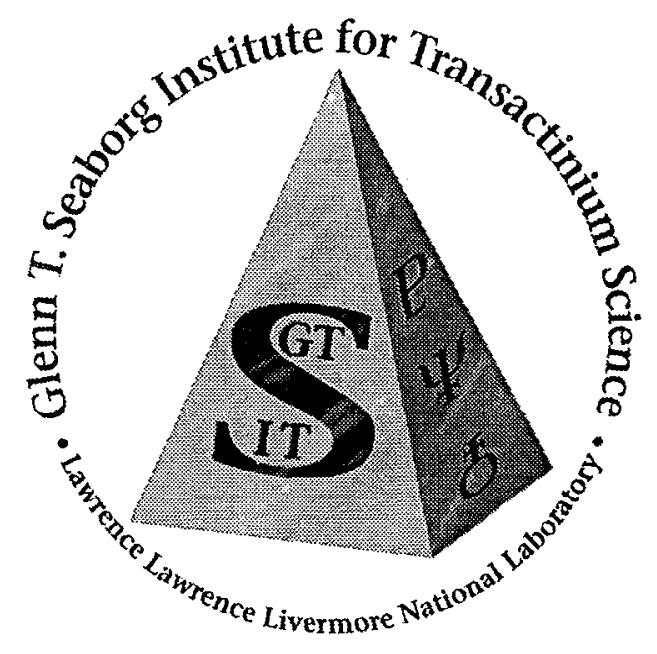

1997-98 ACTIVITY REPORT

Editor: Louis J. Terminello

Editorial Staff: Patrick Allen

Maureen Tortorelli

Kim Hallock 


\begin{tabular}{|c|c|c|c|c|c|c|c|c|c|c|c|c|c|c|}
\hline $\begin{array}{l}90 \\
\text { Th }\end{array}$ & $\begin{array}{l}91 \\
P_{2}\end{array}$ & 92 & $\begin{array}{l}93 \\
N_{I}\end{array}$ & $\begin{array}{r}94 \\
\mathrm{P}\end{array}$ & $\begin{array}{r}95 \\
A\end{array}$ & n & $\begin{array}{l}6 \\
\mathrm{Cm}\end{array}$ & $\begin{array}{l}97 \\
\text { BLK }\end{array}$ & ${ }^{98}$ & 99 & $\begin{array}{c}10 \\
F\end{array}$ & $\begin{array}{c}101 \\
\mathrm{M}\end{array}$ & $\begin{array}{r}10 \\
1\end{array}$ & $\begin{array}{c}103 \\
\mathrm{Lr}\end{array}$ \\
\hline
\end{tabular}

TABLE OF CONTENTS

SECTION 1: OVERVIEW

SECTION 2: ProjeCt REPORTS

Program Funded Projects

Development of a Laser-Induced Breakdown System for Colloid Characterization in Dilute Aqueous Suspensions

Will Crystalline $\mathrm{NpO} 2$ precipitate from a Near-Neutral

Aqueous Solution of $\mathrm{NpO} 2+$ ?

Oscillatory Extraction of Cerium and Uranium

Thermodynamics of the Volatilization of Actinides Metals in the High-Temperature Treatment of Radioactive Wastes

The Sorption of Uranium and Neptunium onto Cementitious Materials 19

Evaluation and Testing of Sequestering Agents for the

Removal of Actinides from Waste Streams

LDRD Funded PROJECTS

Towards a Rational Nuclear Materials Management

Removal of Actinide Ions by Colloid Enhanced Ultrafiltration

Theoretical Chemistry of the Actinides and Transactinides

Amarillo National Resource Center for Plutonium (ANRCP):

Research and Education Program 


\begin{tabular}{|c|c|c|c|c|c|c|c|c|c|c|c|c|c|c|}
\hline 104 & 105 & 106 & 107 & 108 & 109 & 110 & 111 & 112 & (113) & (114) & (115) & (116) & (117) & (118) \\
\hline Rf & Ha & Sg & Ng & Hs & Mt & & & & & &
\end{tabular}

TABLE OF CONTENTS

SECTION 3:PERSONNEL 41

$\begin{array}{ll}\text { Organizational Chart } & 41\end{array}$

$\begin{array}{ll}\text { Patrick Allen } & 42\end{array}$

Udeni Dharmawardana $\quad 43$

Nadia Hakem 44

Darleane Hoffman $\quad 45$

Clinton Nash $\quad 46$

Heino Nitsche $\quad 47$

Cynthia Palmer $\quad 48$

Joe Peterson $\quad 49$

Vadim Romanovski $\quad 50$

Louis Terminello $\quad 51$

Pihong Zhao $\quad 52$

Section 4: Actinide Science Summer School Program 53

David Bao $\quad 54$

Andy Boswell $\quad 55$

Jeff Grell $\quad 56$

Bill Huston $\quad 57$

Megan Leich $\quad 58$

Jason Lowe $\quad 59$

David Schnepple $\quad 60$

Mark Sutton 61

SECTION 5: PUBLICATIONS 63

SeCtion 6: Presentations 67 


\begin{tabular}{|l|l|l|l|l|l|l|l|l|l|l|l|l|l|}
\hline 90 & 91 & 92 & 93 & 94 & 95 & 96 & 97 & 98 & 99 & 100 & 101 & 102 & 103 \\
Th & Pa & U & Np & Pu & Am & Cm & Bk & Cf & Es & Fm & Md & No & Lr \\
\hline
\end{tabular}

OVERVIEW

\section{SECTION 1: OVERVIEW}

\section{HISTORY}

The Glenn T. Seaborg Institute for Transactinium Science (GTS-ITS) was established in 1991 when the University of California approved a joint Lawrence Livermore National Laboratory (LLNL)/Lawrence Berkeley National Laboratory (LBNL) Institute Charter. The GTS-ITS is centered at LLNL, in Livermore, CA. In 1997, a branch was established at Los Alamos National Laboratory (LANL). The GTS-ITS was established to foster the fundamental and applied science and technology of the transactinium elements. Professor Darleane C. Hoffman served as the charter Director of the GTS-ITS from $1992-1996$.

GTS-ITS 's mission is to provide a focus for transactinium science to maintain and enhance US leadership in this science and technology, and to help provide the required pool of scientists and engineers with the quality and breadth to meet the changing national and international needs in the future.

GTS-ITS specializes in the education and training of the future generation of scientists with the knowledge and expertise required to meet the nation's changing needs in:

- Environmental protection and remediation;

- Nuclear waste isolation and disposition;

- National Security and policy;

- Energy; and

- Transactinium metallurgy, physics, and chemistry.

The GTS-ITS operates under the Chemistry and Materials Science Directorate, with its administrative offices, staff and laboratories are located in Building 151. Administrative staff include: Dr. Louis J. Terminello is the Institute Director, Dr. Cynthia Palmer, Deputy Director; and Maureen Tortorelli, Administator.

The Institute was named in honor of Professor Glenn T. Seaborg in recognition of enormous contributions to the field, to science education, and to the many years of service he contributed to the University of California. 


\begin{tabular}{|c|c|c|c|c|c|c|c|c|c|c|c|c|c|c|}
\hline $\begin{array}{c}104 \\
\text { Rf }\end{array}$ & $\begin{array}{c}105 \\
\mathrm{Ha}\end{array}$ & $\begin{array}{r}106 \\
\text { Sg }\end{array}$ & $\begin{array}{c}107 \\
N_{s}\end{array}$ & $\begin{array}{c}108 \\
\mathrm{H}_{8}\end{array}$ & $\begin{array}{c}109 \\
\mathrm{Mt}\end{array}$ & 110 & 111 & 112 & (113) & (114) & (115) & (116) & (117) & (118) \\
\hline
\end{tabular}

\section{OVERVIEW}

\section{MISSION}

- Provide educational and research learning opportunities in transactinium science for practioners of all levels, including undergraduate and graduate students, postdoctoral fellows and other professionals.

- Establish collaborations in transactinium science with academia, national laboratories, and industry.

- Provide US leadership in transactinium science.

The GTS-ITS mission supports the long-term manpower and core competency needs of the defense-related and the environmental programs at LLNL. The importance of the GTS-ITS mission is intensified by the current and impending shortage of actinide experts. This sector continues to retire, leaving ever-widening gaps in the core capabilities of the programs and disciplines throughout the Laboratory and the nation. The GTS-ITS focus is to help the Laboratory fill these voids by educating and training the future generation of scientists with the knowledge and expertise required to meet the nation's changing needs in environmental protection and remediation, nuclear waste isolation, national security nuclear surveillance, nuclear energy and industrial applications of nuclear methods, and fundamental transactinium sciences.

\section{OPPORTUNITIES}

- Education \& training programs.

- Networking capabilities with universities, other national laboratories, and industry.

- Workshops, training seminars, summer school program \& educational opportunities.

- Up-to-date information on transactinide research.

- Access to unique and specialized equipment and research facilities.

- Diverse expertise of LLNL staff members.

- A focal point for interactions with the international community of transactinium scientists.

- Independent review, assessment, and evaluation of environmental safety and disposal issues involving transactinide elements.

- Extensive facilities for transactinium research.

\section{EQUIPMENT AND FACILITIES}

\section{UV-VIS NIR Optical Absorption}

- Spectrometors

Dual Beam

Fiber Optic Wave Guides

- State-of-the-Art Laser Systems 


\begin{tabular}{|l|l|l|l|l|l|l|l|l|l|l|l|l|l|}
\hline 90 & 91 & 92 & 93 & 94 & 95 & 96 & 97 & 98 & 99 & 100 & 101 & 102 & 103 \\
Th & $\mathrm{Pa}_{2}$ & $\mathrm{U}$ & $\mathrm{Np}$ & $\mathrm{Pu}$ & $\mathrm{Am}$ & $\mathrm{Cm}$ & $\mathrm{Bk}$ & $\mathrm{Cf}$ & $\mathrm{Es}$ & $\mathrm{Fm}$ & $\mathrm{Md}$ & $\mathrm{No}$ & $\mathrm{Lr}$ \\
\hline
\end{tabular}

OVERVIEW

Pulsed Nd-YAG Pumped Dye

Pumped Optical Paramagnetic

Oscillator

Excimer

- Advanced Laser Spectroscopic Techniques

Photoacoustic

Thermal Lensing

Fourier Transform Infrared

- Radiation Analysis Equipment

Alpha Solid-state Spectrometers

Intrinsic Germanium Gamma-ray Spectrometers

Liquid Scintillation Systems

\section{Scanning Electron Microscopes}

- Instrumentation \& Beam Lines:

LBNL 88-inch Cyclotron

- Characterization Facilities:-

LBNL Advanced Light Source

Stanford Synchroton Radiation Laboratory

\section{HOSTED}

- Twenty-five national and international particpating guest scientists

- Twenty seminars

- Fifteen presentations/posters at national/international conferences

- Nine student participating guests

- Actinide Sciences Summer School Program 


\begin{tabular}{|c|c|c|c|c|c|c|c|c|c|c|c|c|c|c|}
\hline $\begin{array}{c}104 \\
\text { Rf }\end{array}$ & $\begin{array}{c}105 \\
\mathbf{H a}\end{array}$ & $\begin{array}{r}106 \\
S_{8}\end{array}$ & $\begin{array}{c}107 \\
\mathrm{No}\end{array}$ & $\begin{array}{c}108 \\
\mathrm{H}_{8}\end{array}$ & $\begin{array}{c}109 \\
\mathrm{M}\end{array}$ & 110 & 111 & 112 & (113) & (116) & (115) & (116) & (117) & (118) \\
\hline
\end{tabular}

OVERVIEW

\section{CORE CAPABILITIES}

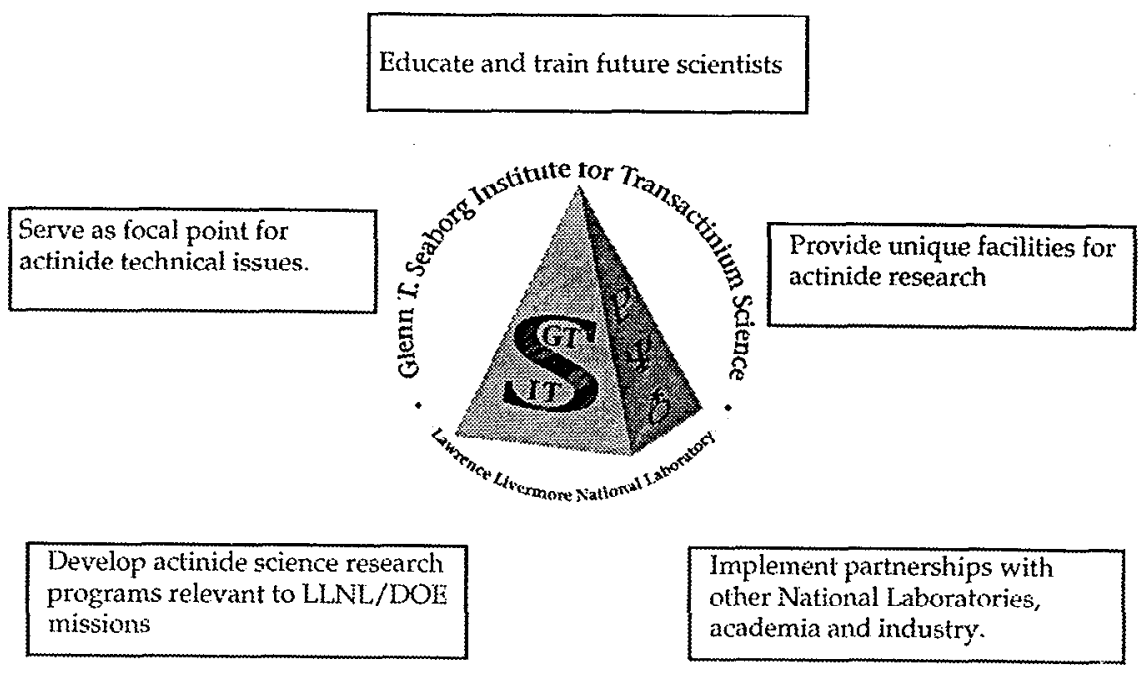




\begin{tabular}{|c|c|c|c|c|c|c|c|c|c|c|c|c|c|}
\hline $\begin{array}{l}90 \\
\text { Th }\end{array}$ & $\mid \begin{array}{l}91 \\
\mathbf{P a}_{2}\end{array}$ & $\int^{92} \mathrm{U}$ & $\begin{array}{l}93 \\
\mathrm{~Np}\end{array}$ & $\mid \begin{array}{l}94 \\
\mathbf{P u}\end{array}$ & $\begin{array}{l}95 \\
\text { Am }\end{array}$ & $\stackrel{96}{\mathrm{Cm}}$ & $\begin{array}{l}97 \\
\text { Bk }\end{array}$ & ${ }^{98} \mathrm{Cf}$ & $\begin{array}{l}99 \\
\text { Es }\end{array}$ & $\begin{array}{c}100 \\
\mathbf{F m}\end{array}$ & $\begin{array}{l}101 \\
\text { Md }\end{array}$ & $\begin{array}{c}102 \\
N_{0}\end{array}$ & $\begin{array}{c}103 \\
\mathrm{Lr}\end{array}$ \\
\hline
\end{tabular}

PROJECT REPORTS

\section{SECTION 2: PROJECT REPORTS}

\section{PROGRAM FUNDED PROJECTS}

\section{Development of a Laser-Induced Breakdown System for Colloid Characterization in Dilute Aqueous Suspensions}

Axel Brachmann

GTS-ITS, Lawrence Livermore National Laboratory

David A. Wruck

Analytical and Nuclear Chemistry Division, Lawrence Livermore National Laboratory

\section{Introduction}

Colloids play an important role in the migration of contaminants in natural waters. Colloidal transport is particularly important for "nonconservative" elements such as rare earths and actinides. These elements may form intrinsic hydrous oxide colloids or be strongly bound to natural organic or silicate colloids.

One component to assessing colloidal transport in a particular natural water is an analysis of the number, size distribution and composition of the native colloidal particles. In groundwater systems the colloid concentrations may lie below the detection limits of common sizing techniques such as light scattering. Thus we are investigating a colloid detection and sizing method based on laserinduced breakdown which is appropriate for dilute aqueous suspensions and allows direct analysis of groundwater samples $(/ 1 /, / 2 /, / 3)$. The following is a brief description of the instrumentation and the results obtained with standard particles.

\section{Experimental Methods}

Figure 1 depicts the experimental setup. The excitation source is the sccond harmonic $(532 \mathrm{~nm}$ wavelength) of a $10 \mathrm{~Hz}$ pulsed Nd:YAG laser. A stepptor-controlled attenuator allows the adjustment of the applied laser energy. A beamsplitter reflects 


\begin{tabular}{|c|c|c|c|c|c|c|c|c|c|c|c|c|c|c|}
\hline 104 & 105 & 106 & 107 & 108 & 109 & 110 & 111 & 112 & (113) & (114) & (115) & $(116)$ & $(117)$ & (118) \\
\hline Rf & $\mathrm{Ha}$ & $\mathrm{Sg}$ & $\mathrm{Ns}$ & $\mathrm{Hs}$ & $\mathrm{Mt}$ & & & & &
\end{tabular}

\section{PROJECT REPORTS}

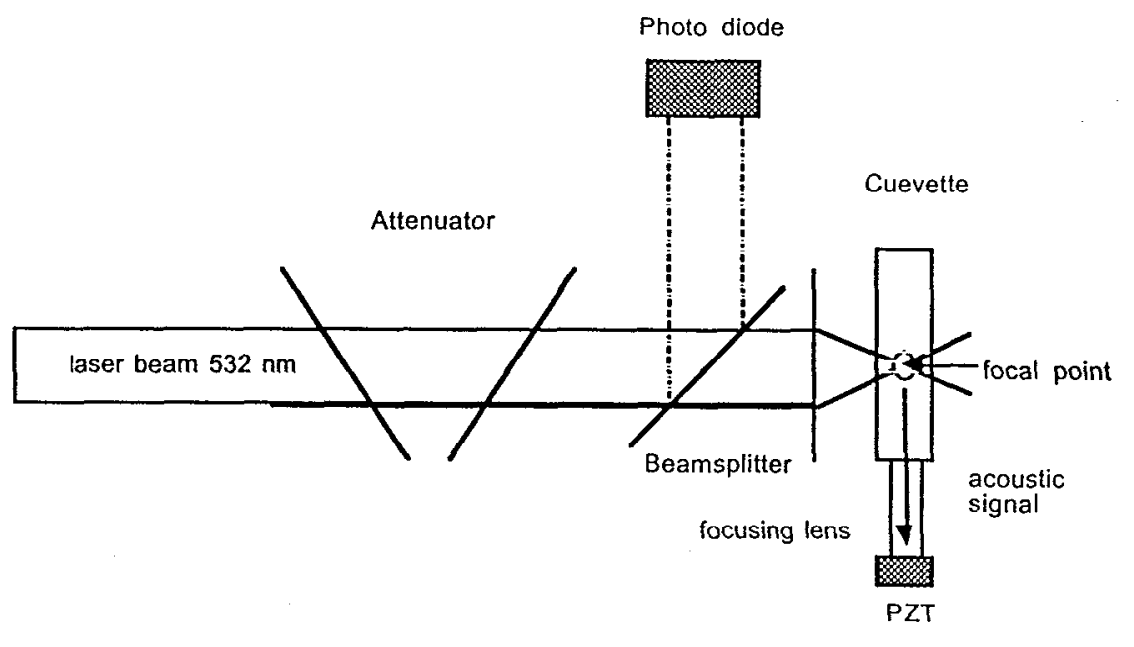

FIGURE Fig.1 : Scheme of experimental setup

a small fraction of the laser beam onto a photodiode to measure the laser pulse energy. The beam is then focussed into the sample cuvette.

The light intensity in the focal region is adjusted to the threshold region for laser-induced dielectric breakdown in the sample. The process is initiated at colloidal particles in the focal volume, because breakdown thresholds in neat water or any gas bubbles are significantly higher. Breakdown results in plasma generation and an acoustic shock wave in the liquid. A piezoelectric transducer (PZT) transforms the acoustic pulse into an electrical signal.

The output of the photodiode and PZT are measured using a boxcar system in a time resolved mode. The breakdown probability at a given laser energy is determined by sampling 250 to 1000 laser shots. Under these conditions standard deviations lower than 5 percent are achieved.

\section{Results}

Polystyrene standard particles with diameters from $20 \mathrm{~nm}$ to $895 \mathrm{~nm}$ were used for testing and calibration of the method. As an example the breakdown probability curves for $496 \mathrm{~nm}$ polystyrene particles are shown in figure 2. 


\begin{tabular}{|c|c|c|c|c|c|c|c|c|c|c|c|c|c|}
\hline 90 & 91 & 92 & 93 & 94 & 95 & 96 & 97 & 98 & 99 & 100 & 101 & 102 & 103 \\
Th & Pa $_{2}$ & U & Np & Pu & Am & Cm & Bk & Cf & Es & Fm & Md & No & Lr \\
\hline
\end{tabular}

PROJECT REPORTS

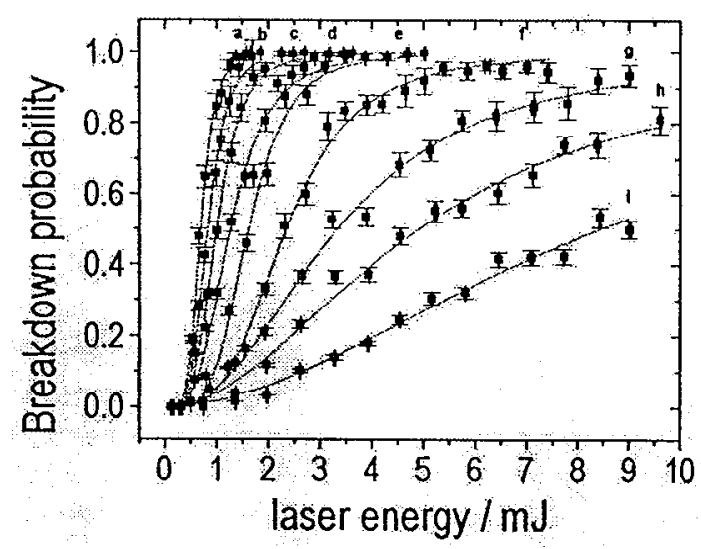

FIGURE Fig. 2: Breakdown Probability as a function of particle number and laser energy for polystyrene standard particles $\mathrm{d}=496 \mathrm{~nm}$ ([particle $/ \mathrm{mL}$ ] from a to i: $1.5 \mathrm{E}+8,7.5 \mathrm{E}+7,3.8 \mathrm{E}+7$, $1.9 \mathrm{E}+7,9.4 \mathrm{E}+6,4.7 \mathrm{E}+6,2.3 \mathrm{E}+6,1.2 \mathrm{E}+6,2.9 \mathrm{E}+5)$

The breakdown probability $y$ is related to the laser pulse energy $x$ by the empirical function:

$$
y=x n /(k n+x n)
$$

The parameter $k$ determines the laser energy at a breakdown probability of 0.5 and is used to characterize the sample.

Figure 3 depicts the laser energy at a breakdown probability of 0.5 for standard polystyrene particles. The curve for the $895 \mathrm{~nm}$ particles increases at higher concentrations due to the effects of light scattering by the particles.

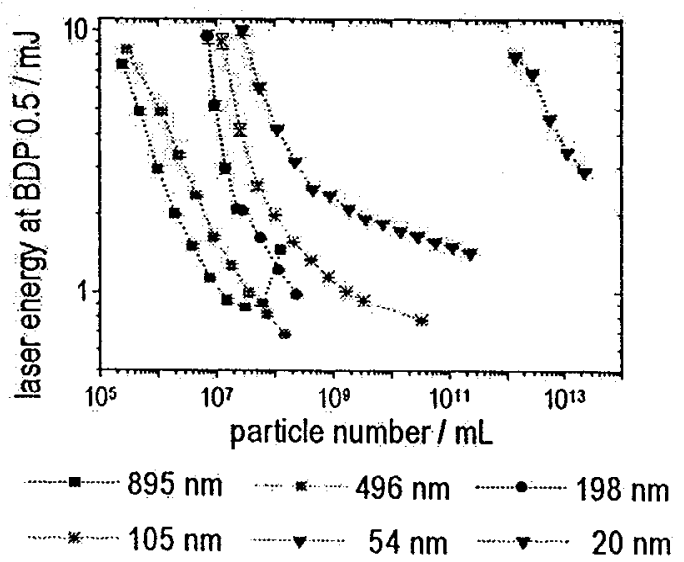

FIGURE Fig. 3: laser energy at $50 \%$ breakdown probability as a function of the particle concentration 


\begin{tabular}{|c|c|c|c|c|c|c|c|c|c|c|c|c|c|c|}
\hline 104 & 105 & 106 & 107 & 108 & 109 & 110 & 111 & 112 & (113) & (114) & $(115)$ & $(116)$ & (117) & (118) \\
\hline Rf & $\mathrm{Ha}$ & $\mathrm{Sg}$ & $\mathrm{Ng}$ & $\mathrm{Hs}$ & $\mathrm{Mt}$ & & & & &
\end{tabular}

\section{PROJECT REPORTS}

Figure 4 shows that detection limits for particle concentrations are improved by about 2 orders of magnitude compared to a commercial light scattering instrument and are at levels appropriate to direct particle sizing in groundwater samples.

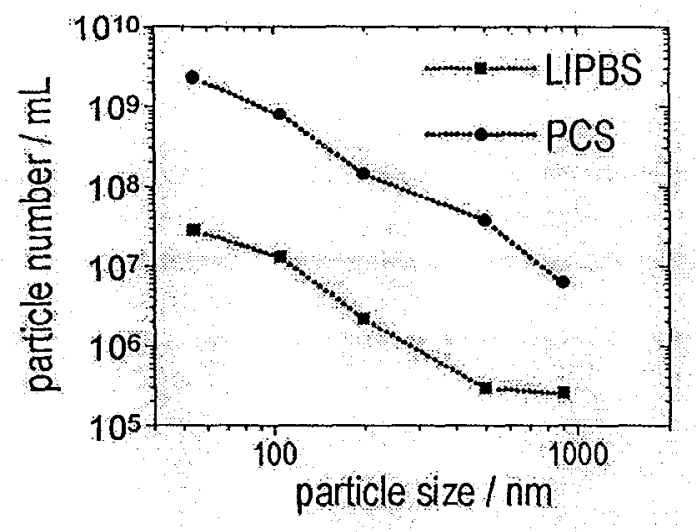

FIGURE Fig. 4: Detection limits of LIPBS and Photon correlation spectroscopy

Images of the spatial distribution of breakdown events in the focal region have shown the effective focal volume is a function of particle size, and the images can be used for particle sizing. For small particles a narrow spatial distribution is observed. With increasing particle size, breakdown occurs in a larger volume. We have demonstrated an alternative sizing method which does not require expensive imaging equipment. The distribution of acoustic pulse amplitudes is measured during the acquisition of the breakdown probability data. The effective focal volume behavior is reflected in the distribution of acoustic pulse amplitudes, which can be characterized by a bimodal gaussian distribution (Figure 5). Peak positions and peak widths at half maximum are independent of particle concentration and laser energy, but the peak centers shift towards higher amplitudes with increasing particle size (Figure 6). Analysis of the acoustic pulse amplitudes allows the determination of average particle sizes smaller than $500 \mathrm{~nm}$. At larger average particle sizes the peak shift becomes insignificant. 


\begin{tabular}{|c|c|c|c|c|c|c|c|c|c|c|c|c|c|}
\hline 90 & 91 & 92 & 93 & 94 & 95 & 96 & 97 & 98 & 99 & 100 & 101 & 102 & 103 \\
Th & Pa & U & Np & Pu & Am & Cm & Bk & Cf & Es & Fm & Md & No & Lr \\
\hline
\end{tabular}

PROJECT REPORTS

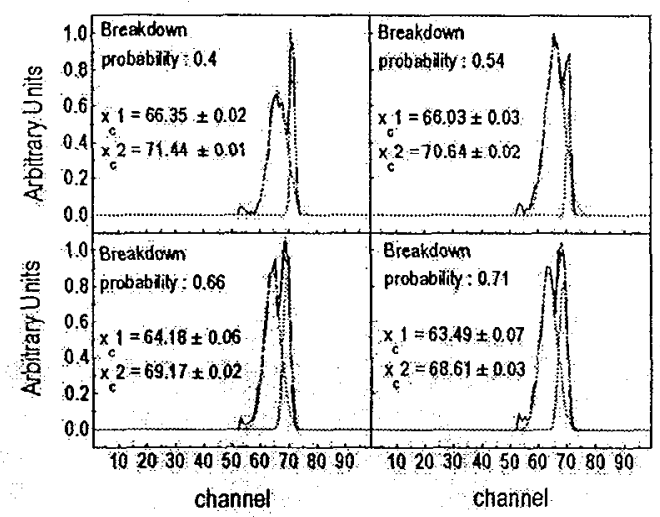

FIGURE 5 PZT voltage distribution for particle size $105 \mathrm{~nm}(9.8 * 107$ particles / $\mathrm{mL})$

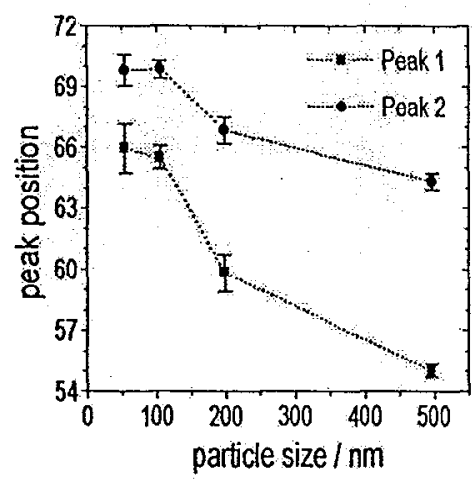

FIGURE Fig. 6: Peak positions of PZT voltage signal as a function of particle size

\section{Summary}

A laser-induced breakdown system was developed for colloid detection and sizing in aqueous suspensions. Particle concentration detection limits are appropriate to dilute laboratory samples and natural groundwater systems. At the current state of development the method allows the measurement of size and concentration of monomodal particle size distributions. Future developments may include the application of an on-line size separation method such as field flow fractionation for direct measurement of polymodal size distributions. 


\begin{tabular}{|c|c|c|c|c|c|c|c|c|c|c|c|c|c|c|}
\hline 104 & 105 & 106 & 107 & 108 & 109 & 110 & 111 & 112 & & & & & & \\
Rf & $\mathrm{Ha}$ & $\mathrm{Sg}$ & $\mathrm{Ng}$ & $\mathrm{Hs}$ & $\mathrm{Mt}$ & & & & $(113)$ & $(114)$ & $(115)$ & $(116)$ & $(117)$ & $(118)$ \\
\hline
\end{tabular}

PROJECT REPORTS

\section{References}

1. F.J. Scherbaum, R. Knopp and J.I. Kim,Appl. Phys. B 63, 299-306 (1996).

2. Knopp, R., Munic, Technical. University Diss. (1996).

3. T. Kitamori, K. Yokose, M. Sakagami and T. Sawada, Jpn. J. Appl. Phys. 28, 1195-1198 (1989). 


\begin{tabular}{|c|c|c|c|c|c|c|c|c|c|c|c|c|c|}
\hline$\frac{90}{T h}$ & $\begin{array}{l}91 \\
\mathbf{P}_{\mathbf{a}}\end{array}$ & ${ }^{92} \mathrm{U}$ & $\begin{array}{l}93 \\
\mathrm{~Np}\end{array}$ & $\begin{array}{l}94 \\
\mathbf{P u}\end{array}$ & $\begin{array}{l}95 \\
\mathrm{Am}\end{array}$ & $\begin{array}{l}96 \\
\mathrm{Cm}\end{array}$ & $\begin{array}{l}97 \\
\text { BK }\end{array}$ & ${ }^{98}$ Cf & 99 & $\begin{array}{c}100 \\
\mathbf{F}_{\mathrm{m}}\end{array}$ & $\begin{array}{l}101 \\
\text { Md }\end{array}$ & $\begin{array}{l}102 \\
\text { No }\end{array}$ & $\begin{array}{c}103 \\
\mathrm{~L}\end{array}$ \\
\hline
\end{tabular}

PROJECT REPORTS

\title{
Will Crystalline $\mathrm{NpO}^{2}$ precipitate from a Near- Neutral Aqueous Solution of $\mathrm{NpO} \quad{ }_{2}^{+}$?
}

\author{
Kevin E. Roberts, Cynthia E. A. Palmer, and Tom J. Wolery \\ GTS-ITS, Anylical and Nuclear Chemistry Division, Geosciences and Environmental Technologies, Lawrence \\ Livermore National Laboratory.
}

\section{Introduction}

The nation is faced with the serious issue of disposing of high-level nuclear waste. The DOE is pursuing the establishment of a permanent, geological disposal site at Yucca Mountain, NV. Current thinking in the U.S. is to use a conservative approach when conducting potential radiation dose and repository performance calculations. Incorporation of published neptunium concentrations observed in short term experiments has yielded calculated doses in excess of proposed long-term dose-based regulatory limits. These results may grossly exaggerate the long-term reality in an actual repository by ignoring the role of certain insoluble $\mathrm{Np}$ solids that may form only at very slow rates.

Of the spent-fuel constituents, ${ }^{237} \mathrm{~Np}$ is of particular concern because of its long half-life. Compounding this problem is neptunium's preference for presenting itself in the +5 oxidation state under oxidizing environmental conditions. $\mathrm{Np}(\mathrm{V})$ tends to be more soluble in aqueous solutions and less strongly sorbed by geologic material than other oxidation states. Under reducing conditions, Np takes the +4 oxidation state, which is far less soluble. Consequently, Np poses a potentially serious threat for radionuclide migration and subsequent dose distribution.

Existing thermodynamic data at $25^{\circ} \mathrm{C}$ show that experimentally observed, approximately $10^{-3} \mathrm{M}$ $\mathrm{Np}$ concentrations at $\mathrm{pH} 6$ are supersaturated with respect to $\mathrm{Np}$ (IV) oxide, $\mathrm{NpO}_{2}$. However, the observed solid phases were $\mathrm{Np}(\mathrm{V})$ solids, both $\mathrm{NaNpO}_{2} \mathrm{CO}_{3}$, and $\mathrm{Np}_{2} \mathrm{O}_{5}$. Thermodynamic calculations made using the computer code EQ3/6 confirm equilibrium with these phases, but cannot show why $\mathrm{NpO}_{2}$ was not obtained instead.

Our hypothesis is that $\mathrm{NpO}_{2}$ is slow to form on the time scale of the earlier laboratory experiments. Accordingly, we are studying the precipitation kinetics of $\mathrm{NpO}_{2}$ at higher temperatures. Under these conditions, the formation of this phase should occur faster if our hypothesis is correct.

Our goal is to better understand the ambient-temperature equilibrium distribution of the $N p(I V)$ and $\mathrm{Np}(\mathrm{V})$ solution and solid species by using high temperature to accelerate any slow reaction kinetics. The precipitation of a crystalline $\mathrm{NpO}_{2}$ solid phase would go hand in hand with significantly lower aqueous $\mathrm{Np}$ concentrations. Such concentrations, if observed, would support calculated doses far below proposed long-term dose-based regulatory limits. 


\begin{tabular}{|c|c|c|c|c|c|c|c|c|c|c|c|c|c|c|}
\hline 104 & 105 & 106 & 107 & 108 & 109 & 110 & 111 & 112 & & & & & \\
Rf & $\mathrm{H} / \mathrm{a}$ & $\mathrm{Sg}$ & $\mathrm{Ns}$ & $\mathrm{Hs}$ & $\mathrm{Mt}$ & & & & $(113)$ & $(115)$ & $(116)$ & $(117)$ & $(118)$ \\
\hline
\end{tabular}

\section{PROJECT REPORTS}

During FY 1997, we prepared our equipment and materials. We conducted our first elevated temperature solubility experiment. An initial soluble $\mathrm{Np}(\mathrm{V})$ concentration of $10^{-4} \mathrm{M}$ and a pH of 6 were chosen so the aqueous solution would be undersaturated with respect to $N p(V)$ solids yet supersaturated with respect to $\mathrm{Np}$ (IV) solids. Both solution and air were present in the reaction vessel, which was placed in a heated oven and allowed to react for 2 weeks at $200^{\circ} \mathrm{C}$. A duplicate experiment was allowed to react at $25^{\circ} \mathrm{C}$. After two weeks of reaction time, the $200^{\circ} \mathrm{C}$ experiment showed a significant decrease in the aqueous $\mathrm{Np}$ concentration. The concentration in the $25^{\circ} \mathrm{C}$ experiment went unchanged. In both experiments, the soluble $\mathrm{Np}$ remained in the +5 oxidation state. A small amount of precipitate was collected from the elevated temperature experiment.

During FY 1998 , we analyzed the solid obtained in the $200^{\circ} \mathrm{C}$ solubility experiment by $\mathrm{x}$-ray powder diffraction (XRD), $x$-ray absorption spectroscopy (XAS), and scanning electron microscopy (SEM). Based on the results from all three analyses, we concluded that the reduction in the aqueous $\mathrm{Np}$ concentration was accompanied by the precipitation of crystalline $\mathrm{NpO}_{2}$. This is the first time that crystalline $\mathrm{NpO}_{2}$ has been observed to precipitate from an aqueous solution of initially $\mathrm{Np}(\mathrm{V})$. It appears that the thermodynamic calculations made using $\mathrm{EQ} 3 / 6$ were correct, that $\mathrm{NpO}_{2}$ is the solubility controlling solid phase under near-neutral aqueous solution conditions, and that slow kinetics has prevented the experimental observation of this precipitation reaction until now.

To confirm this initial result a second experiment was conducted. All conditions were identical to the first experiment other than a five fold increase in the solution volume to $80 \mathrm{ml}$ and switching from a teflon-lined, stainless steel reaction vessel to a pure titanium metal reaction vessel. These changes were made so that periodic measurement of the aqueous $\mathrm{Np}$ concentrations could be made.

Figure 1 shows the measured aqueous $\mathrm{Np}$ concentrations as a function of time for the second $200^{\circ} \mathrm{C} \mathrm{Np}(\mathrm{V})$ solubility experiment. After 102 days of reaction time, steady state had been reached, so the experiment was terminated. Again, the solids were collected and analyzed by $\mathrm{XRD}, \mathrm{XAS}$, and SEM. The resulting data confirmed the first experiment's result in that crystalline $\mathrm{NpO}_{2}$ will precipitate from a near-neutral aqueous solution of $\mathrm{Np}(\mathrm{V})$.

Figure 2 shows a scanning electron micrograph of the solid obtained from the second experiment. The octahedra ranged in size from a few tens of microns to nearly 100 microns, and indicate the formation of high-purity $\mathrm{NpO}_{2}$ crystals.

Additional experiments have been started to investigate the $\mathrm{pH}$ dependence on this precipitation reaction, and will be accompanied by additional work at other temperatures in order to determine the activation energy associated with the formation of $\mathrm{NpO}_{2}$ from aqueous solution.

Special thanks to: T. Prussin (LLNL) for XRD measurements; P. Allen (LLNL), D. Shuh (LBNL), and J. Bucher (LBNL) for XAS measurements; and R. Finch (ANL) for SEM measurements. 


\begin{tabular}{|c|c|c|c|c|c|c|c|c|c|c|c|c|c|}
\hline $\begin{array}{l}90 \\
\text { Th }\end{array}$ & $\begin{array}{l}91 \\
\mathrm{~Pa}_{2}\end{array}$ & ${ }^{92} \mathrm{U}$ & $\begin{array}{l}93 \\
\mathrm{~N}_{p}\end{array}$ & $\begin{array}{l}94 \\
\mathrm{Pu}\end{array}$ & $\begin{array}{l}95 \\
\mathrm{Am}\end{array}$ & $\begin{array}{l}96 \\
\mathrm{Cm}\end{array}$ & $\begin{array}{l}97 \\
\text { Bk }\end{array}$ & ${ }^{98} \mathrm{Cf}$ & $\stackrel{99}{\text { Es }}$ & $\begin{array}{c}100 \\
F_{m}\end{array}$ & $\begin{array}{l}101 \\
\text { Md }\end{array}$ & $\begin{array}{c}102 \\
\text { No }\end{array}$ & $\begin{array}{c}103 \\
\text { Lr }\end{array}$ \\
\hline
\end{tabular}

PROJECT REPORTS

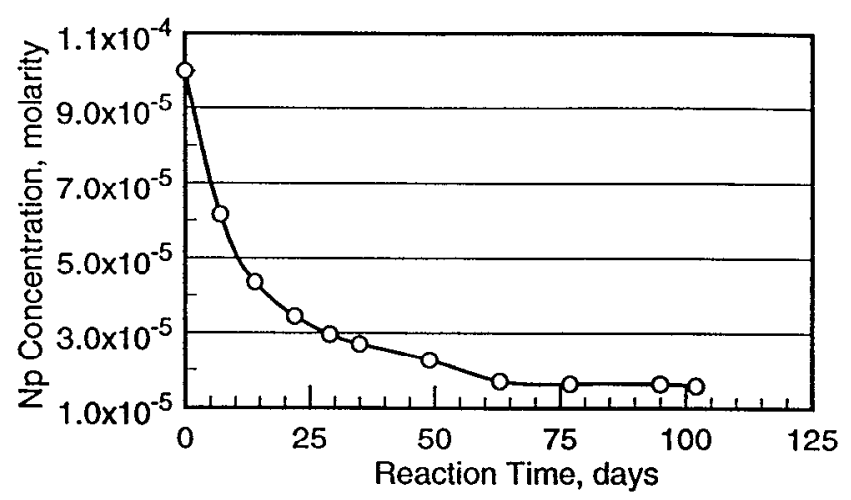

FIGURE 1. Aqueous neptunium concentration as a function of time.

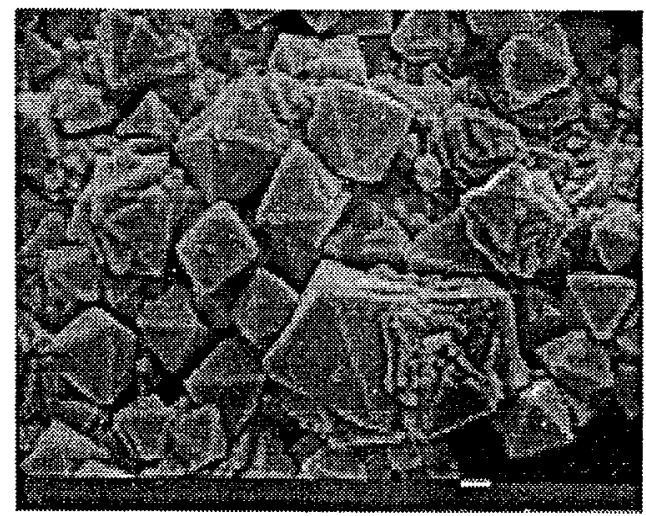

FIGURE 2. SEM micrograph of the $\mathrm{NpO} 2$ solid obtained in the 102 day $200{ }^{\circ} \mathrm{C}$ solubility experiment. 


\begin{tabular}{|c|c|c|c|c|c|c|c|c|c|c|c|c|c|c|}
\hline $\begin{array}{c}104 \\
\text { Rf }\end{array}$ & $\begin{array}{c}105 \\
\mathrm{Ha}\end{array}$ & $\begin{array}{r}106 \\
\text { Sg }\end{array}$ & $\begin{array}{r}107 \\
N\end{array}$ & $\begin{array}{c}108 \\
\mathrm{Hs}_{s}\end{array}$ & $\begin{array}{c}109 \\
\mathrm{Mt}\end{array}$ & 110 & 111 & 112 & (113) & (114) & (115) & (116) & (117) & (118) \\
\hline
\end{tabular}

\section{PROJECT REPORTS}

\section{Oscillatory Extraction of Cerium and Uranium}

Mikhail A. Afonin

Saint Petersburg Institute of Technology

Vadim V. Romanovski, Louis J. Terminello

GTS-ITS, Lawrence Livermore National Laboratory

\section{Introduction}

The discovery of a new type of reaction, the oscillatory Belousov-Zhabotinsky reaction (B-Z reaction), made possible the implementation of an extraction reaction under non-equilibrium conditions, far from thermodynamic equilibrium. B-Z reaction consists of the acidic bromate oxidation of an organic substrate (malonic acid), catalyzed by a transition metal ion. Oscillations in the $\left[\mathrm{Me}^{\mathrm{n}+1}\right] /$ $\left[\mathrm{Me}^{\mathrm{n}}\right]$ ratio can be observed with a platinum electrode, and color changes are visible. Oscillations also occur in the concentrations of bromide ion. The overall stoichiometry in terms of only stoichiometric significant species is:

$$
2 \mathrm{BrO}^{3}-3 \mathrm{CH}_{2}(\mathrm{COOH})_{2}+2 \mathrm{H}+=2 \mathrm{BrCH}(\mathrm{COOH}) 2+3 \mathrm{CO}_{2}+4 \mathrm{H}_{2} \mathrm{O}(\mathbf{1})
$$

During a conventional chemical reaction, the concentration of reactants constantly decreases, the concentration of products constantly increases, and the concentrations of intermediates approach low, relatively constant values because of their rate of production is essentially equal to their rate of destruction. During an oscillating chemical reaction the concentrations of reactants still must decrease, the concentrations of products still must increase, but the concentrations of intermediates or catalyst species execute oscillations as the conversion of reactants to products rushes towards equilibrium. Oscillations in the concentrations of intermediates and catalyst species are driven by a monotonic decrease in free energy as the overall reaction occurs.

One of the key components of the classical $\mathrm{B}-\mathrm{Z}$ reaction is cerium, which is present in both the +3 and +4 oxidation states. This rare-earth metal ion plays the role of a catalyst in the process of oxidation of an organic acid by potassium bromate. In the $\mathrm{B}-\mathrm{Z}$ reaction the $[\mathrm{Ce}(\mathrm{IV})] /[\mathrm{Ce}$ (III)] ratio changes periodically not allowing the system to reach equilibrium for a time varying from several seconds to several hours.

Oscillatory extraction is a process in which the $B-Z$ reaction is used in the aqueous phase to drive the extraction of components into an organic phase. In a heterogeneous solvent extraction system, the periodic transition of one form into another influences the partition of $\mathrm{Ce}$ and of another metal ion present between the organic and the aqueous phase since the various species have different distribution coefficients.

In this work, oscillatory extraction experiments with uranyl nitrate introduced in the system were undertaken. The objective of this work was to investigate the uranium extraction processes under 


\begin{tabular}{|c|c|c|c|c|c|c|c|c|c|c|c|c|c|}
\hline 90 & 91 & 92 & 93 & 94 & 95 & 96 & 97 & 98 & 99 & 100 & 101 & 102 & 103 \\
Th & $\mathbf{P a}_{2}$ & $\mathbf{U}$ & $\mathbf{N p}$ & $\mathbf{P u}$ & $\mathrm{Am}$ & $\mathbf{C m}$ & $\mathrm{Bk}$ & $\mathrm{Cf}$ & $\mathrm{Es}$ & $\mathbf{F m}$ & $\mathbf{M d}$ & $\mathbf{N o}$ & $\mathbf{L r}$ \\
\hline
\end{tabular}

PROJECT REPORTS

non-equilibrium non-stationary conditions, driven by the oscillatory $\mathrm{B}-\mathrm{Z}$ reaction occurring in the aqueous phase.

The setup for the investigation of the oscillatory extraction was assembled at the LLNL in the Glenn T. Seaborg Institute lab. It contained the glass reactor with a water heat exchanger, where the oscillatory extraction took place. Aqueous and organic solutions were placed in reactor and mixed with a magnet stirrer.

The redox potential, $\mathrm{pH}$ and temperature of the system were measured with the two-channel $\mathrm{pH} /$ ion meter. The organic flow was pumped through the flow cell of the spectrophotometer by peristaltic pump and cycled back into the reactor. The electrical signals from $\mathrm{pH}$-meter and spectrophotometer were sent to the computer and were continuously recorded during the experiment using the software written by Dr. Afonin.

Seven experiments were performed. First five experiments were homogenous $B-Z$ reactions with no organic phase present. Those experiments were necessary to check the equipment and to determine the optimum aqueous phase composition. Last two experiments were the oscillatory extraction of uranium and cerium - $0.5 \mathrm{M}$ tri-n-butyl-phosphate in dodecane was mixed with the aqueous phase which contained the $B-Z$ reaction reagents and uranyl nitrate. The conditions of these two experiments were different.

Periodic oscillations of redox potential and temperature were observed. The amplitude of the redox potential oscillations was in the range from 130 to $150 \mathrm{mV}$. The $\mathrm{pH}$ of the system increased slowly with a time due to the consumption of malonic acid. During the experiment the samples of organic and aqueous phases were taken for the subsequent ICP-MS and ICP-ES analysis. 


\begin{tabular}{|c|c|c|c|c|c|c|c|c|c|c|c|c|c|c|}
\hline 104 & 105 & 106 & 107 & 108 & 109 & 110 & 111 & 112 & & & & & & \\
Rf & Ha & S & Ns & Hs & Mt & & & & $(113)$ & $(114)$ & $(115)$ & $(116)$ & $(117)$ & $(118)$ \\
\hline
\end{tabular}

PROJECT REPORTS

\title{
Thermodynamics of the Volatilization of Actinides Metals in the High-Temperature Treatment of Radioactive Wastes
}

\author{
Nadia Hakem \\ GTS-ITS, Lawrence Livermore National Laboratory \\ Martin Adamson \\ Lawrence Berkeley National Laboratory.
}

\section{Introduction}

Federal land disposal restrictions allow radioactive wastes to be disposed of in geologic repositories. Wastes which contain hazardous organics as well as radioactive materials are designated as mixed waste and cannot be disposed directly because any sort of geological disposal for hazardous organics is not permitted. The wastes must first be treated to destroy or remove the hazardous organics. Normally that can be achieved by incineration of the waste.

The primary safety concern for any mixed waste thermal treatment process is the possibility that radionuclides and to a lesser extent heavy metals could be emitted to the atmosphere in the offgas stream. In thermal treatment technology there are two sources of radioactive and heavy metal emissions in the off-gas : volatilization and entrainment.

The purpose of this study is to evaluate the volatilities of actinides such $\mathrm{Pu}, \mathrm{U}, \mathrm{Np}$ and maybe $\mathrm{Am}$.

\section{Objective}

In this project we will perform a detail study of the volatilization behavior of $\mathrm{Pu}, \mathrm{U}, \mathrm{Np}$ and maybe Am under conditions relevant to the thermal treatment (destruction) of actinide-containing organicbased mixed and radioactive wastes. The primary scientific goal of this study is to develop a basic scientific (thermodynamic) understanding of actinide volatilization and partitioning/speciation behavior in the thermal processes that are central to DOE/EM's mixed waste treatment program. The proposed work is a combination of three tasks:

1. Effect of halogens on the volatilization of actinide oxides in flowing $\mathrm{O}_{2}(\mathrm{~g})+\mathrm{H}_{2} \mathrm{O}(\mathrm{g})$ mixtures: Previous studies have shown that the presence of chlorine or fuorine in oxidizing thermal process flow gases enhances the volatility of uranium by formation of species such as $\mathrm{UO}_{2} \mathrm{Cl}_{2}(\mathrm{~g})$ and $\mathrm{UO}_{2} \mathrm{~F}_{2}(\mathrm{~g})$, we propose to study the volatility of $\mathrm{PuO} 2$ in presence of $\mathrm{Cl} 2$. 


\begin{tabular}{|c|c|c|c|c|c|c|c|c|c|c|c|c|c|}
\hline $\begin{array}{l}90 \\
\text { Th }\end{array}$ & $\begin{array}{l}91 \\
\mathbf{P a}_{2}\end{array}$ & ${ }^{92} \mathrm{U}$ & $\begin{array}{l}93 \\
\mathrm{~Np}\end{array}$ & $\begin{array}{l}94 \\
\mathbf{P u}_{\mathbf{u}}\end{array}$ & $\begin{array}{l}95 \\
\text { Am }\end{array}$ & $\begin{array}{l}96 \\
\mathrm{Cm}\end{array}$ & 97 & 98 & $\begin{array}{c}99 \\
\text { Ess }\end{array}$ & $\begin{array}{c}100 \\
\mathrm{Fm}_{\mathrm{m}}\end{array}$ & $\begin{array}{l}101 \\
\mathrm{Md}\end{array}$ & $\begin{array}{c}102 \\
\text { No }\end{array}$ & $\begin{array}{c}103 \\
\text { Lr }\end{array}$ \\
\hline
\end{tabular}

PROJECT REPORTS

2. Volatilization of uranium under reducing conditions: under pyrolysis conditions, it has been postulated that the actinide metals such as uranium may form gaseous organometallic species with sufficient stability that their formation during waste processing could lead to uranium volatility. The purpose of this task is to verify this postulate.

3. Thermochemical analysis and modeling: a data base for expected actinide gaseous species will be developed from literature data, from the purposed measurements and from the data predictions using thermodynamic estimation methods. These data will be incorporated into a comprehensive thermochemical model such as FACT/EQUILIBRIUM computer code that can be used to make volatility and speciation predictions for a variety of thermal processors and operating conditions.

\section{Approach}

The approach used here to obtain actinides volatilities is to apply the transpiration technique to experimentally measure the effect $\mathrm{Cl}_{2}$ (g) on the volatilization behavior of $\mathrm{PuO}_{2}(\mathrm{~s}), \mathrm{NpO}_{2}$ and $\mathrm{AmO}_{2}(\mathrm{~s})$ in the presence of $\mathrm{O}_{2}(\mathrm{~g})$ and $\mathrm{H}_{2} \mathrm{O}(\mathrm{g})$ at $1200-1600^{\circ} \mathrm{C}$.

From the volatility data, the thermodynamics of formation of $\mathrm{PuO}_{2}(\mathrm{OH})_{2}(\mathrm{~g})$ is described as following :

$$
\begin{aligned}
& \mathrm{PuO}_{2}(\mathrm{~s})+\mathrm{H}_{2} \mathrm{O}(\mathrm{g})+1 / 2 \mathrm{O}_{2}(\mathrm{~g})=\mathrm{PuO}_{2}(\mathrm{OH})_{2}(\mathrm{~g})(\mathrm{l}) \\
& \Delta \mathrm{G}^{\circ}(\mathrm{T})=231.3-10.9 \times 10-3 \mathrm{~T} \pm 30, \mathrm{KJ} / \mathrm{mol}(2)
\end{aligned}
$$

Based in the equation (1) and on the equations related to the $U$ and $A m$, very small amounts of the actinide will be vaporized as $\mathrm{AcO} 2(\mathrm{OH}) 2(\mathrm{~g})$ in mixed waste thermal oxidation processors. Also, if halogen gases such as $\mathrm{Cl}_{2}$ are present in concentration greater than $0.1 \%$ in the combustion gas, then actinide oxyhalide vapor species will be important in the off-gas and may dominate over the actinide oxyhydroxydes.

In the presence of $\mathrm{NaCO}_{3}(\mathrm{~s})$ in the bed incinerator $\mathrm{HCl}$ or $\mathrm{Cl}_{2}$ will form $\mathrm{NaCl}$ (s). The actinide oxyhalideses volatilities are then expected to be much smaller than the actinide oxyhroxydes volatilities.

\section{Description of the Transpiration Method}

A known amount of a carrier gas is slowly passed over a solid or liquid in a furnace chamber, such that any volatile gases produced become entrained in the carrier gas and are swept out of the chamber where the volatilized gas is then condensed and analyzed.

The carrier gas may also contain reactive gases such as $\mathrm{O}_{2}, \mathrm{H}_{2} \mathrm{O}$ or $\mathrm{Cl}_{2}$ which contribute to forming the volatilizing species (see equation 1).A special care must be taken to assure the right gas flow rate: at low rates of flow, the apparent pressure of the oxide built up in the $\mathrm{O} 2$ is too high, due 


\begin{tabular}{|c|c|c|c|c|c|c|c|c|c|c|c|c|c|c|}
\hline $\begin{array}{c}104 \\
\text { Rf }\end{array}$ & $\begin{array}{c}105 \\
\mathrm{Ha}\end{array}$ & $\begin{array}{r}106 \\
\mathrm{Sg}\end{array}$ & $\begin{array}{c}107 \\
N\end{array}$ & $\begin{array}{c}108 \\
\mathrm{Hs}_{\mathrm{s}}\end{array}$ & $\begin{array}{c}109 \\
\mathrm{Mt}\end{array}$ & 110 & 111 & 112 & (113) & (114) & (115) & (116) & (117) & (118) \\
\hline
\end{tabular}

\section{PROJECT REPORTS}

to diffusion of volatile oxide into the cold parts of the apparatus, at high rates the apparent pressures are too low due to lack of saturation of the $\mathrm{O} 2$ vith the oxide. The right flow rate is established where the equilibrium vapor pressure persists over a range of flow rates, this is the "plateau region".

The vapor pressure of the volatilized gas under equilibrium conditions is determined from the ideal gas law by taking the ratio of moles of volatilized species to total moles of gas passed through the chamber to be proportional to the partial pressure of volatilized species to total pressure of the carrier gas passed (Dalton's law). The transpiration method can also provide information on the formula of the volatilized species. This is done by varying the partial pressures of the reactive gases and noting the law of mass action effects on the volatilized species. 


\begin{tabular}{|l|l|l|l|l|l|l|l|l|l|l|l|l|l|}
\hline 90 & 91 & 92 & 93 & 94 & 95 & 96 & 97 & 98 & 99 & 100 & 101 & 102 & 103 \\
Th & Pa & U & Np & Pu & Am & Cm & Bk & Cf & Es & Fm & Md & No & Lr \\
\hline
\end{tabular}

PROJECT REPORTS

\title{
The Sorption of Uranium and Neptunium onto Cementitious Materials
}

\author{
Pihong Zhao \\ GTS-ITS, Lawrence Livermore National Laboratory \\ Brian E. Viani \\ Earth \& Environmental Sciences, Lawremce Livermore National Laboratory’
}

\section{Introduction}

Cementitious materials are expected to be present in nuclear wasie repositories in significant quantities. Much of the cementitious material; e.g., the concrete flooring to support the waste canisters, would have a high probability of interacting with radionuclidebearing fluids derived from failed waste packages.

Cements provide a highly alkaline environment. The pore fluids in concrete can have $\mathrm{pH}>10$ for thousands to hundreds of thousands of years. Studies have shown that fresh concretes and cement phases strongly retard or immobilize certain actinides. Consequently, cementitious materials may serve as a barrier to the release of the radionuclides to the far field. On the other hand, colloidal silica-rich particles are abundant in the pore fluids of concrete which can sorb radionuclides and facilitate their migration through the near-field into the adjacent geological environment. Due to the uncer-tainties of these two opposite effects, it is important to investigate the interaction of actinides with concrete under varying conditions.

It is expected that cementitious materials in repositories will be subjected to and altered by hot dry and/or humid conditions for hundreds to thousands of years by the time they interact with radionuclide-bearing fluids. After alteration, the chemical and mineralogical properties of these materials will be significantly different from that of the as-placed or fresh concrete. To assess the effect that this alteration would have on radionuclide interactions, samples of fresh concrete were hydrothermally heated at $200{ }^{\circ} \mathrm{C}$ for 8 months. Hydrothermal treatment resulted in the conversion of $\mathrm{Ca}(\mathrm{OH})_{2}$ (portlandite) and calcium silicate hydrate gels to crystalline calcium silicate hydrate minerals.

This report presents the experimental results of batch sorption experiments to obtain partition coefficients $\left(K_{d}\right)$ of uranium $6+$ and neptunium $5+$ oxidation states on untreated (fresh) and hydrothermally altered concrete at mass/volume ratio of $0.4 \mathrm{~g} / \mathrm{L}$. Samples of crushed $(<53 \mathrm{~mm})$ treated and untreated concrete were reacted with uranium and neptunium bearing solutions at room temperature $\left(22 \pm 2^{\circ} \mathrm{C}\right)$ in an argon glove-box for periods of up to 35 days. The aqueous phase used was $0.01 \mathrm{M} \mathrm{NaCl}$ and the ambient $\mathrm{pH}$ of this solution in contact with untreated and hydrothermally altered concrete was $11.13 \pm 0.1$ and $10.35 \pm 0.1 \mathrm{pH}$ unit, respectively. Samples of the solution in 


\begin{tabular}{|c|c|c|c|c|c|c|c|c|c|c|c|c|c|c|}
\hline 104 & 105 & 106 & 107 & 108 & 109 & 110 & 111 & 112 & $(113)$ & $(114)$ & $(115)$ & $(116)$ & $(117)$ & $(118)$ \\
Rf & $\mathrm{Ha}$ & Sg & Ns & Hs & Mt & & & & &
\end{tabular}

\section{PROJECT REPORTS}

contact with the concrete were counted before and after filtration to assess the $U(V I)$ and $N p(V)$ associated with suspended colloidal particles.

Figure 1 shows the partition coefficient of $U(V I)$, as a function of initial concentration of $U(V I)$ in unfiltered $0.01 \mathrm{M} \mathrm{NaCl}$ solution with untreated

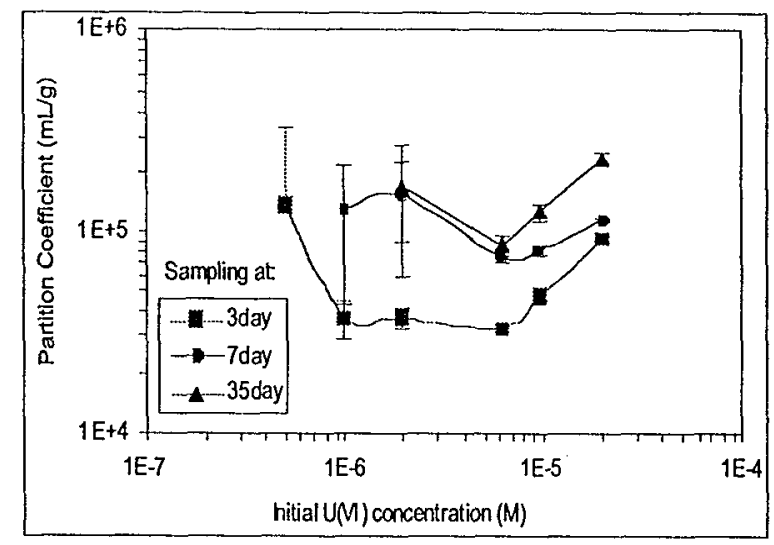

FIGURE 1. Partition coefficient of U(VI) on untreated concrete for unfiltered solution ver-sus initial concentration of $\mathrm{U}(\mathrm{VI})$ in $0.01 \mathrm{M} \mathrm{NaCl}$ solution. Vertical lines represent un-certainty associated with counting.

concrete. The partition coefficients $\left(\mathrm{K}_{\mathrm{d}}\right)$ are very high for the untreated concrete and Kd increases with increasing initial concentration of $U(V I)$ for initial concentrations $>5 \times 10-6 \mathrm{M}$. The plot also shows that the Kd increases with contact time. Because the total sorption of $\mathrm{U}(\mathrm{VI})$, (on both the concrete and the suspended colloids) is nearly $100 \%$, the concentration of soluble uranium in the aqueous phase was under the detection limit. Therefore, the partition coefficient of $U(V I)$ based on analysis of filtered solutions can not be calculated.

Figure 2 shows the partition coefficient of $U(V I)$ as a function of initial concentration of $U(V I)$ in $0.01 \mathrm{M} \mathrm{NaCl}$ solution with treated concrete. Although the partition coefficients are still high for the treated concrete, they are one to two orders of magnitude lower than those for untreated concrete. Unlike untreated concrete, the $K_{d}$ for based on unfiltered samples decreases with increasing initial $U(V I)$ concentration at low initial concentrations $(0-2 \times 10-6 M)$. The $K_{d}$ for unfiltered solutions increases with time, similar to the results for the untreated concrete. 


\begin{tabular}{|c|c|c|c|c|c|c|c|c|c|c|c|c|c|}
\hline 90 & 91 & 92 & 93 & 94 & 95 & 96 & 97 & 98 & 99 & 100 & 101 & 102 & 103 \\
Th & Pa & U & Np & Pu & Am & Cm & Bk & Cf & Es & Fm & Md & No & Lr \\
\hline
\end{tabular}

PROJECT REPORTS

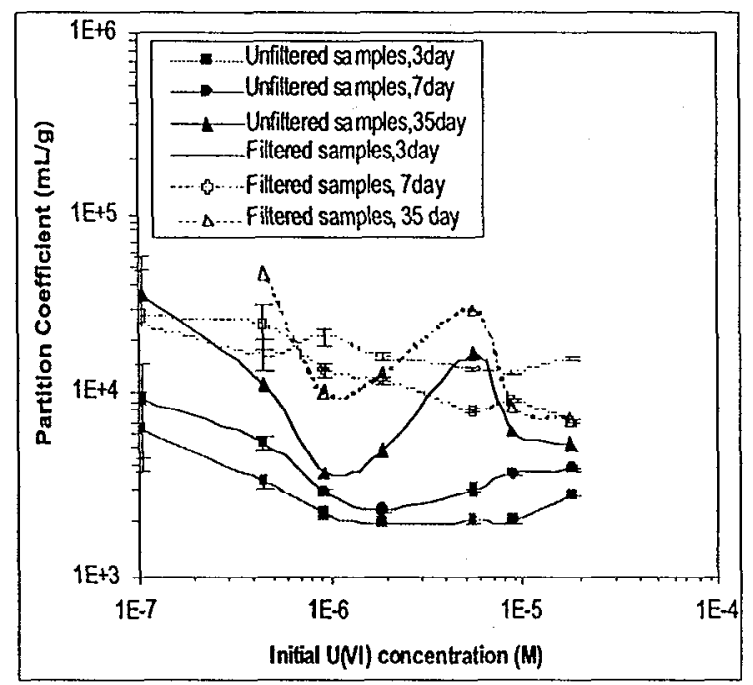

FIGURE 2. Partition coefficient of U(VI) on hydrothermally treated concrete for both filtered and unfiltered solutions versus initial concentration of $U(V I)$ in $0.01 \mathrm{M} \mathrm{NaCl}$ solution.

The $K_{d}$ based on analysis of the filtered solutions appears to decrease over time, although the trend is not consistent at all concentrations. The $K_{d}$ 's at initial concentration of $5 \times 10^{-6} \mathrm{M}$ for both filtered and unfiltered samples are considered to be associated with large experimental errors due to their higher than expected values.

Similar experiments were also conducted to study the sorption behavior of neptunium onto concrete. Figure 3 shows the partition coefficient of $\mathrm{Np}(\mathrm{V})$ as a function of $\mathrm{Np}(\mathrm{V})$ initial concentration in filtered and unfiltered $0.01 \mathrm{M} \mathrm{NaCl}$ solution with untreated concrete. 


\begin{tabular}{|c|c|c|c|c|c|c|c|c|c|c|c|c|c|c|}
\hline 104 & 105 & 106 & 107 & 108 & 109 & 110 & 111 & 112 & & & & & & \\
Rf & $\mathrm{Ha}$ & $\mathrm{Sg}$ & $\mathrm{Ng}$ & $\mathrm{Hs}$ & $\mathrm{Mt}$ & & & & $(113)$ & $(114)$ & $(115)$ & $(116)$ & $(117)$ & (118) \\
\hline
\end{tabular}

\section{PROJECT REPORTS}

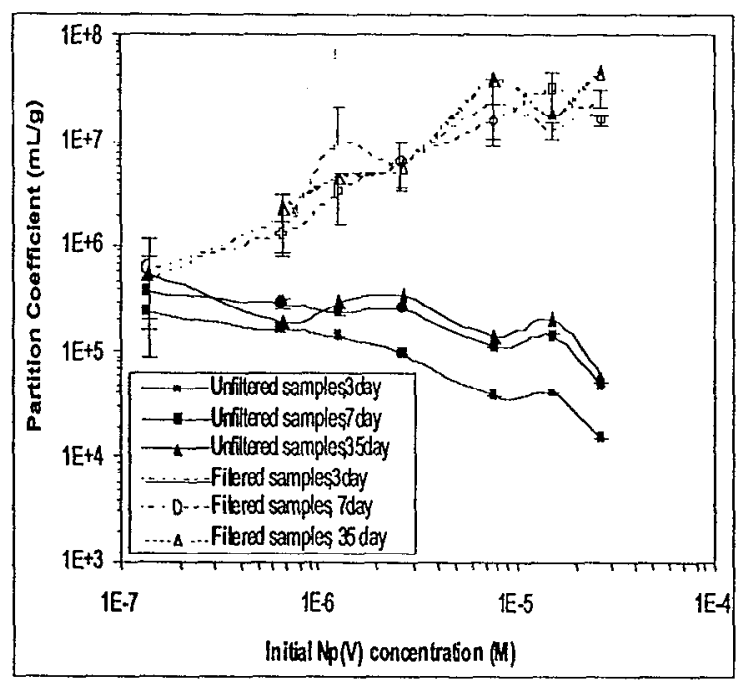

FIGURE 3. Partition coefficient of $\mathrm{Np}(\mathrm{V})$ on untreated concrete for filtered and unfiltered solutions versus initial concentration of $\mathrm{Np}(\mathrm{V})$ in $0.01 \mathrm{M} \mathrm{NaCl}$.

The partition coefficients $\left(K_{d}\right)$ for unfil-tered solutions are in the range of $1 \times 10^{4}$ to $6 \times 10^{5}$. The $K_{d}$ decreases with increasing ini-tial concentration of $\mathrm{Np}(\mathrm{V})$, and it also increases with time. The latter results are consistent with the results obtained from similar $\mathrm{U}(\mathrm{VI})$ sorption experiments. On the other hand, the $\mathrm{K}_{\mathrm{d}}$ 's calculated from filtered solutions apparently increases with $\mathrm{Np}(\mathrm{V})$ initial concentration, and don't change much with time. However, the concentrations of $\mathrm{Np}$ in filtered solutions were so low that all the measurements were at (or below) the detection limit. The increase in $K_{d}$ with increasing initial concentration of $N p(V)$ may simply reflect this fact; i.e. the measured concentration of $\mathrm{Np}(\mathrm{V})$ in solution is essentially constant for all initial concentrations. As observed for $\mathrm{U}(\mathrm{VI})$, the total sorption of $\mathrm{Np}(\mathrm{V})$, on both the concrete and the suspended colloids is nearly $100 \%$.

Figure 4 shows partition coefficients of $U(V I)$ and $N p(V)$ as functions of $\mathrm{pH}$. It is obvious that the partition coefficients are $\mathrm{pH}$ dependent. $K_{d}$ varies by 0.5 order of magnitude for $U(V I)$ and 2 orders of magnitude for $\mathrm{Np}(\mathrm{V})$ in the $\mathrm{pH}$ range between 9.8 to 11.8. Uranium has a maximum $\mathrm{K}_{\mathrm{d}}$ between $\mathrm{pH} 10.5$ and 11, while neptunium's $\mathrm{K}_{\mathrm{d}}$ increases monotonically with increasing $\mathrm{pH}$. 


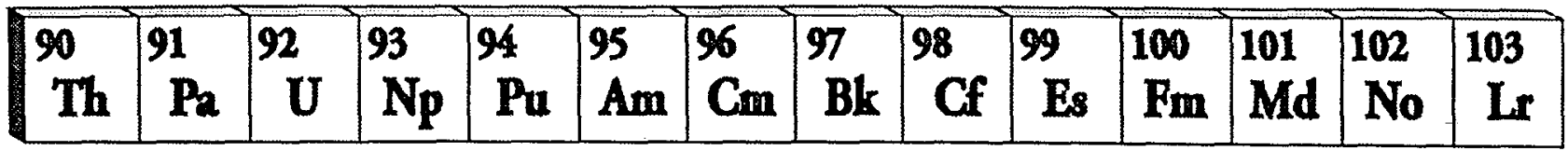

PROJECT REPORTS

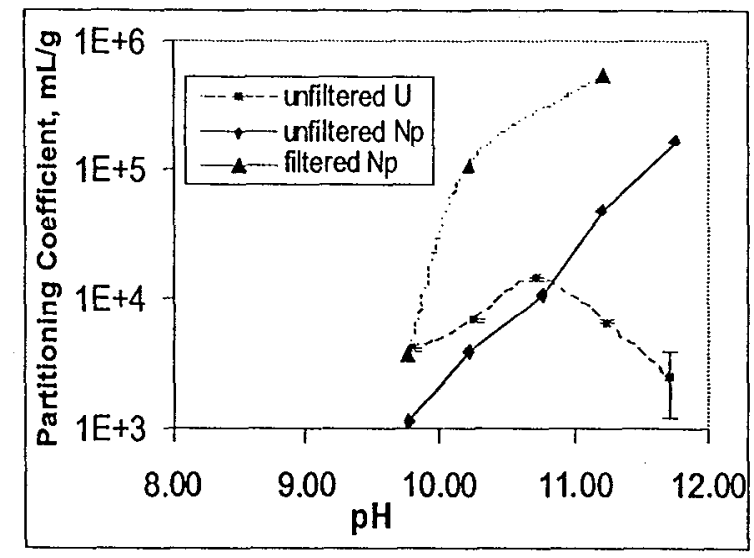

FIGURE 4. Partition coefficient of $U(V I)$ and $\mathrm{Np}(\mathrm{V})$ versus $\mathrm{pH}$ in $0.01 \mathrm{M} \mathrm{NaCl}$ with initial concentrations at $1 \times 10-5 \mathrm{M}$ and $\mathrm{M} / \mathrm{V}$ of $4 \mathrm{~g} / \mathrm{L}$.

The filtration results show that both treated and untreated concrete form a considerable amount of colloids in $0.01 \mathrm{M} \mathrm{NaCl}$ solution. The uranium and neptunium associated with the suspended colloids in $0.01 \mathrm{M} \mathrm{NaCl}$ solutions with untreated concrete are the predominant species for all conditions tested. However, with treated concrete the soluble species of $U(V I)$ in the solution can become predominant over time. The results also show that the 'apparent' $K_{d}$ as calculated based on analysis of the unfiltered samples increases with time. This observation is most likely due to the coagulation and settling of the actinide-bearing cement colloids with time. The "apparent" $K_{d}$ based on the unfiltered samples is a 'conser-vative' measure of the ability of concrete to retard $\mathrm{U}(\mathrm{VI})$ and $\mathrm{Np}(\mathrm{V})$. The $\mathrm{pH}$ behavior of sorption, coupled with the apparently very large $\mathrm{Kd}$ based on analysis of the filtered samples suggests that in addition to adsorption, precipitation of insoluble $\mathrm{U}(\mathrm{VI})$ and/or $\mathrm{Np}(\mathrm{V})$ phases may play a role in the partition between solid and solution. Further work is underway to assess this hypothesis. 


\begin{tabular}{|c|c|c|c|c|c|c|c|c|c|c|c|c|c|c|}
\hline 104 & 105 & 106 & 107 & 108 & 109 & 110 & 111 & 112 & & & & & & \\
Rf & $\mathrm{Ha}$ & $\mathrm{Sg}_{\mathrm{g}}$ & $\mathrm{Ns}$ & $\mathrm{H} / \mathrm{s}$ & $\mathrm{Mt}$ & & & & $(113)$ & $(114)$ & $(115)$ & $(116)$ & $(117)$ & $(118)$ \\
\hline
\end{tabular}

PROJECT REPORTS

\title{
Evaluation and Testing of Sequestering Agents for the Removal of Actinides from Waste Streams
}

\author{
Vadim V. Romanovski, Pihong Zhao, Patrick G. Allen, Darleane C. Hoffman, Cynthia E. A. Palmer
}

GTS-ITS, Lawrence Livermore National Laboratory

\section{Introduction}

Efficient chemical unit processes for the selective removal of actinide elements are needed for the treatment and minimization of wastes. To accomplish this objective, new extractants capable of withstanding harsh chemical and radiation environments must be developed, modified, and tested for use in practical extraction systems. In most of the proposed waste treatment schemes there are junctures where it would be advantageous to use highly selective complexing agents to remove plutonium and perhaps other transuranic elements from high ionic strength solutions which may vary widely in $\mathrm{pH}$ depending upon the exact flow sheet.

The purpose of the project is to evaluate and test the complexing ability of a variety of promising new complexing agents.

The ligands used in our project to chelate plutonium are synthetic derivatives of a class of naturally occurring biomolecules called siderophores. Siderophores are produced by microorganisms to sequester iron from their environment, in order to promote growth. Siderophores function with an incredible degree of efficiency and selectivity, and bind $\mathrm{Fe}$ (III) more strongly than any other class of iron chelators.

Because of the very similar ionic properties of Fe(III) and Pu(IV), synthetic derivatives of siderophores prove very useful in the selective complexation of Pu(IV).

To make the siderophore analogs practical for use in environmental restoration, they need to be modified to function as solid-liquid or liquid-liquid extractants.

\section{Ion Exchange Study Results}

The Catechol, 1,2-HOPO, 3,2-HOPO and 3,4-HOPO dien resins have been shown to remove low concentrations of $\mathrm{Pu}(\mathrm{IV})$ ions from acidic aqueous solutions. All three of our resins showed appreciable sorption, with the 1,2-HOPO resins showing $>98 \%$ sorption from nitric acid media. 


\begin{tabular}{|c|c|c|c|c|c|c|c|c|c|c|c|c|c|}
\hline 90 & 91 & 92 & 93 & 94 & 95 & 96 & 97 & 98 & 99 & 100 & 101 & 102 & 103 \\
Th & Pa & U & Np & Pu & Am & Cm & Bk & Cf & Es & Fm & Md & No & Lr \\
\hline
\end{tabular}

PROJECT REPORTS

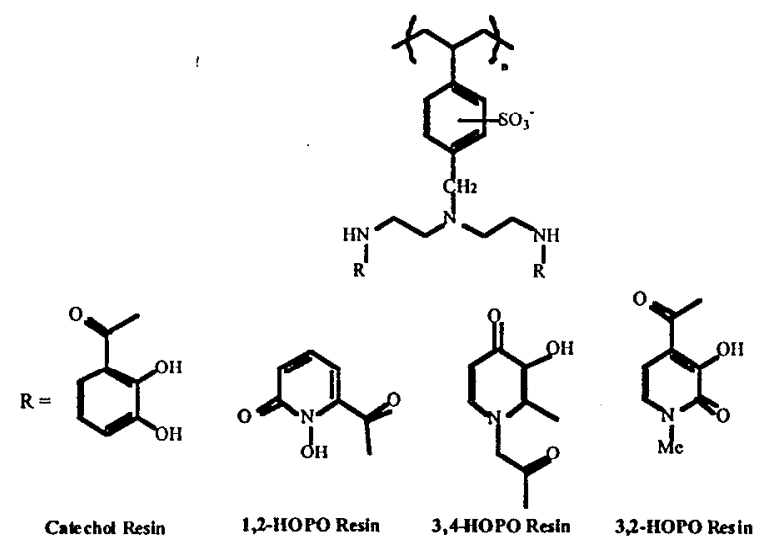

FIGURE 1. Polystyrene-divinylbenzene based resins.

The uptake of $\mathrm{Pu}(\mathrm{VI})$ by 1,2 -HOPO was studied. Sorption of $\mathrm{Pu}(\mathrm{VI})$ is depressed by increasing nitric acid concentration more strongly than sorption of $\mathrm{Pu}(\mathrm{IV})$. The presence of sodium nitrate, that is often present in the waste, affects the sorption of

$\mathrm{Pu}(\mathrm{VI})$ much less than the presence of acid. Uptake of $\mathrm{Pu}(\mathrm{IV})$ and $\mathrm{Pu}(\mathrm{VI})$ are comparable from solutions with high concentrations of sodium nitrate. The sodium concentration effect is represented on Fig.2. The kinetics of sorption and distribution ratios both decrease with increasing concentrations of sodium nitrate in the aqueous phase. Pu(VI) sorption by 3,4-HOPO Resin from acidic solutions was low $\left(K_{d}=179\right.$ for $\left.0.1 \mathrm{M} \mathrm{HNO}_{3}\right)$.
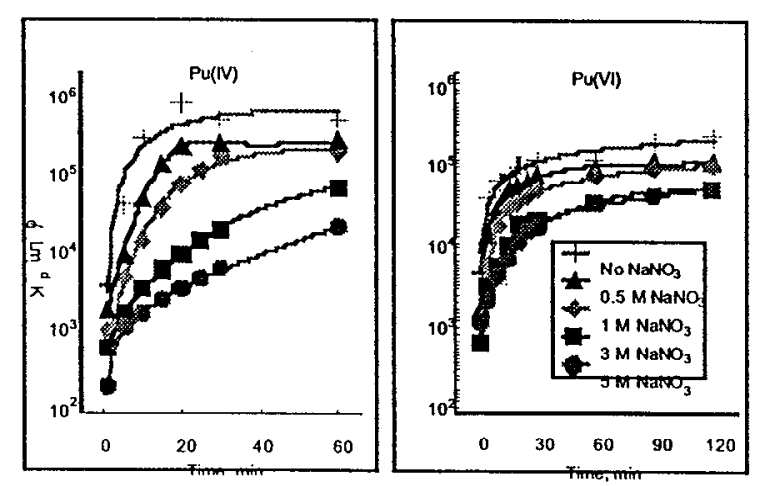

FIGURE 2. Pu uptake by 1,2-HOPO Resin from $0.1 \mathrm{M} \mathrm{HNO3} \mathrm{in} \mathrm{presence} \mathrm{of} \mathrm{Na.}$ 


\begin{tabular}{|c|c|c|c|c|c|c|c|c|c|c|c|c|c|c|}
\hline 104 & 105 & 106 & 107 & 108 & 109 & 110 & 111 & 112 & & & & & \\
Rf & Ha & Sg & Ns & Hs & Mt & & & & $(113)$ & $(114)$ & $(115)$ & $(116)$ & $(117)$ & (118) \\
\hline
\end{tabular}

\section{PROJECT REPORTS}

Since 1,2-HOPO is very strong sorbing agent for Pu(IV), it is difficult to strip it back from the resin. Even $10 \mathrm{M} \mathrm{HCl}$ is inefficient for Pu(IV) removal from 1,2-HOPO resin (D 2400): $30 \%$ of Pu is still left in resin phase after 2 hours contact with $\mathrm{HCl}$. Similar results were for $0.1 \mathrm{M}$ and $0.3 \mathrm{M}$ solutions of 1-hydroxyethane-1,1-diphosphonic acid (HEDPA) which is strong complexing agent for actinide ions. Only significant concentration of HEDPA $(1 \mathrm{M})$ is extremely effective for Pu stripping.

Four more resins with a simple diamine support have been synthesized at UC Berkeley and tested at LLNL. Pu(IV) sorption experiments by the resins with the various carbon chains, $\mathrm{C}_{0^{-}}, \mathrm{C}_{2^{-}}, \mathrm{C}_{4^{-}}$ and $\mathrm{C}_{6}{ }^{-1}, 2-\mathrm{HOPO}$, were conducted from the nitric acid solutions. The performance of $\mathrm{C}_{2^{-}}, \mathrm{C}_{4^{-}}$and $\mathrm{C}_{6}-1,2-\mathrm{HOPO}$ resins was very similar, and no significant preference to any length of carbon chain was observed. $\mathrm{C}_{0}-1,2-\mathrm{HOPO}$ Resin has the best performance among the resins tested. It has the highest loading capacity (except Catechol Resin) and the highest distribution ratios for sorption of $\mathrm{Pu}(\mathrm{IV})$ from concentrated nitric acid media. Even for $5 \mathrm{M} \mathrm{HNO}_{3}$ distribution ratio of $\mathrm{Pu}(\mathrm{IV})$ is very high - over $10^{5}$. Sorption of $\mathrm{Pu}(\mathrm{VI})$ is depressed by increasing nitric acid concentration more strongly than sorption of $\mathrm{Pu}(\mathrm{IV})$. For example, $\mathrm{Pu}(\mathrm{VI})$ distribution ratio is about $10^{3}$ for $5 \mathrm{M} \mathrm{HNO}_{3}$. The distribution ratios of $\mathrm{Pu}(\mathrm{IV})$ and $\mathrm{Pu}(\mathrm{VI})$ both decrease when sodium or aluminum is added to the aqueous phase. Aluminum has a most diminishing effect on Pu sorption, especially on $\mathrm{Pu}(\mathrm{VI})$ sorption. Pu sorption is depressed the most by iron(III), zirconium(IV) and aluminum, then goes nitric acid and then sodium nitrate. The $\mathrm{C}_{0^{-1}}, 2-\mathrm{HOPO}$ Resin sorbs $\mathrm{Pu}$ as though there is no competition from EDTA.

Fig.3 represents the performance by the $\mathrm{C}_{0}-1,2-\mathrm{HOPO}, 1,2-\mathrm{HOPO}, 3,2-\mathrm{HOPO}, 3,4-\mathrm{HOPO}$ and Catechol resins in acidic media. Pu sorption is depressed by nitric acid and sodium. $\mathrm{C}_{0}-1,2-\mathrm{HOPO}$ and 1,2-HOPO resins are less affected, then goes 3,2-HOPO. The uptake by Catechol and 3,4HOPO resins are decreasing drastically with increasing acidity.
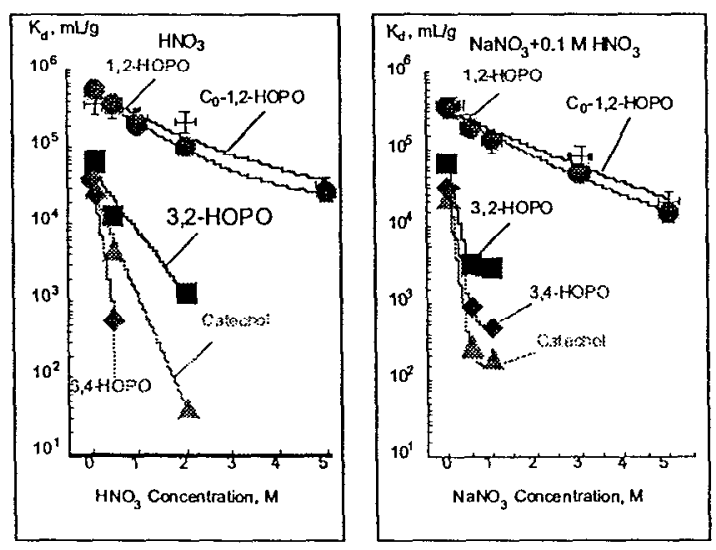

FIGURE 3. Pu(IV) sorption by various resins.

The advantages of $\mathrm{C}_{0}-1,2-\mathrm{HOPO}$ Resin are higher loading capacity ( $-56 \%$ more than $\left.1,2-\mathrm{HOPO}\right)$, it is easier and cheaper to synthesize. 


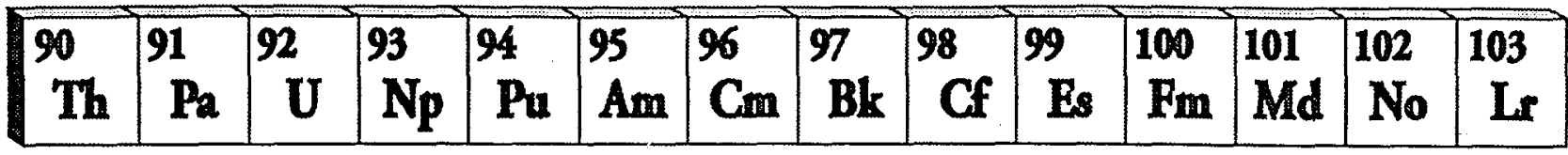

PROJECT REPORTS

\section{Solvent Extraction Study Results}

The chelating groups selective for $\mathrm{Pu}(\mathrm{IV})$ can also be incorporated into molecules appropriate for use as liquid/liquid extractants. Detailed investigation of the 1-hydroxy-6-N-octylcarboxamide2(1H)-pyridinone (1,2-HOPO octyl amide) for Pu solvent extraction was conducted. The extraction of $\mathrm{Pu}$, especially of $\mathrm{Pu}(\mathrm{IV})$, is very high in the wide range of the acidity up to 11 molar nitric acid.

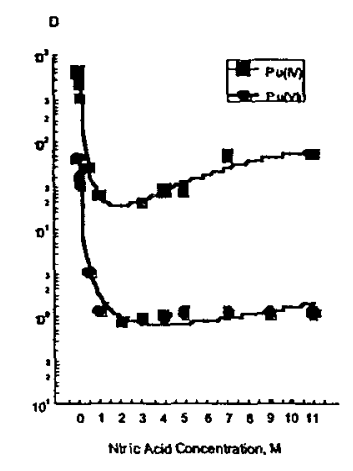

FIGURE 4. Distribution coefficients of Pu(IV) and Pu(VI) for extraction into $3 \mathrm{mM}$ 1,2-HOPO solution in octanol.

The effects of sodium and aluminum nitrates were investigated (see Fig.5).

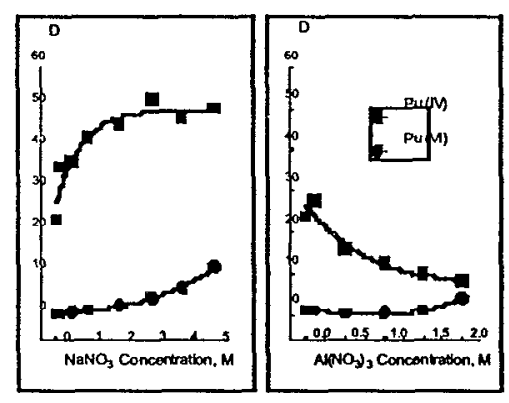

FIGURE 5. Effects of $\mathrm{Na}$ and $\mathrm{Al}$ nitrates on $\mathrm{Pu}(\mathrm{IV})$ and $\mathrm{Pu}(\mathrm{VI})$ distribution coefficients for extraction into $3 \mathrm{mM} \mathrm{1,2-HOPO}$ solution in octanol from $1 \mathrm{M} \mathrm{HNO}_{3}$.

The effect of aluminum nitrate is quite different for $\mathrm{Pu}(\mathrm{IV})$ than for $\mathrm{Pu}(\mathrm{VI})$. The Pu(IV) distribution coefficient decreases sharply while the $\mathrm{Pu}(\mathrm{VI})$ distribution coefficient stays nearly constant and then increases slightly above $1 \mathrm{M}$ aluminum nitrate, possibly due to $\mathrm{Pu}$ solubilization by octanol itself. $\mathrm{Pu}(\mathrm{VI})$ distribution coefficients for extraction into pure octanol with no octyl-1,2-HOPO present were found to be about the same values, thus confirming this effect.

The extraction experiments were performed for Pu(IV) in the presence of an Fe(III) excess, one of the most competitive ions for $\mathrm{Pu}$ (IV) sorption. With the iron(III) to $\mathrm{Pu}$ (IV) ratio adjusted up to $5000: 1$ 


\begin{tabular}{|c|c|c|c|c|c|c|c|c|c|c|c|c|c|c|}
\hline 104 & 105 & 106 & 107 & 108 & 109 & 110 & 111 & 112 & (113) & (114) & (115) & $(116$ & (117) & (118) \\
\hline Rf & $\mathrm{Ha}$ & $\mathrm{Sg}$ & $\mathrm{Ng}$ & $\mathrm{Hs}$ & $\mathrm{Mt}$ & & & &
\end{tabular}

\section{PROJECT REPORTS}

$\left(0.1 \mathrm{M} \mathrm{Fe}\left(\mathrm{NO}_{3}\right)_{3}\right)$, the $\mathrm{Pu}(\mathrm{IV})$ distribution coefficient was 2.8 or $73 \%$ extraction. In case of $2500: 1$ ratio $\left(0.05 \mathrm{M} \mathrm{Fe}\left(\mathrm{NO}_{3}\right)_{3}\right)$, the distribution coefficient of $\mathrm{Pu}(\mathrm{IV})$ was 5.8 or more than $85 \%$ extraction.

Plutonium extraction is very high even from very concentrated nitric acid (see Fig. 4.). That means that mineral acid cannot be used as a back extraction agent. 1-hydroxyethane-1,1,-diphosphonic acid (HEDPA) was studied as a back extraction agent for both $\mathrm{Pu}(\mathrm{IV})$ and $\mathrm{Pu}(\mathrm{VI})$. Distribution coefficients (D) of Pu(IV) and Pu(VI) between $3 \mathrm{mM} \mathrm{1,2-HOPO}$ octylcarboxyamide in octanol and HEDPA solutions were measured as a function of HEDPA concentration in the aqueous phase. 0.05 to $0.1 \mathrm{M}$ solution of HEDPA is a good agent for $\mathrm{Pu}(\mathrm{VI})$ removal from 1,2-HOPO octylamide octanol solutions. Ten times more concentrated solutions of HEDPA are required in case of Pu(IV).

The relatively high HEDPA concentration, $1 \mathrm{M}$, is required to successfully remove Pu(IV). The concentrated solutions of HEDPA might create waste problems. That is why we tried to use the agents with a chemical group, which is similar to that on the extractant. Three water soluble HOPO ligands were tested as the back extraction agents. The structures of the ligands are presented in Fig. 6. The ligand with a simple structure, 1,2-dimethyl-3,4-HOPO, did not work for either $\mathrm{Pu}$ (IV) $(0.6 \%$ of $\mathrm{Pu}$ retained in aqueous phase) or $\mathrm{Pu}(\mathrm{VI})$ (32\% Pu retained in aqueous phase). Best results were for $\mathrm{H}(2,2)-1,2-\mathrm{HOPO}$. Even very dilute, $10^{-3} \mathrm{M}$ solution of $\mathrm{H}(2,2)-1,2-\mathrm{HOPO}$, retained $97.7 \%$ of $\mathrm{Pu}(\mathrm{IV})$ and $95.4 \%$ of $\mathrm{Pu}(\mathrm{VI})$ in the aqueous phase.

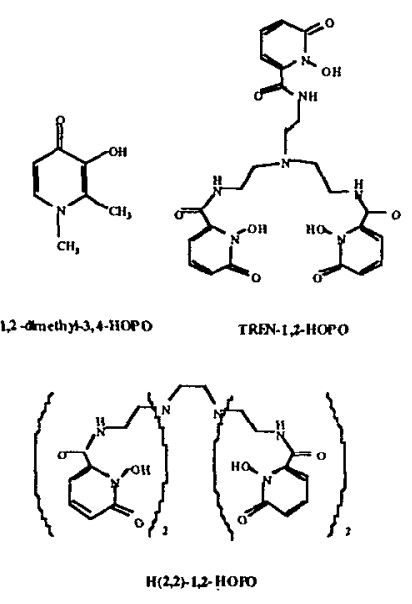

FIGURE 6. Structure of water soluble HOPO ligands.

The results show that $1,2-\mathrm{HOPO}$ octyl amide is a promising extractant which has a high specificity for Pu(IV). 


\begin{tabular}{|l|l|l|l|l|l|l|l|l|l|l|l|l|l|}
\hline 90 & 91 & 92 & 93 & 94 & 95 & 96 & 97 & 98 & 99 & 100 & 101 & 102 & 103 \\
Th & Pa & U & Np & Pu & Am & Cm & Bk & Cf & Es & Fm & Md & No & Lr \\
\hline
\end{tabular}

PROJECT REPORTS

\section{Spectroscopic Study of Chelation between Pu and Modified Siderophores}

There was a potential of reduction of Pu species by binding groups such as hydroxy-pyridinone, and catechol. The oxidation states of Pu in the chelating agents were characterized using $X$-ray absorption near-edge structure (XANES) spectroscopy and UVNIS spectroscopy in order to obtain information about these complexes at molecular levels. XANES is generally applicable to characterizing the bonding geometry and valence of selected elements in a given compound or complex. This technique can be applied to both liquid and solid phases.

The experiments indicated that Catechol resin reduced $\mathrm{Pu}$ (IV) to $\mathrm{Pu}$ (III) over time. It was confirmed with XANES and UVNIS spectroscopy that 1,2-HOPO Resin first formed complexes with $\mathrm{Pu}(\mathrm{VI})$, and later $\mathrm{Pu}(\mathrm{VI})$ in the resin phase was reduced to $\mathrm{Pu}(\mathrm{IV})$.

The results also indicated that plutonium in both 1,2-HOPO resin and octyl-1,2-HOPO extractant has $\mathrm{a}+4$ oxidation state, despite initial introduction of $\mathrm{PuO}_{2} 2^{+}$into solutions with the chelating agents. It was confirmed with UVNIS spectroscopy that 1,2-HOPO resin and octyl-1,2-HOPO extractant form complexes with $\mathrm{Pu}(\mathrm{VI})$ first and later $\mathrm{Pu}(\mathrm{VI})$ reduces to $\mathrm{Pu}(\mathrm{IV})$ in the resin phase or in the organic phase. The concentration of plutonyl in octanol dropped almost 10 times after 17 days due to reduction. Approximately $60 \%$ of initial $\mathrm{Pu}(\mathrm{VI})$ have been reduced after 6 days. 


\begin{tabular}{|c|c|c|c|c|c|c|c|c|c|c|c|c|c|c|}
\hline $\begin{array}{c}104 \\
\text { Rf }\end{array}$ & $\begin{array}{c}105 \\
\mathrm{Hg}\end{array}$ & $\begin{array}{c}106 \\
\mathrm{Sg}\end{array}$ & $\begin{array}{c}107 \\
\mathrm{Ns}\end{array}$ & $\begin{array}{c}108 \\
\mathrm{H} s\end{array}$ & $\begin{array}{c}109 \\
\mathrm{Mt}\end{array}$ & 110 & 111 & 112 & $(113)$ & $(114)$ & $(115)$ & $(116)$ & $(117)$ & $(118)$ \\
\hline
\end{tabular}

\title{
PROJECT REPORTS
}

\section{LDRD FUNDED PROJECTS}

\section{Towards a Rational Nuclear Materials Management}

\author{
Patrick Allen and Kevin Roberts \\ GTS-ITS, Lawrence Livermore National Laboratory \\ Jerome Bucher and David Shuh \\ Chemical Sciences Division, Lawrence BerkeleyNational Laboratory
}

\section{Introduction}

A complete understanding of actinide interactions in the geosphere is paramount for developing a rational Nuclear and Environmental Materials Management Policy. One of the key challenges towards understanding the fate and transport of actinides is determining their speciation (i.e., oxidation state and structure). Since an element's specialization directly dictates physical properties such as toxicity and solubility, this information is critical for evaluating and controlling the evolution of an actinide through the erivironment. Specific areas within nuclear and environmental management programs where speciation is important are 1) waste processing and separations; 2) wasteform materials for long-term disposition; and 3 ) aqueous geochemistry.

The goal of this project is to develop actinide X-ray Absorption Spectroscopy (XAS) as a core capability at LLNL and integrate it with existing facilities, providing a multi-technique approach to actinide speciation. XAS is an element-specific structural probe which determines the oxidation state and structure for most atoms. XAS can be more incisive than other spectroscopies because it originates from an atomic process and the information is always attainable, regardless of an element's speciationspeciation. Despite the utility, XAS is relatively complex due to the need for synchrotron radiation and significant expertise with data acquisition and analysis. The coupling of these technical hurdles with the safe handling of actinides at a general user synchrotron facility make such experiments even more difficult. As a result, XAS has been underutilized by programs that could benefit by its application.

\section{Actinide XAS Studies}

From the initial point of funding (midyear FY98), we began developing various key components for actinide XAS experiments. We also coordinated the preparation of environmental samples with 


\begin{tabular}{|c|c|c|c|c|c|c|c|c|c|c|c|c|c|}
\hline $\begin{array}{l}90 \\
\mathrm{Th}\end{array}$ & $\begin{array}{l}91 \\
\mathrm{~Pa}\end{array}$ & $\begin{array}{l}92 \\
\mathrm{U}\end{array}$ & $\mid \begin{array}{l}93 \\
\mathrm{~N}_{p}\end{array}$ & $\begin{array}{l}94 \\
\mathrm{Pu}_{\mathrm{u}}\end{array}$ & $\begin{array}{l}95 \\
\text { Am }\end{array}$ & $\begin{array}{l}96 \\
\mathrm{Cm}\end{array}$ & $\begin{array}{l}97 \\
\text { Bk }\end{array}$ & ${ }^{98} \mathrm{Cf}$ & $\begin{array}{l}99 \\
\text { Es }\end{array}$ & $\begin{array}{c}100 \\
\mathrm{Fm}_{\mathrm{m}}\end{array}$ & $\begin{array}{l}101 \\
\mathrm{Md}\end{array}$ & $\begin{array}{c}102 \\
\mathrm{~N}_{0}\end{array}$ & $\begin{array}{c}103 \\
\mathrm{~L}\end{array}$ \\
\hline
\end{tabular}

PROJECT REPORTS

existing LLNL programs to conduct the first series of actinide XAS experiments at the Stanford Synchrotron Radiation Laboratory (SSRL).

In a geological repository, ${ }^{237} \mathrm{~Np}$ is of special concern because it is a constituent in spent nuclear fuel and is the primary source of radiological hazard to the biosphere for waste storage times in excess of 10,000 years. Compounding the long half-life of this isotope is neptunium's preference to present itself in the $\mathrm{Np}(\mathrm{V})$ oxidation

state under oxidizing environmental conditions. This oxidation state tends to be more soluble than $\mathrm{Np}(\mathrm{IV})$ in aqueous solutions and less strongly sorbed by geologic material surrounding a nuclear waste repository (e.g. Yucca Mountain).

In our first XAS measurements, we studied a series of Np solid precipitates. These compounds were prepared in related experiments conducted to study the solubility and thermodynamic stability of $\mathrm{Np}$ at Yucca Mountain. Figure 1 shows $\mathrm{Np} \mathrm{L}_{11}$-edge XAS Fourier Transforms (FTs) for the $\mathrm{Np}(\mathrm{V})$ species $\mathrm{NpO}_{2}+$, the $\mathrm{Np}(\mathrm{IV})$ solid compound $\mathrm{NpO}_{2}$, and one of the solid $\mathrm{Np}$ precipitates. The FTs represent pseudo-radial distribution functions of the structure surrounding the $\mathrm{Np}$ atoms in these samples. The FT peaks correspond to nearest-neighbor atoms (O and $\mathrm{Np})$ at discrete distances from a central $\mathrm{Np}$ atom (e.g. Np-O or Np-Np bonding). The results of this study demonstrate that the $\mathrm{Np}$ precipitate has a local structure similar to that of the known tetravalent $\mathrm{Np}$ compound $\mathrm{NpO}_{2}$. This is interesting because the starting material for the solubility experiment was composed of a pentavalent $\mathrm{Np}$ species possessing a dramatically different bonding pattern (Figure 1). The detection of $\mathrm{Np}(\mathrm{V}) \rightarrow \mathrm{Np}(\mathrm{IV})$ transformation may prove to be important for understanding the fate of $\mathrm{Np}$ at Yucca Mountain.

In FY99, we plan to continue our development of the actinide XAS capability using new custom designed $x$-ray detectors and sample positioning devices. The systems we plan to investigate include: i) plutonium sorbed onto colloidal silicate minerals representative of systems found in the vicinity of the Nevada Test Site; ii) uranium and neptunium absorbed and reacted with cementitious materials intended for use in repository construction at Yucca Mountain; and iii) a continuation of the studies on neptunium precipitates derived from solubility experiments discussed above. Determining the oxidation state and structure of the actinides elements in these laboratory based systems is crucial for understanding their fate and transport in the environment. 


\begin{tabular}{|c|c|c|c|c|c|c|c|c|c|c|c|c|c|c|}
\hline $\begin{array}{c}104 \\
\text { Rf }\end{array}$ & $\begin{array}{c}105 \\
\mathrm{Ha} \\
\end{array}$ & $\begin{array}{r}106 \\
S_{8}\end{array}$ & $\begin{array}{c}107 \\
\mathrm{~N}_{8}\end{array}$ & $\begin{array}{c}108 \\
\mathrm{Hs}_{s}\end{array}$ & $\begin{array}{c}109 \\
\mathrm{Mt}\end{array}$ & 110 & 111 & 112 & (113) & (114) & (115) & (110) & (117) & (118) \\
\hline
\end{tabular}

PROJECT REPORTS

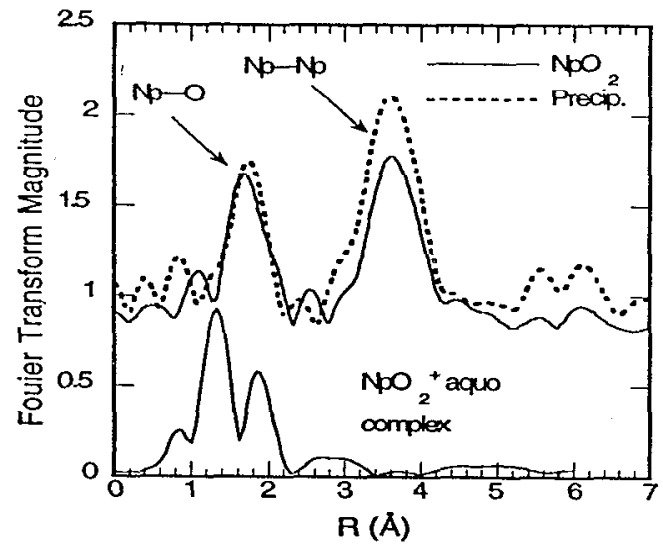

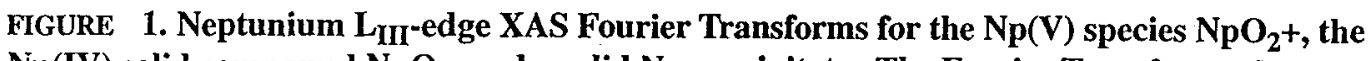
$\mathrm{Np}$ (IV) solid compound $\mathrm{NpO}_{2}$, and a solid $\mathrm{Np}$ precipitate. The Fourier Transforms show peaks which correspond to near-neighbors at discrete distances from a central $\mathrm{Np}$ atom (e.g. $\mathrm{Np}-\mathrm{O}$ or $\mathrm{Np}$ Np bonding). 


\begin{tabular}{|c|c|c|c|c|c|c|c|c|c|c|c|c|c|}
\hline 90 & 91 & 92 & 93 & 94 & 95 & 96 & 97 & 98 & 99 & 100 & 101 & 102 & 103 \\
Th & Pa & U & Np & Pu & Am & Cm & Bk & Cf & Es & Fm & Md & No & Lr \\
\hline
\end{tabular}

PROJECT REPORTS

WORK FOR OTHERS PROJECTS
A system to carry out sorption experiments directly on rock fracture surfaces and a simplified coupled modelling approach based on NCR-SCS concepts to study the migration of radionuclides in a fractured granitic environment (Palmottu site)

C. Le Guern, P. Baranger, T. Ruskecnicmi, J. Suksi

\section{Abstract}

Complementary experimental and modelling approaches have been developed for a better understanding of the $U$ migration in a fractured granitic environment at Palmottu site. On one side, an experimental system was built to study the chemical interactions between the fracture surface of rock samples and their corresponding groundwater. The system is based on the mechanical insulating of the fracture surface from the rest of the core. Several samples were studied. The chemical exchanges between the fracture coating and the solution have been followed by analysing the uranium (ICP/MS), the anions SO42-, $\mathrm{Cl}$ - (lon chromatography) and $\mathrm{HCO} 3-$ (IR detection of acid digestion $\mathrm{CO} 2$ ) and cations $\mathrm{K}+\mathrm{Ca} 2+, \mathrm{Na}+, \mathrm{Mg} 2+$ (Capillary ion analysis) in the liquid phase.

On the other side, a model was constructed, using the coupled "Network of Chemical Reactor Specific Chemical Simulator" (NCR-SCS) concept. The modelled area is divided into unit volumes, or chemical reactors, taking in to account the chemical and mineralogical heterogeneity of the system. For each reactor, a Specific Chemical Simulator (SCS) is built, which contains the main mechanisms involved in the considered elements partitioning between the solid and liquid phase: speciation, sorption, dissolution/precipitation. Each chemical reactor includes the SCS, a hydrological module based on a relation between head and flow rate, and several modules that contain a flow molar balance equation for each of the chemical elements considered. This strategy of mod- 


\begin{tabular}{|c|c|c|c|c|c|c|c|c|c|c|c|c|c|c|}
\hline 104 & 105 & 106 & 107 & 108 & 109 & 110 & 111 & 112 & (113) & $(114)$ & $(115)$ & $(116$ & $(117)$ & (118) \\
\hline Rf & $\mathrm{H}_{2}$ & $\mathrm{~S}_{8}$ & $\mathrm{Na}$ & $\mathrm{H}_{3}$ & $\mathrm{Mt}$ & & & &
\end{tabular}

\section{PROJECT REPORTS}

elling relies on the use of the user-friendly and modulable ALLAN-NEPTUNIX modelling tools package.

For all the experimentally studied rock samples, each contact of U-free synthetic groundwater with the fracture surface results in a rapid release of uranium, followed by a steady state or a slower increase of the $\mathrm{U}$ content. The slower increase of the $\mathrm{U}$ content is often associated to the release of $\mathrm{K}$ and $\mathrm{Cl}$ in the solution. By single reactor tests of the model, the experimentally observed rapid U-release is reproduced, which appears linked to surface complexation reactions rather than exchanges with sites of the clay fraction.

The coupling of several reactors in series, each corresponding to a specific observation point along the assumed hydrodynamic, mass-transfer pathway, conducts to more or less comparable trends as seen at the site. 


\begin{tabular}{|l|l|l|l|l|l|l|l|l|l|l|l|l|l|}
\hline 90 & 91 & 92 & 93 & 94 & 95 & 96 & 97 & 98 & 99 & 100 & 101 & 102 & 103 \\
\hline $\mathbf{T h}$ & $\mathrm{Pa}$ & $\mathrm{U}$ & $\mathrm{Np}$ & $\mathrm{Pu}$ & $\mathrm{Am}$ & $\mathrm{Cm}$ & $\mathrm{Bk}$ & $\mathrm{Cf}$ & $\mathrm{Es}$ & $\mathrm{Fm}$ & $\mathrm{Md}$ & $\mathrm{No}$ & $\mathrm{Lr}$ \\
\hline
\end{tabular}

PROJECT REPORTS

\title{
Removal of Actinide Ions by Colloid Enhanced Ultrafiltration Using Specific Ligands
}

\author{
Udeni R. Dharmawardana \\ GTS-ITS, Lawrence Livermore National laboratory, Livermore \\ Institute of Applied Surfactant Research, Department of Chemistry, University of Oklahoma
}

\section{Introduction}

The development of cost-effective and efficient methods to decontaminate radioactive waste sites has been a challenging task. Uranium, thorium and plutonium have been some of the major contaminant elements produced by the nuclear industry as by products in the last decades. Separation of such contaminants has been difficult due to the presence of many interfering ions in the solution. There have been a variety of techniques proposed or developed for such decontamination processes and each method has several specific problems associated with it. Precipitation methods cannot be used efficiently to separate pollutants from dilute solutions. Although the fixed bed ion-exchange resins can separate pollutant ions from dilute solutions, problems arise when the waste water matrix contains a variety of ionic material such as salt, natural colloids, charged pollutants etc. In addition, those methods can be less efficient due to slow mass transfer kinetics in heterogeneous systems. In contrast, the colloid enhanced ultrafiltration technique which is always performed in homogeneous phase can be highly efficient. Colloid Enhanced Ultrafiltration may be called Micellar Enhanced Ultrafiltration (MEUF) or Polyelectrolyte Enhanced Ultrafiltration (PEUF) depending upon the nature of the colloid (surfactant or polyelectrolyte) being used. When a ligand is added to the system to obtain the desired specificity, the method is generally known as Ligand Modified-PEUF or-MEUF. In this process a colloid is added to the waste stream with the specific ligand for the target actinide ion and the separation is achieved by ultrafiltration using a membrane of appropriate molecular weight cut off.

We have been able to use the water soluble Poly(diallyldimethylammonium chloride) polymer with carbonate ion and 1,2-Dihydroxy-3,5-benzenedisulfonic acid disodium salt (Tiron) ligands to separate uranium(vi) from solutions having $0.1-1 \mathrm{mM}$ concentrations to achieve separations of the order of up to 1000 to 10,000 times in the absence of any other salts. Interestingly, the ligand 1,2Dihydroxy-3,5-benzenedisulfonic acid has been found to give excellent separations even in the presence of excess added salt.

This separation technique which is analogous to solvent extraction in a liquid phase, has shown to be an effective method in the separation of copper ions in the presence of calcium. We intend to use a variety of specific ligands in this work, suitable for different environments of the waste matrices. The work using the carbonate ion and the tiron ligand has been partly completed. The carbonate anion binds strongly to uranyl ions specifically in the presence of many other ions. The subsequent formation of $\left[\mathrm{UO}_{2}\left(\mathrm{CO}_{3}\right)_{2}\right]^{2-}\left[\mathrm{UO}_{2}\left(\mathrm{CO}_{3}\right)_{3}\right]^{4-}$ and possibly some $\left.\left[\left(\mathrm{UO}_{2}\right)_{3} \mathrm{CO}_{3}\right)_{6}\right]^{6-}$ charged carbonate complexes with uranyl ion makes the tendency of the highly charged com- 


\begin{tabular}{|c|c|c|c|c|c|c|c|c|c|c|c|c|c|c|}
\hline 104 & 105 & 106 & 107 & 108 & 109 & 110 & 111 & 112 & (113) & (114) & (115) & (116) & (117) & (118) \\
\hline Rf & $\mathrm{Ha}$ & Sg & $\mathrm{N}_{8}$ & Hs & Mt & & & & &
\end{tabular}

\section{PROJECT REPORTS}

plexes to bind oppositely charged polymers great enough to result in strong binding. Similarly, the ligand 1,2-Dihydroxy-3,5-benzenedisulfonic acid disodium salt (tiron) forms a 3:3 complex having a high negative charge $(-8)$ at an optimum $\mathrm{pH}$ value of 5.3 which shows that this ligand can be better in tolerating higher excess salt concentrations. The PEUF being a continuous steady-state process, has the advantage over packed bed ion exchange processes in generating lower waste volume during recovery of the polymer or resin. The unique nature of the Ligand Modified Polyelectrolyte Enhanced Ultrafiltration method is that it can even be used with a mixture of a variety of ligands specific to each contaminant metal ion if necessary. These polyelectrolyte-based techniques generally have the potential to be economical low-energy processes with little or no discharge of hazardous material to the environment.

In studying the LM-PEUF process, dialysis experiments are allowed to progress until equilibrium is achieved. Although ultrafiltration and dialysis are fundamentally different processes, the concentration of ions passing through the membrane has been shown to closely approximate those concentrations in ultrafiltration under normal conditions in PEUF.

In the next stage of this research we intend to design some ligands forming inclusion complexes with actinides enabling us to achieve excellent separations in the presence of excess salts. Research is in progress to study the recovery of the polymer and the ligand from the concentrated waste.

\section{Note}

This work is funded by U.S. Department of Energy through Department of Chemistry, University of Oklahoma, Norman, Oklahoma, and the Glenn T. Seaborg institute for Transactinium Science at Lawrence Livermore National Laboratory.

\section{References}

1. An Equilibrium Model for Ligand-Modified Micellar Enhanced Ultrafiltration Using a Water-Insoluble Ligand Udeni R. Dharmawardana; Sherril D. Christian; Richard W. Taylor and John F. Scamehorn, Langmuir, 1992, 8, 414.

2. Ligand-Modified Polyelectrolyte-Enhanced Ultrafiltration: Use of Carbonate and 1,2-Dihydroxy-3,5benzenedisulfonic Acid to Remove U(VI) from Aqueous Solutions. Udeni R. Dharmawardana; Sherril D. Christian; Edwin E. Tucker; Richard W. Taylor and John F. Scamehorn, Poster Presentation, EMSP Work Shop, July 1998 


\begin{tabular}{|c|c|c|c|c|c|c|c|c|c|c|c|c|c|}
\hline $\begin{array}{l}90 \\
\text { Th }\end{array}$ & $\begin{array}{l}91 \\
\mathrm{~Pa}_{\mathrm{a}}\end{array}$ & $\begin{array}{r}92 \\
\mathrm{U}\end{array}$ & $\begin{array}{l}93 \\
N_{p}\end{array}$ & $\begin{array}{l}94 \\
\mathbf{P u}\end{array}$ & $\begin{array}{l}95 \\
\text { Am }\end{array}$ & $\begin{array}{l}96 \\
\mathrm{Cm}\end{array}$ & $\begin{array}{l}97 \\
\text { Bk }\end{array}$ & ${ }^{98}$ Cf & $\begin{array}{l}99 \\
\text { Es }\end{array}$ & $\begin{array}{c}100 \\
\mathrm{Fm}_{\mathrm{m}}\end{array}$ & $\begin{array}{l}101 \\
\text { Md }\end{array}$ & $\begin{array}{c}102 \\
\text { No }\end{array}$ & $\begin{array}{c}103 \\
\mathrm{~L}\end{array}$ \\
\hline
\end{tabular}

PROJECT REPORTS

\title{
Theoretical Chemistry of the Actinides and Transactinides
}

\author{
C.S. Nash \\ GTS-ITS, Lawrence Livermore National Laboratory
}

\section{INTRODUCTION}

The focus of our work has involved the development and application of relativistic effective core and spin-orbit potentials (RECPs) and the associated valence basis sets for the post-plutonium actinide $(95<Z \leq 103$ ) and transactinide $(103<Z \leq 118)$ elements. One might expect that these elements would behave according to their chemical group membership, but this is by no means certain. Unfortunately, the prospect of direct, experimental observation of the chemistry of many of these species seems bleak owing to their extremely short half-lives. This is especially true of the elements beyond fermium for which only a few atoms at a time have been produced.

The use of these effective core potentials permits a theoretical investigation of such atoms and their molecules and provides for us a window on a chemistry that might be otherwise inaccessible. RECPs allow the straightforward and computationally tractable incorporation of the major relativistic effects (spin-orbit coupling and shell structure effects, illustrated in Figure 1) into standard electronic structure calculations. They also permit the use of post-Hartree-Fock methods (configuration interaction, many-body perturbation theory, coupled-cluster theory, etc.) that include the effects of electron correlation which is necessary for even a semi-quantitative description of such things as bond energetics and molecular geometries, especially for these superheavy systems. We have thus far focused on the electronic structures of isolated atoms and simple molecules of actinides and transactinides. Among the latter are metallic hydrides, fluorides, and dimers. The goal of this initial research has been to illuminate the bonding interactions inherent in these systems in comparison to familiar analogs of the lower periods. We have found that the spin-orbit effect among the 7p-block transactinide elements results in a secondary periodicity wherein the closing of spin-orbit components of atomic shells is more chemically relevant than those of the atomic shells as a whole. We intend to continue and expand this work to include more chemically plausible systems and will address questions such as the stability of the $6 \mathrm{~d}$ analog of ferrocene, the determination of the macroscopic phase behavior element 114 (there are real prospects for the production of element 114 in quantity), and the chemical ramifications of the 'actinide contraction.'

So while the theoretical exploration of the chemistry of the synthetic actinide and transactinide elements remains one of the more robust challenges of modern chemistry, from the experimentalist's point of view more immediate difficulties arise from the need to perform many repeated, multistage chemical manipulations very quickly. It is therefore desirable to inform experimental design and implementation with predictions of how the synthesized elements might be expected to behave. Investigation of the most experimentally accessible species, the transactinide halides and oxyhalides, provides an opportunity for both established and developmental methods of computational 


\begin{tabular}{|c|c|c|c|c|c|c|c|c|c|c|c|c|c|c|}
\hline $\begin{array}{c}104 \\
\text { Rf }\end{array}$ & $\begin{array}{c}105 \\
\mathrm{H}\end{array}$ & $\begin{array}{r}106 \\
\mathrm{Sg}\end{array}$ & $\begin{array}{c}107 \\
N_{8}\end{array}$ & $\begin{array}{r}108 \\
\mathrm{H}\end{array}$ & $\begin{array}{r}109 \\
\mathrm{M}\end{array}$ & 110 & 111 & 112 & (113) & (114) & (115) & (116) & (117) & (118) \\
\hline
\end{tabular}

\section{PROJECT REPORTS}

chemistry to fill the void left by the paucity of experimental data regarding the chemistry of very heavy elements. The goal has been both to assist and support the experimental effort in the field by providing potentially useful insight into developing a consistent conceptual model of superheavy element chemistry.

We also plan to further pursue projects concerning the theoretical aqueous and solid state chemistry of the early to middle actinides. In particular, the oxoions AnOnq+ (An=Th-Es; $q=1,2,3$; $n=1,2,3)$ and their complexes are being studied. Such species are pertinent in any discussion of speciation and migration of plutonium in the environment. Although a good deal of work concerned with the macroscopic modeling of actinide-containing materials in soils and groundwaters is extant, these primarily rely on thermodynamic properties and very little is known of the relevant microscopic interactions involved. There has been surprisingly little work done on this problem at either the ab initio or density functional levels of theory, and we will continue our work to help to fill these gaps in the literature.

The questions we consider are these: (1) To what extent do relativistic effects (spin-orbit coupling and shell-structure effects) affect the chemistry of An-containing ions? (2) What role do non-relativistic quantum effects play in this chemistry and under what conditions, if any, is it appropriate to parameterize the actinyl ion in a molecular mechanics force field? (3) To what extent do ab initio solvation methods such as the effective fragment potential and polarized continuum models serve to represent the behavior of actinyl complexes in condensed phases? and (4) What is the most appropriate (useful and cost-effective) way to study actinide-containing species in Molecular Dynamics simulations of actinyl ions in condensed phases?

In addition, computational and methodological advances have allowed the detailed study of surface reactions and dynamics. A thorough understanding of surface reactivity is vital to address issues such as the long-term storage/disposal of actinide-containing materials. It is therefore of scientific and social interest to gain as much insight as possible into the chemical and physical properties of likely actinide wasteforms. An theoretical study into, for example, the interaction of water with an exposed $\mathrm{PuO}_{2}$ surface in its various allotropic forms would go a long way toward the refinement of such insight.

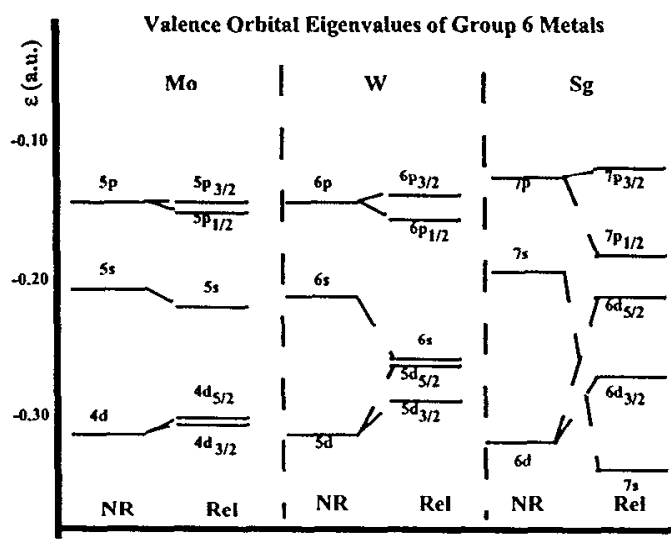

FIGURE 1. A comparison of relativistic (Rel) and non-relativistic (NR) atomic orbitals eigenvalues for the Group VI atoms. 


\begin{tabular}{|l|l|l|l|l|l|l|l|l|l|l|l|l|c|}
\hline 90 & 91 & 92 & 93 & 94 & 95 & 96 & 97 & 98 & 99 & 100 & 101 & 102 & 103 \\
Th & $\mathrm{Pa}_{2}$ & $\mathrm{U}$ & $\mathrm{Np}$ & $\mathrm{Pu}$ & $\mathrm{Am}$ & $\mathrm{Cm}$ & $\mathrm{Bk}$ & $\mathrm{Cf}$ & $\mathrm{Es}$ & $\mathrm{Fm}$ & $\mathrm{Md}$ & $\mathrm{No}$ & $\mathrm{Lr}$ \\
\hline
\end{tabular}

PROJECT REPORTS

\title{
Amarillo National Resource Center for Plutonium (ANRCP): Research and Education Program
}

\author{
Darleane C. Hoffman and Clinton Nash \\ GTS-I'TS, Lawrence Livermore National Laboratory and University of California:Berkeley and Lawrence Ber- \\ keley National Laboratory
}

\section{Introduction}

The U.S. Department of Energy is the only known entity performing research in actinide chemistry in the United States. There is no commercial incentive for performing research in actinide chemistry. The Glenn T. Seaborg Institute for Transactinium Science at Lawrence Livermore National Laboratory (GTS-ITS), is uniquely suited to conduct this type of research.

In consultation with the ANRCP staff, the scope of this project is entirely devoted to implementation and preparation of a reference report pertaining to the Advances in the Chemistry of Plutonium, 1967-97. This reference report will concentrate on the fundamental advances in the chemistry of plutonium made since 1967; the last time such a report was amassed.

This is a multi-authored report on advances in plutonium chemistry over the last 30 years and is intended as an authoritative and scholarly reference for the research chemist, professors, and upper division undergraduate and graduate students in chemistry and related disciplines. Included are chapters on the historical aspects of the discovery and use of plutonium, the currently known isotopes and a brief summary of their nuclear properties; electronic structure and properties, redox and radiolysis, amphorous solids, extended solids, separations chemistry (including some processing), metallurgy, environmental chemistry, non-ideal systems, interfacial/surface science, bioinorganic \& microbial, and future.

The GTS-ITS reference report is intended as one of three documents commissioned by the Amarillo National Resource Center for Plutonium. The other two reports, independent of this one, will cover "Plutonium in the Environment" (edited/written by Professor Randy Charbeneau) and "Health Effects and Radiation Safety Considerations," (edited/written by Professor John Poston) respectively.

The GTS-ITS will make a comprehensive review of the existing literature (in English) and prepare a bibliography of previously published reviews of plutonium chemistry and metallurgy, including reference books, text books, monographs, etc. (The most recent books devoted to plutonium chemistry were "The Chemistry of Plutonium" by J. M. Cleveland, published by the American Nuclear Society in 1979, and "Plutonium Chemistry", the collected papers from an ACS Symposium held in 1982, edited by Choppin \& Carnall. There is also a 2nd volume entitled "Plutonium Handbook--A Guide to the Technology" edited by O. J. Wick and published by the American Nuclear Society in 1980.) The GTS-ITS will determine what published unclassified reports or manuals exist at the DOE National Laboratories on plutonium chemistry, handling, and safe storage, and decide what 


\begin{tabular}{|c|c|c|c|c|c|c|c|c|c|c|c|c|c|c|}
\hline 104 & 105 & 106 & 107 & 108 & 109 & 110 & 111 & 112 & (113) & (114) & (115) & $(116)$ & (117) & (118) \\
\hline Rf & $\mathrm{Ha}$ & $\mathrm{Sg}$ & $\mathrm{Ng}$ & $\mathrm{Hs}$ & $\mathrm{Mt}$ & & & & &
\end{tabular}

\section{PROJECT REPORTS}

needs to be updated in the older books and handbook. The GTS-ITS will then go about preparing a comprehensive reference report on plutonium chemistry which can serve as a reference text for undergraduates and as a text for a specialized graduate level course as well as an authoritative source for workers in the field. The GTS-ITS has contacted experts in the field of actinide chemistry, both nationally and internationally, to ask for their input into this project. Meetings were held to discuss the chapter outlines for this reference report. Leading experts in the field have been identified and contacted to author chapters in this report. This report will contain information on the historical aspects, which will serve as an overall introduction to this report. Further information that this report will contain, Nuclear Properties, Electronic Structure and Properties, Redox and Radiolysis, Complexes and Coordination Chemistry, Organometallic Chemistry, Amphorous Solid, Extended Solids, Separations Chemistry, Environmental Chemistry, Non-ideal Systems, Interfacial/Surface Science, Bioinorganic \& Microbial, and a section on the Future of Pu chemistry, what can be expected, potential applications. Authors collaborating on this report include national/international representation from over thirteen experts in the field of actinide chemistry, from both national laboratories and academia. 


\begin{tabular}{|c|c|c|c|c|c|c|c|c|c|c|c|c|c|}
\hline 90 & 91 & 92 & 93 & 94 & 95 & 96 & 97 & 98 & 99 & 100 & 101 & 102 & 103 \\
Th & $\mathbf{P a}$ & $\mathrm{U}$ & $\mathrm{Np}$ & $\mathrm{Pu}$ & $\mathrm{Am}$ & $\mathrm{Cm}$ & $\mathrm{Bk}$ & $\mathrm{Cf}$ & $\mathrm{Es}$ & $\mathrm{Fm}$ & $\mathrm{Md}$ & No & $\mathrm{Lr}$ \\
\hline
\end{tabular}

PERSONNEL

\section{SECTION 3:PERSONNEL}

\section{Organizational Chart}

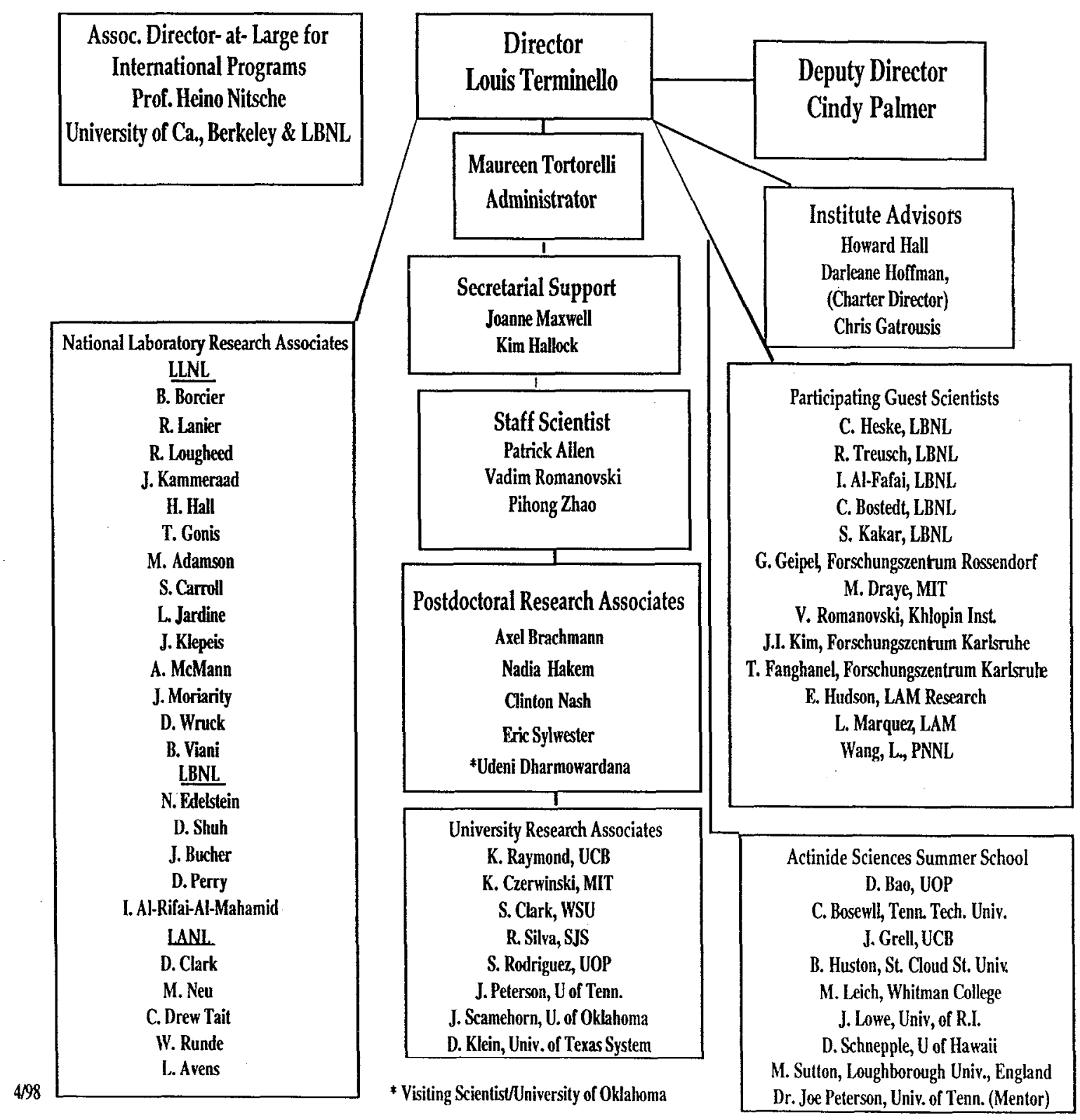




\begin{tabular}{|r|c|c|c|c|c|c|c|c|c|c|c|c|c|c|}
\hline 104 & 105 & 106 & 107 & 108 & 109 & 110 & 111 & 112 & (113) & $(114)$ & $(115)$ & $(116)$ & $(117)$ & $(118)$ \\
\hline Rf & $\mathrm{Ha}_{2}$ & $\mathrm{Sg}$ & $\mathrm{Ns}$ & $\mathrm{H} s$ & $\mathrm{Mt}$ & & & & &
\end{tabular}

PERSONNEL

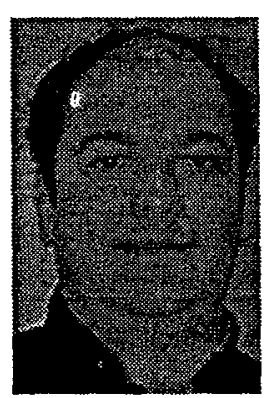

\section{Patrick Allen}

STAFF SCIENTIST

Phone: (925) 423-8955

Fax: (925) 422-3160

Email: allen42@IInl.gov

\section{Background}

Fourteen years experience in physical chemistry; Staff Chemist, GTS-ITS, 1998-present; Staff Chemist, Lawrence Berkeley National Laboratory, 1997; Post-doc, LLNL, 1995-1996; Post-doc, Los Alamos National Laboratory, 1993-1994; Ph.D., University of Michigan,1993; B.S. 1986, University of Cincinnati.

\section{Research Interests}

Structural and environmental chemistry of actinide elements and fission products; Spectroscopic characterization techniques-primarily Synchrotron based X-ray Absorption Spectroscopy (XAS); studies on the speciation and chemistry of actinides in aqueous systems and solid -state materials.

\section{Recent Publications}

1. P.W. Durbin, B. Kullgren, J. Xu, K.N. Raymond, P.G. Allen, J.J. Bucher, N.M. Edelstein, and D.K. Shuh., "Neptunium(237): Oxidation State In Vivo and Chelation by Multidentate Catecholate and Hydroxypyridinonate Ligands," Health Physics, 75, 34-50, 1998.

2. X. Feng, H. Li, J. G. Darab, M. J. Schweiger, J. D. Vienna, B. C. Bunker, P. G. Allen, D. K. Shuh, J. J. Bucher, N. M. Edelstein, R. C. Ewing, and L. M. Wang, "Distribution and Solubility of Radionuclides in Waste Forms for Disposition of Pu and Spent Nuclear Fuels," Int'l. Symp. On Waste Mgmt. Tech., American Ceramic Society National Meeting, Cincinnati, OH, May 1998.

3. M. A. Denecke, T. Reich, S. Pompe, M. Bubner, K. H. Heise, P. G. Allen, D. K. Shuh, J. J. Bucher, N. M. Edelstein. "Determination of Structural Parameters of Uranyl Ions Complexed with Organic Acids Using EXAFS.," J. Alloys and Compounds, 271, 123-127, 1998. 


\begin{tabular}{|c|c|c|c|c|c|c|c|c|c|c|c|c|c|}
\hline $\begin{array}{l}90 \\
\text { Th }\end{array}$ & $\stackrel{91}{\mathrm{~Pa}^{2}}$ & $\int^{92} \mathrm{U}$ & $\begin{array}{l}93 \\
\mathbf{N p}\end{array}$ & $\mathrm{94}_{\mathrm{Pu}}$ & $\begin{array}{l}95 \\
\text { Am }\end{array}$ & $\begin{array}{l}96 \\
\mathrm{Cm}\end{array}$ & $\begin{array}{l}97 \\
\text { Bk }\end{array}$ & ${ }^{98}$ Cf & $\begin{array}{l}99 \\
\text { Es }\end{array}$ & $\begin{array}{c}100 \\
\mathrm{Fm}_{\mathrm{m}}\end{array}$ & $\begin{array}{l}101 \\
\text { Md }\end{array}$ & $\begin{array}{c}102 \\
\text { No }\end{array}$ & $\begin{array}{c}103 \\
\mathrm{Lr}\end{array}$ \\
\hline
\end{tabular}

PERSONNEL

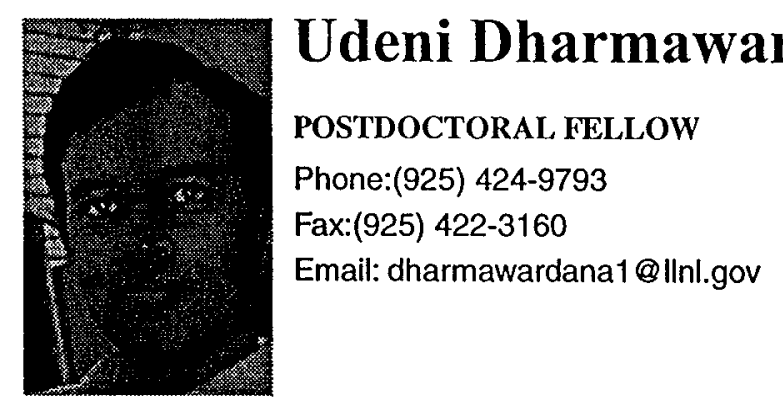

\section{Background}

Participating Guest, GTS-ITS 1998; Research Scientist, Institute of Applied Surfactant Research, University of Oklahoma, 1992-1997; Ph. D. , Physical Chemistry, University of Oklahoma, 1992; B.S. \& M. Phil., University of Colombo, Colombo, Sri Lanka, 1986.

\section{Research Interests}

Fundamental surfactant properties and applications; Inclusion complexes of cyclodextrins with surfactant molecules; Ultrafiltration and use of colloids in waste remediation; Studies of surfactant flusing of soils to remove contaminants from the ground. Metal-Ligand complexation studies; Use of ligand localized synthetic polymers, ligand incorporated surfactant micelles and ligand attached polyelectrolytes in selective separation of metal ions. Selective separation of radionuclide ions $(U$, Th and $\mathrm{Pu}$ ) from nuclear waste by Ligand-Modified Colloid Enhanced Ultrafiltration. Thermodynamic modeling of separation processes.

\section{Recent Publications}

1. U. R. Dharmawardana, S. D. Christian, E. E. Tucker; R. W. Taylor; J. F. Scamehorn. "A Surface Tension Method to Determine Binding Constants of Inclusion Complexes of b-cyclodextrin With Surfactants," Langmuir, 9,2258, 1993.

2. U. R. Dharmawardana; S. D. Christian; R. W. Taylor; J. F. Scamehorn., "An Equilibrium Model for the Ligand Modified Micellar Enhanced Ultrafiltration process Using a Water insoluble Ligand," Langmuir, 8, 414, 1992. 


\begin{tabular}{|c|c|c|c|c|c|c|c|c|c|c|c|c|c|c|}
\hline $\begin{array}{c}104 \\
\mathbf{R f} \\
\end{array}$ & $\begin{array}{c}105 \\
\mathrm{Ha} \\
\end{array}$ & $\begin{array}{r}106 \\
\mathrm{Sg} \\
\end{array}$ & $\begin{array}{c}107 \\
\mathrm{Ns}_{\mathrm{s}}\end{array}$ & $\begin{array}{c}108 \\
H_{s}\end{array}$ & $\begin{array}{c}109 \\
\mathrm{Mt}\end{array}$ & 110 & 111 & 112 & (113) & (114) & (115) & (116) & (117) & (118) \\
\hline
\end{tabular}

\section{PERSONNEL}

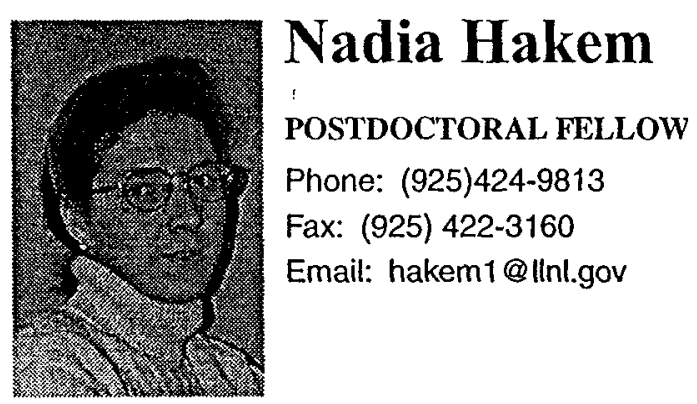

\section{Background}

Postdoctoral fellow, GTS-ITS, 1998-present ; Postdoctoral fellow, Lawrence Berkeley National Laboratory, University of California, Berkeley1995-98-; Ph.D. in Radiochemistry, University of Paris-XI, France, 1995; Masters degree in Radiochemistry, University of Paris-XI, France, 1992; Research Interests; Engineering Degree,Environmental Chemistry, Polytechnic School of Algeria, 1991.

\section{Research Interests}

Behavior of radionuclides in the environment; Plutonium complexation with organic and inorganic chelating agents (OHER Project); Neptunium Solubility in Concentrated Salt Solutions (WIPP Project); Sorption of Cesium and Strontium on Savannah River Soil and Hanford Sand (VLB project); Accumulation of Plutonium and Neptunium by bacteria (LDRD, LBNL); Thermodynamics of the Volatilization of Actinides Metals in the High-Temperature, Treatment of Radioactive Wastes (EMSP Project).

\section{Recent Publications}

1. G.F. Novak, I. Al Mahamid, K. Becraft, S. Carpenter, N.Hakem and T. Prussin, "Measurement and Thermodynamic Modeling of $\mathrm{Np}(\mathrm{V})$ Solubility in Aqueous K2 $\mathrm{CO} 3$ Solutions to High Concentrations", Journal of Solution Chemistry, 26, (7), 1997.

2. I. Al Mahamid, G.F. Novak, K. Becraft, S. Carpenter, N.Hakem, " Solubility of $\mathrm{Np}(\mathrm{V})$ in $\mathrm{K}-\mathrm{Cl}-\mathrm{CO} 3$ and $\mathrm{Na}-\mathrm{K}-\mathrm{Cl}-\mathrm{CO} 3$ Solutions to High Concentrations: Measurements and Thermodynamic Model Predictions, Radiochimica Acta, 81, (1998).

3. N. Hakem, I. Al Mahamid, J. Apps and G. Moridis, "Sorption of Cesium and Strontium on Savannah River Soil Impregnated with Colloidal Silica", Lawrence Berkeley National Laboratory Report, LBNL39498, UC-600 (1997). 


\begin{tabular}{|c|c|c|c|c|c|c|c|c|c|c|c|c|c|}
\hline 90 & 91 & 92 & 93 & 94 & 95 & 96 & 97 & 98 & 99 & 100 & 101 & 102 & 103 \\
\hline $\mathbf{T h}$ & $\mathrm{Pa}$ & $\mathrm{U}$ & $\mathrm{Np}$ & $\mathbf{P u}$ & $\mathrm{Am}$ & $\mathrm{Cm}$ & $\mathrm{Bk}$ & $\mathrm{Cf}$ & $\mathrm{Es}$ & $\mathrm{Fm}$ & $\mathrm{Md}$ & $\mathrm{No}$ & $\mathrm{Lr}$ \\
\hline
\end{tabular}

PERSONNEL

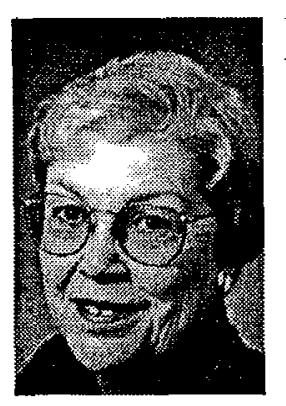

\section{Darleane Hoffman}

\section{CHARTER DIRECTOR}

Phone: (925) 423-5031

Fax: (925) 422-3160

Email: hoffman@|bl.gov

\section{Background}

Recipient of the 1997 National Medal of Science Award. Group Leader, Heavy Element Nuclear \& Radiochemistry Group, Lawrence Berkeley National Laboratory (1984 -present); Charter Director, GTS-ITS, (1991 - 96). Previous positions: Los Alamos National Laboratory, Division Leader, Chemistry-Nuclear Chemistry, and Isotope and Nuclear Chemistry Divisions, 1979-84; Los Alamos Scientific Laboratory, Staff Member, Associate Group Leader, Radiochemistry Group, 19531979; Guggenheim Fellowship at Lawrence Berkeley National Laboratory, 1978-79.

\section{Research Interests}

Atom-at-a-time studies of the nuclear and chemical properties of the heaviest elements and spontaneous fission properties, studies of radionuclide migration in the environment, and fast radiochemical separations of actinides and lanthanides. Dr. Hoffman has approximately 200 publications in these fields.

\section{Recent Publications}

1. D. C. Hoffman, "Frontiers of Heavy Element Nuclear and Radiochemistry", Asia-Pacific Symposium on RadioChemistry '97, Kumamato, Japan, Oct. 6-9, 1997, LBNL-40908 (October, 1997), Proceedings, J. Radioanal. Nucl. Chem. 239, (1), 1999.

2. W. Paulus, J. V. Kratz, E. Strub, S. Zauner, W. Brüchle, V. Pershina, M. Schädel, B. Schausten, J. L. Adams, K. E. Gregorich, D. C. Hoffman, C. Laue, D. M. Lee, C. A. McGrath, D. K. Shaughnessy, D. A. Strellis, E. R. Sylwester, "Extraction of the Fluoride-, Chloride-, and Bromide Complexes of the Elements Nb, Ta, Pa, and 105 into Aliphatic Amines", Actinides -97, Baden-Baden, Germany, Sept. 21-26, 1997, J. of Alloys and Comp., 292, 271-273, 1998.

3. M. Schädel, W. Brüchle, R. Dressler, B. Eichler, H. W. Gäggeler, R. Günther, K. E. Gregorich, D. C. Hoffman, S. Hübener, D. T. Jost, J. V. Kratz, W. Paulus, D. Schumann, S. Timokhin, N. Trautmann, A. Türler, G. Wirth and A. Yakuschev, "Chemical properties of element 106 (seaborgium)", Nature (Letters), 388, 55, 1997. 


\begin{tabular}{|c|c|c|c|c|c|c|c|c|c|c|c|c|c|c|}
\hline $\begin{array}{c}104 \\
\text { Rf }\end{array}$ & $\begin{array}{c}105 \\
\mathrm{Ha} \\
\end{array}$ & $\begin{array}{r}106 \\
\mathrm{Sg}\end{array}$ & $\begin{array}{r}107 \\
\text { No }\end{array}$ & $\begin{array}{c}108 \\
\mathrm{H}_{\mathrm{s}} \\
\end{array}$ & $\begin{array}{c}109 \\
\mathrm{M}\end{array}$ & 110 & 111 & 112 & (113) & (114) & (115) & (116) & (117) & (118) \\
\hline
\end{tabular}

\section{PERSONNEL}

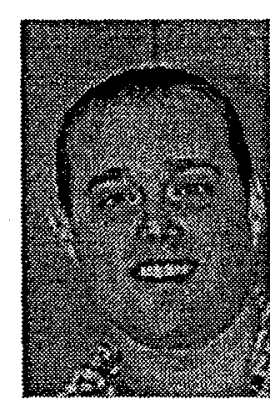

\section{Clinton Nash}

\section{POSTDOCTORAL FELLOW}

Phone: (925) 423-7517

Fax: (925) $422-3160$

Email: nash6@ilnl.gov

\section{Background}

Postdoctoral Fellow, GTS-ITS, 1997 - present;Lecturer, General Chemistry for Non-Majors, Ohio State University, 1997; Ph. D. , Physical Chemistry, Ohio State University, 1996. Lecturer, General Chemistry Laboratory, Department of Chemistry, Ohio Wesleyan University, 1995-; M.S. , Physical Chemistry, Ohio State University, 1994; Graduate Research/Teaching Associate, Department of Chemistry-Ohio State University, 1990-96; ACS certified B.A. in Chemistry -Ohio Wesleyan University,1990. Graduated magna cum laude, Phi Beta Kappa.

\section{Research Interests}

Pu chemistry, solvent extraction, ion exchange and ultrafiltration techniques for waste treatment, oscillatory extraction of rare earth and uranium, fissile materials disposition.

\section{Recent Publications}

1. C. S. Nash and B. E. Bursten "Spin-Orbit Coupling vs. the VSEPR. Method: On the Possibility of a Nonplanar Structure for the Superheavy Noble-Gas Tetrafluoride [118]F4." Angewandte Chimie 38 (151), 1999.

2. C.S. Nash, B. E. Bursten, and W. C. Ermler "Ab Initio Relativistic Effective Core Potentials with SpinOrbit Operators VII. Am-Element 118." Journal of Chemical Physics 106, 5133-5142, 1997.

3. C. S. Nash and B. E. Bursten"Comparisons among transition metal, actinide, and transactinide complexes: The relativistic electronic structures of $\mathrm{Cr}(\mathrm{CO}) 6, \mathrm{~W}(\mathrm{CO}) 6, \mathrm{U}(\mathrm{CO}) 6$, and $\mathrm{Sg}(\mathrm{CO}) 6$." New J. Chem 19, 669-675, 1995. 


\begin{tabular}{|c|c|c|c|c|c|c|c|c|c|c|c|c|c|}
\hline 90 & 91 & 92 & 93 & 94 & 95 & 96 & 97 & 98 & 99 & 100 & 101 & 102 & 103 \\
Th & Pa & U & Np & Pu & Am & Cm & Bk & Cf & Es & Fm & Md & No & Lr \\
\hline
\end{tabular}

PERSONNEL

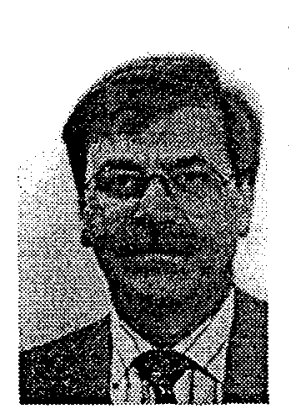

\section{Heino Nitsche}

\section{ASSOCIATE DIRECTOR- AT -LARGE FOR}

INTERNATIONAL PROGRAMS

University of California -Berkeley and Lawrence Berkeley National Laboratory

Phone: (510) 486-5615

Fax: (510) 486-7444

Email: Hnitsche@lbl.gov

\section{Background}

University of California Berkeley, Department of Chemistry, November 1998 -present: Professor of Chemistry (senior faculty); Lawrence Berkeley National Laboratory, November 1998-present: Director, Center for Advanced Environmental and Nuclear Studies; Forschungszentrum Rossendorf e.V., 1993 -98: Director, Institute of Radiochemistry Head (elected), Scientific Technical Council, 1996 -98; Technische Universität Dresden, 1993-98; Professor of Radiochemistry, tenured (C4); Gesellschaft Deutscher Chemiker (GDCh, German Chemical Society), Fachgruppe Nuklearschmie (Nuclear Chemistry Section), Chairman, 1997-98; GTS-ITS at LLNL: Associate Director-at-Large for International Programs, 1993-present; Lawrence Berkeley Laboratory/University of California, 1980-93; Principal Investigator, Staff Scientist 3, Earth Sciences Division, 1984 -93; Staff Scientist 2, Materials and Molecular Sciences Division, 1980 -84; California State University, 1989 -93; Senior Lecturer, Nuclear and Radiochemistry, Actinide and Lanthanide Chemistry.

\section{Research Interests}

Molecular-level research related to the behavior of actinides in the environment; mechanistic understanding of transport processes and migration of radioactive substances in the biosphere; thermodynamic and kinetic properties of actinides; production and chemistry of the heaviest elements; analytical chemistry of radionuclides. Development of metal-biological systems for bioremediation. Synchrotron research to elucidate molecular-level interfacial processes of radioactive materials with natural and anthropogenic substrates. In vivo application of radionuclides in nuclear medicine.

\section{Recent Publications}

1. S. Pompe, A. Brachmann, M. Bubner, G. Geipel, K.H. Heise,G. Bernhard, H. Nitsche, "Determination and comparison of uranyl complexation constants with natural and model humic acids," Radiochim. Acta 82, 89. 1998.

2. G. Bernhard, G. Geipel, V. Brendler, H. Nitsche, Uraniumspeciation in waters of different uranium mining areas; J. Alloys and Compounds 201, 271-273, 1998. 


\begin{tabular}{|c|c|c|c|c|c|c|c|c|c|c|c|c|c|c|}
\hline 104 & 105 & 106 & 107 & 108 & 109 & 110 & 111 & 112 & (113) & (114) & (115) & (116) & (117) & (118) \\
\hline
\end{tabular}

\title{
PERSONNEL
}

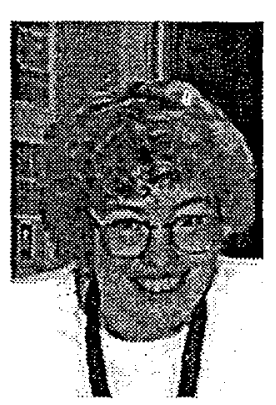

\section{Cynthia Palmer}

\author{
DEPUTY DIRECTOR
}

Phone: (925) 422-5693

Fax: (925) $422-3160$

Email: palmer2@Innl.gov

\section{Background}

Deputy Project Leader for the Yucca Mountain Project, and Deputy Director of the GTS-ITS 1989 Present. In the environmental field: PI for the Waste Isolation Pilot Plant, the Nevada Environmenatal Applied Research Project, and the Hydrology and Radianuclide Migration Project. In addition, Core Sampling Project Leader, Detector Custodian (neutrons and charged particles, Radio chemical Diagnostic Chemist and current Task Leader in the Plutonium Diposition Program. P.I. for LDRD project funded through the Energy Directorate. B.S., Chemistry, Worcester Polytechnic Institute, 1991;Postdoctoral Research Associate, LLNL, 1987-89; Ph.D., Inorganic Chemistry, Purdue Unviersity ,1987.

\section{Research Interests}

Physical, inorganic chemistry, actinide spectroscopy (optical), and thermodynamic properties of the actinides and fission products.

\section{Recent Publications}

1. P. Zhao, V.V. Romanovski, D.C. Hoffman, C.E.A. Palmer, D.W. Whisenhunt Jr., P.G. Allen, D.K. Shuh, J.J. Butcher, N.M. Edelstein, D. J. White, X. Jide, K.N. Raymond, "Spectroscopic Study of Chelation between Pu and Modified Siderophores." In Proc. of the Plutonium Futures - The Science, Topical Conference on Plutonium and Actinides, August 25-27, 1997, pp. 73-75, Santa Fe, New Mexico,USA.

2. D.A. Wruck, P. Zhao, C. E. A. Palmer, R.J. Silva, "Stability of Quotients of Neodymium Acetate Complexes from 20 to $70^{\circ} \mathrm{C}$ by Laser-Induced Photoacoustic Spectroscopy." J. Solution Chemistry 26(3), 267-275, 1997.

3. P. G. Allen, D. K. Shuh, J. J. Bucher, N. M. Edelstein, C. EA. Palmer, L. N. Marquez, E. A. Hudson, R. J. Silva, S. N. Nguyen. "EXAFS Determinations of Uranium Structures: Schoepite and Other U(VI) Oxide Precipitatcs," Radiochim. Acta 75, 47-53, 1997. 


\begin{tabular}{|c|c|c|c|c|c|c|c|c|c|c|c|c|c|}
\hline 90 & 91 & 92 & 93 & 94 & 95 & 96 & 97 & 98 & 99 & 100 & 101 & 102 & 103 \\
Th & Pa & U & Np & Pu & Am & Cm & Bk & Cf & Es & Fm & Md & No & Lr \\
\hline
\end{tabular}

PERSONNEL

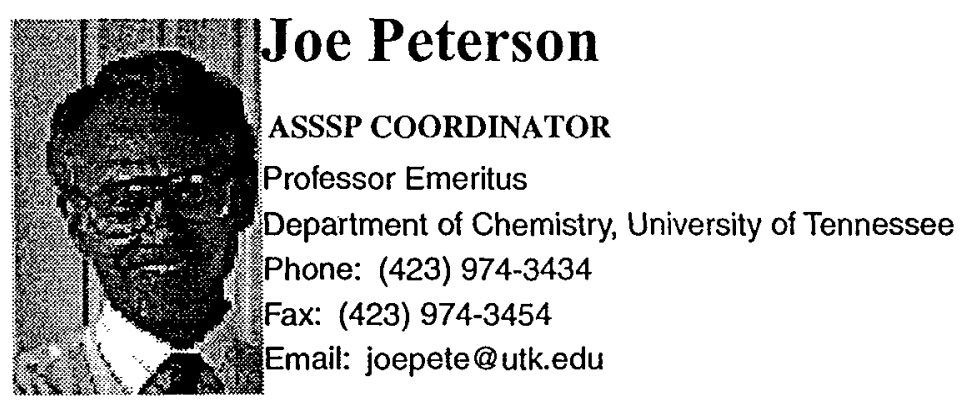

\section{Background}

1997- Present, Professor Emeritus, University of Tennessee, Knoxville ; 1997, Visiting Scientist, Institute for Nuclear Chemistry, Johannes-Gutenberg University, Mainz, Germany;1993-present, Adjunct Research and Development Participant III, Oak Ridge National Laboratory;1979-Present, Professor, University of Tennessee, Knoxville; 1981-84, 1986-89, Visiting Scientist, European Institute for Transuranium Elements, Karlsruhe, Germany; 1981-82, Visiting Scientist, Nuclear Research Center, Karlsruhe, Germany; 1977-93, Adjunct Research and Development Participant II, Oak Ridge National Laboratory ; 1973-79, Associate Professor, University of Tennessee, Knoxville; 1971-73, Assistant Professor (with tenure), University of Tennessee, Knoxville; 1969-70, NATO Postdoctoral Fellow in Science, University of Liège (Belgium), Assistant Professor (without tenure), University of Tennessee, Knoxville,1967-70.

\section{Research Interests}

Determination, interpretation, and correlation of the basic chemical and physical properties of the $f$ elements-the lanthanides (4f) and actinides (5f). Knowledge of the properties of these elements (especially the actinides) is important for understanding their position in the periodic tableand for it's fundamental architecture, as influenced by relativistic effects which become more prominent in the heavy element region.

\section{Recent Publications}

1. J. B. Burns, R. G. Haire, and J. R. Peterson, "Enthalpy of Solution of Californium Oxychloride; Calculationof the Standard Enthalpy of Formation of CfOCl," J. Alloys Comp., 271-273,676-679, 1998.

2. J. R.Peterson, N. Erdmann, M. Nunnemann, K. Eberhardt, G., Herrmann, G. Huber, J. V. Kratz, G. Passler, O. Stetzer, P., Thörle, N. Trautmann, and A. Waldek., "Determination of the First Ionization Potential of Einsteiniumby Resonance Ionization Mass Spectroscopy (RIMS)," J. Alloys Comp., 271273, 876-878,1998. 


\begin{tabular}{|c|c|c|c|c|c|c|c|c|c|c|c|c|c|c|}
\hline 104 & 105 & 106 & 107 & 108 & 109 & 110 & 111 & 112 & & & & & & \\
Rf & $\mathrm{Ha}$ & $\mathrm{S}$ & $\mathrm{N}$ & $\mathrm{Hs}$ & $\mathrm{Mt}$ & & & & $(113)$ & $(114)$ & $(115)$ & $(110)$ & $(117)$ & $(118)$ \\
\hline
\end{tabular}

\section{PERSONNEL}

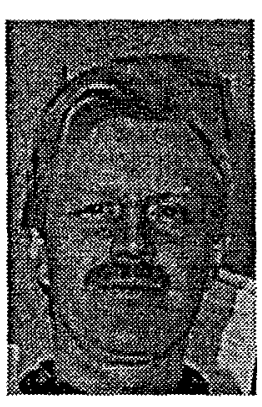

\section{Vadim Romanovski}

\section{STAFF CHEMIST}

Phone: (925) 423-9044

Fax: 925) 422-3160

Email: romanovski1@llnl.gov

\section{Background}

Fourteen years experience in radiochemistry and radiochemical technology; Staff Scientist, GTSITS, 1998-present; Postdoctoral Research Associate, 1995-98; Visiting Scientist, Battelle Pacific Northwest Laboratories, 1993-94; Staff Scientist, 1993-95; Graduate Student 1990-93, M.S. 1987, Ph.D. 1993, Engineer 1987-90, St.-Petersburg Institute of Technology.

\section{Research Interests}

Pu chemistry, solvent extraction, ion exchange and ultrafiltration techniques for waste treatment, oscillatory extraction of rare earth and uranium, fissile materials disposition

\section{Recent Publications}

1. V.V. Romanovski, D.J. White, Jide Xu, D.C. Hoffman, and K.N. Raymond, "Plutonium(IV) and Plutonium(VI) Extraction by 1-hydroxy-6-N-octylcarboxamide-2(1H)-pyridinone," Accepted for publication in Solvent Extraction and Ion Exchange, 1998

2. M.A. Afonin, V.V. Romanovski, and V.A. Scherbakov, "Oscillatory Extraction of Uranium," Solvent Extraction and Ion Exchange 16, pp. 1215-1231,1998.

3. P. Zhao, V.V. Romanovski, D.W. Whisenhunt Jr., T. R. Mohs, Jide Xu, D.C. Hoffman, K.N. Raymond, "Extraction of Plutonium by Chelating Hydroxypyridinone and Catecholamide resins," Submitted to Solvent Extraction and Ion Exchange, 1998 


\begin{tabular}{|l|l|l|l|l|l|l|l|l|l|l|l|l|l|}
\hline 90 & 91 & 92 & 93 & 94 & 95 & 96 & 97 & 98 & 99 & 100 & 101 & 102 & 103 \\
Th & $\mathrm{Pa}_{2}$ & $\mathrm{U}$ & $\mathrm{Np}$ & $\mathrm{Pu}$ & $\mathrm{Am}$ & $\mathrm{Cm}$ & $\mathrm{Bk}$ & $\mathrm{Cf}$ & $\mathrm{Es}$ & $\mathrm{Fm}$ & $\mathrm{Md}$ & $\mathrm{No}$ & $\mathrm{Lr}$ \\
\hline
\end{tabular}

PERSONNEL

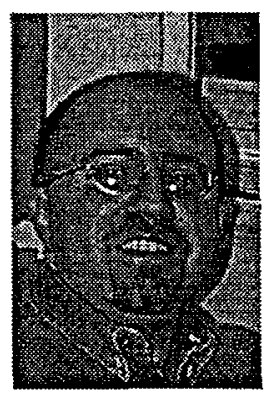

\section{Louis Terminello}

DIRECTOR

Phone: (925)423-3755

Fax: (925) 422-3160 Fax

Email: terminello1@IInl.gov

\section{Background}

Director, GTS-ITS, 1996 - Present; Lou Terminello was appointed as an Adjunct Associate Professor, in the Dept. of Applied Science, University of California, Davis, 1995. Principal investigator, Basic Energy Sciences initiative on Advanced Heterointerfaces ,as well as, other materials characterization projects, 1993. Postdoctoral fellow, IBM Yokrtown Heights, 1991. Ph. D. , Physical Chemistry, Univ. of Calif.-Berkeley, 1988; B.S., Chemistry, M.I.T., 1983.

\section{Research Interests}

Atomic and electronic structure determination of novel materials using synchrotron radiation photo-emission and absorption; including photoelectron holography and valence band imaging studies of electronic materials surfaces and interfaces. He nearly 100 publications, given 135 presentations, and edited 4 books.

\section{Recent Publications}

1. Jimenez, I; Garcia, MM; Albella, JM; Terminello, LJ., "Orientation of graphitic planes during the biasenhanced nucleation of diamond on silicon: An x-rayabsorption near-edge study.," Applied Physics Letters 73(20), 2911-2913, 1998.

2. Jimenez, I; Sutherland, DGJ; vanBuuren, T; Carlisle, JA; Terminello, LJ; Himpsel, FJ, “ Photoemission and $\mathrm{x}$-ray-absorption study of boron carbide and its surface thermal stability," Physical Review B-Condensed Matter 57(20), 13167-13174, 1998.

3. Garcia, MM; Jimenez, I; Vazquez, L; GomezAleixandre, C; Albella, JM; Sanchez, O; Terminello, LJ; Himpsel, FJ. "X-ray absorption spectroscopy and atomic force microscopy study of bias-enhanced nucleation of diamond films," Applied Physics Letters 72(17), 2105-2107, 1998. 


\begin{tabular}{|c|c|c|c|c|c|c|c|c|c|c|c|c|c|c|}
\hline $\begin{array}{c}104 \\
\text { Rf }\end{array}$ & $\begin{array}{c}105 \\
\mathbf{H a}\end{array}$ & $\begin{array}{c}106 \\
\text { Sg }\end{array}$ & $\begin{array}{c}107 \\
\mathrm{Ns}\end{array}$ & $\begin{array}{c}108 \\
\mathrm{H}_{8}\end{array}$ & $\begin{array}{c}109 \\
\text { Mt }\end{array}$ & 110 & 111 & 112 & (113) & (114) & (115) & (116) & (117) & (118) \\
\hline
\end{tabular}

\section{PERSONNEL}

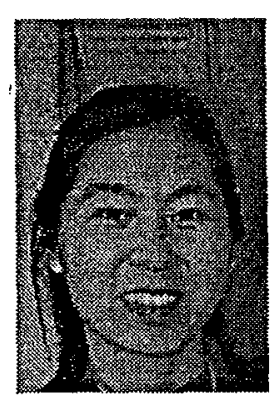

\section{Pihong Zhao}

\section{STAFF SCIENTIST}

(925) $422-4973$

(925) 422-3160 Fax

zhao1@Ilnl.gov

\section{Background}

Staff Scientist, GTS-ITS, 1997-present; Postdoctoral Fellow, University of the Pacific, 1994-1997; Ph.D., University of the Pacific, 1994; Lecturer, Wuhan University, 1985-1989; B.S.1982, M.S.1985, Wuhan University, China

\section{Research Interests}

Actinide chemistry focusing on thermodynamic studies of actinides in aqueous solutions relevant to environmental conditions; migration of radioactive nuclides in waste forms, repositories and geologic media; development of Pu separation techniques for nuclear waste remediation.

\section{Presentations}

1. Pihong Zhao, V. V. Romanovski, D.C. Hoffman, C. E. A. Palmer, D.W. Whisenhunt Jr., P.G. Allen, D.K. Shuh, J.J. Bucher, N.M. Edelstein, T.R. Mohs, D.J. White, J. Xu, K.N. Raymond "Studies on Chelating Reactions between Plutonium and Siderophore-Based Resins." Oral Presentation, 34th ACS Western Regional Meeting, San Francisco, CA, Oct. 28-31, 1998.

2. W.L. Bourcier, P. Zhao, B.K. Esser "Dissolution Testing and Modeling of Titanate-Based Ceramic Waste Forms for Fissile Materials Disposition." Oral Presentation, ANS 3rd Topical Meeting on DOE Spent Nuclear Fuel and Fissile Materials Management, Charleston, SC, Sep. 8-11, 1998.

3. W.L. Bourcier, P. Zhao, B.K. Esser "Dissolution Testing and Modeling of Ceramic Waste Forms for Fissile Materials Disposition." Oral presentation, 215th ACS National Meeting, Dallas TX, March 1998. 


\begin{tabular}{|c|c|c|c|c|c|c|c|c|c|c|c|c|c|}
\hline 90 & 91 & 92 & 93 & 94 & 95 & 96 & 97 & 98 & 99 & 100 & 101 & 102 & 103 \\
$\mathrm{Th}$ & $\mathrm{Pa}$ & $\mathrm{U}$ & $\mathrm{Np}$ & $\mathrm{Pu}$ & $\mathrm{Am}$ & $\mathrm{Cm}$ & $\mathrm{Bk}$ & $\mathrm{Cf}$ & $\mathrm{Es}$ & $\mathrm{Fm}$ & $\mathrm{Md}$ & $\mathrm{No}$ & $\mathrm{Lr}$ \\
\hline
\end{tabular}

\section{SECTION 4: ACTINIDE SCIENCE SUMMER SCHOOL PROGRAM}

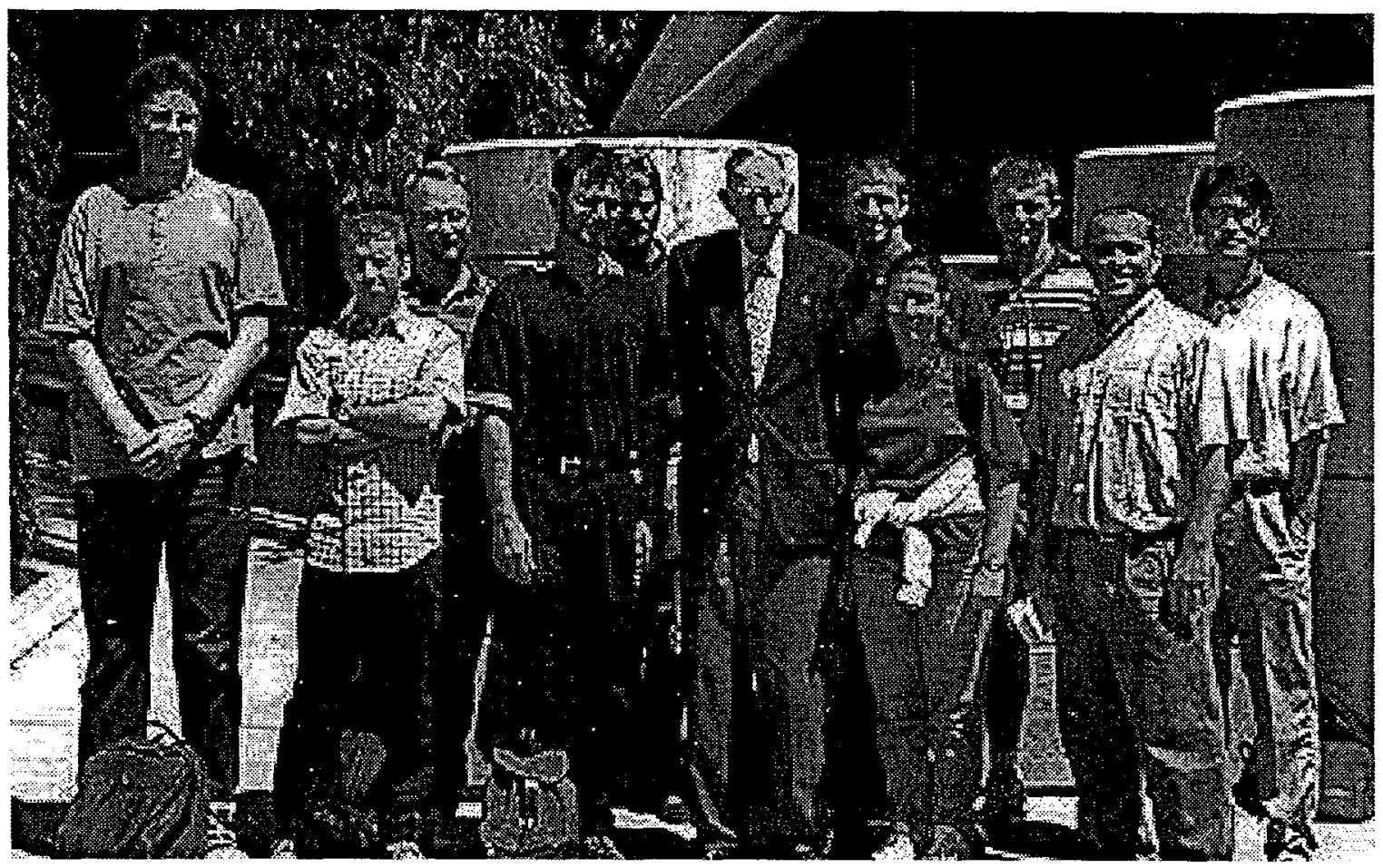




\begin{tabular}{|c|c|c|c|c|c|c|c|c|c|c|c|c|c|c|}
\hline 104 & 105 & 106 & 107 & 108 & 109 & 110 & 111 & 112 & (113) & (114) & (115) & $(110)$ & (117) & (118) \\
\hline Rf & $\mathrm{H}_{2}$ & $\mathrm{~S}_{8}$ & $\mathrm{Ns}$ & $\mathrm{H}_{8}$ & $\mathrm{Mt}$ & & & &
\end{tabular}

\section{ASSSP}

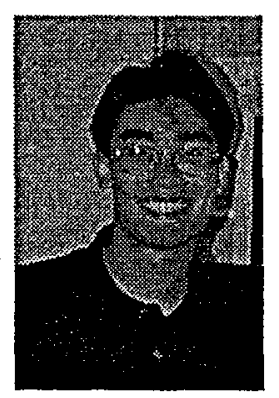

\section{David Bao}

Background

David Bao is an honors pharmacy student at the University of the Pacific in Stockton, California pursuing a PharmD degree. He has been awarded a Regent's scholarship to UOP, as well as scholarships from his hometown medical center in Los Alamitos, California. He is ranked in the top $10 \%$ in ACS general chemistry standardized exams. A current member of the Academy of Students of Pharmacy, David is also actively involved in UOP student life as a resident assistant and as an academic advisor to freshman pre-pharmacy students. David has had previous laboratory experience at LLNL as a Student Guest.

\section{Research Interests}

Use of radioactive nuclides in medicine.

\section{Summer LLNL Project}

David is working with mentor David Wruck of the Isotope Sciences Division and fellow ASSSP student Megan Leich on Raman spectroscopy of samples containing thorium. Their work will determine the locations of the peaks that are characteristic to various thorium compounds. The sets of peaks will act as "fingerprints" for the thorium compounds, allowing for easy identification in a wide variety of applications. One common use will be in detecting the presence of these thorium compounds in unknown samples by use of the fingerprints. Knowing the Raman spectrum will also help determine the structure of a thorium compound. Detecting thorium compounds in nuclear wastes is a particularly interesting application, because of its usefulness in characterizing nuclear waste for disposal in a repository. 


\begin{tabular}{|l|l|l|l|l|l|l|l|l|l|l|l|l|c|}
\hline 90 & 91 & 92 & 93 & 94 & 95 & 96 & 97 & 98 & 99 & 100 & 101 & 102 & 103 \\
\hline Th & Pa & U & Np & Pu & Am & Cm & Bk & Cf & Es & Fm & Md & No & Lr \\
\hline
\end{tabular}

ASSSP

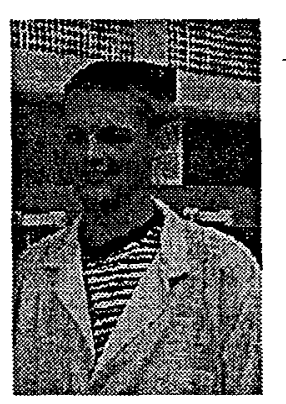

\section{Andy Boswell}

Background

Andy Boswell received a BS in chemistry from Tennessee Technological University in May 1998. He will pursue a $\mathrm{PhD}$ in bioorganic chemistry at Washington University in St. Louis beginning in August 1998. In 1997, Andy attended the DOE-funded ACS Summer School in Nuclear and Radiochemistry at San Jose State University. He has presented his undergraduate research involving computational protein chemistry at two national ACS meetings. He received one of only 20 National Meritorious Service awards from Phi Kappa Phi.

\section{Research Interests}

Radiopharmaceuticals and the use of radioactive nuclides in biomedical research.

\section{Summer LLNL. Project}

Andy worked with Pihong Zhao of the Chemistry \& Materials Science Directorate, Isotope Sciences Division on two research projects: one involving plutonium immobilization; the other related to the Yucca Mountain Project (YMP). In the Plutonium Immobilization Project (PIP) study, he measured the leaching rates of uranium, titanium, hafnium, cerium, and calcium out of a ceramic powder at various $\mathrm{pH}$ values. If found to be resistant to groundwater leaching, the ceramic may prove to be useful for incorporating plutonium into solid disks which can be sealed in metal canisters and buried in underground waste repositories. In the YMP-related study, Andy worked on determining whether or not iodide ion may be used as a tracer in core-flow experiments. To serve as a conservative tracer, iodide ion must not sorb onto the concrete proposed for use in the construction of the waste repository. Using a calibrated ion-selective electrode, Andy measured the iodide ion concentration before and after exposure to treated concrete, with the difference corresponding to the sorbed iodide ion. 


\begin{tabular}{|c|c|c|c|c|c|c|c|c|c|c|c|c|c|c|}
\hline 104 & 105 & 106 & 107 & 108 & 109 & 110 & 111 & 112 & $(113)$ & $(114)$ & $(115)$ & $(116)$ & $(117)$ & $(118)$ \\
Rf & Ha & Sg & Ns & Hs & Mt & & & & &
\end{tabular}

ASSSP

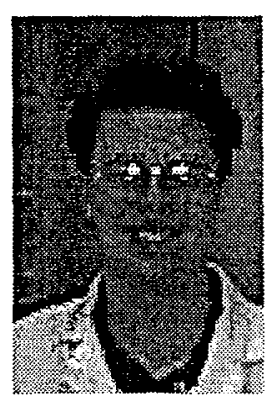

\section{Jeff Grell}

Background

Jeffrey S. Grell is a senior honor student majoring in chemistry at the University of California, Berkeley. Jeffrey was previously awarded one of 12 fellowships valued in excess of $\$ 10,000$ to attend the 1997 Summer School in Nuclear and Radiochemistry held at Brookhaven National Laboratory. Jeffrey was named the top student in the laboratory portion of the summer school and received an A grade for his work in the lecture portion.

\section{Research Interests}

Physical chemistry, studying spectral hole burning in the infrared; radiochemistry, to advance the application of analytical and physical chemical techniques to radioactive species; and nuclear chemistry.

\section{Summer LLNL Project}

Jeffrey's research project involves the isolation of niobium in the soil after a nuclear device has exploded. The primary environmental application is waste remediation and detection. The efficient procedures developed in this project will allow for rapid determination of niobium in the soil. This research will also expand current scientific knowledge due to its characterization of the low energy $X$ rays from the activated niobium. The niobium that is isolated can also be used to estimate the yield of the device. The isotopic ratios of niobium in the soil are altered after an explosion, because a nuclear device may contain a significant amount of niobium alloyed with uranium. An explosion causes the activation of natural $\mathrm{Nb}$-93. After dissolving the soil samples, a carrier-free separation method is used to produce a tracer solution. The separation involves coprecipitation of niobium, solvent extractions, and redox chemistry, with the goal of producing radiochemically pure niobium. 


\begin{tabular}{|c|c|c|c|c|c|c|c|c|c|c|c|c|c|}
\hline $\begin{array}{l}90 \\
\text { Th }\end{array}$ & $\begin{array}{l}91 \\
\mathrm{~Pa}_{2}\end{array}$ & $\begin{array}{c}92 \\
\mathrm{U}\end{array}$ & $\begin{array}{l}93 \\
N_{p}\end{array}$ & $\begin{array}{l}94 \\
\mathrm{Pu}\end{array}$ & $\begin{array}{l}95 \\
\text { Am }\end{array}$ & $\begin{array}{l}96 \\
\mathrm{Cm}\end{array}$ & $\begin{array}{l}97 \\
\mathrm{BK}\end{array}$ & 98 & 99 & $\begin{array}{c}100 \\
\mathrm{Fm}_{\mathrm{m}}\end{array}$ & $\begin{array}{l}101 \\
\text { Md }\end{array}$ & $\begin{array}{c}102 \\
\text { No }\end{array}$ & $\begin{array}{c}103 \\
\text { Lr }\end{array}$ \\
\hline
\end{tabular}

ASSSP

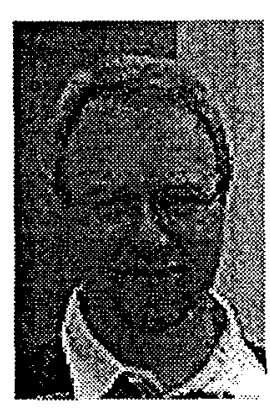

\section{Bill Huston}

Background

Bill Huston graduated from Saint Cloud State University in 1998 with a BS in physical science and secondary education. He has an extensive background in the nuclear field, having served in the United States Navy. At Saint Cloud State University, Bill was awarded the SCSU Excellence in Leadership Award. He has been a student affiliate member of the American Chemical Society since 1995 and has recently become involved with the Division of Nuclear Chemistry and Technology. He attended the 1997 ACS Summer School in Nuclear and Radiochemistry at San Jose State University, where he was named the Outstanding Student.

\section{Research Interests}

Nuclear chemistry with environmental applications, exploration of nuclear properties of elements, and nuclear forensics analysis.

\section{Summer LLNL Project}

In collaboration with staff scientists, Bill's project was to create a portable detection system that could be used to determine if a sample of uranium is depleted, natural, or enriched. The goals were to produce a detection kit that is portable and usable by law enforcement officials with no specialized training. The desired technique would take advantage of a colorimetric reaction to give a rough value for the total uranium concentration. This would then be coupled with an alpha count rate on a nomograph to provide an idea of the enrichment level. If this provided a result that was of concern, it would then be possible to use more sophisticated techniques in the laboratory to determine more information about the sample. 


\begin{tabular}{|c|c|c|c|c|c|c|c|c|c|c|c|c|c|c|}
\hline 104 & 105 & 106 & 107 & 108 & 109 & 110 & 111 & 112 & & & & & & \\
$\mathrm{Rf}$ & $\mathrm{Ha}$ & $\mathrm{Sg}$ & $\mathrm{Ns}$ & $\mathrm{Hs}$ & $\mathrm{Mt}$ & & & & $(113)$ & $(114)$ & $(115)$ & $(116)$ & $(117)$ & $(118)$ \\
\hline
\end{tabular}

ASSSP

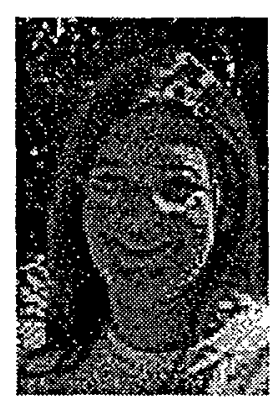

MEGAN LEICH

Background

Megan Leich graduated in May 1998 from Whitman College in Walla Walla, Washington with a BA in Chemistry and a minor in math. She was recently honored with a nomination to Phi Lambda Upsilon, a national chemistry honor society. In September, she will begin graduate school at the University of Oregon in physical chemistry. Megan was a participant in the NSF Research Experiences for Undergraduates (REU) program at Colorado State University in Fort Collins. There, under the guidance of Neil Mackie and Professor Ellen Fisher, she studied aldehyde retention in thin films deposited from pulsed benzaldehyde plasmas.

\section{Research Interests}

Laser spectroscopy, with particular interest in using lasers to investigate the properties of molecules at interfaces.

\section{Summer LLNL Project}

Megan has been studying the vibrational properties of actinide compounds using Raman and FTIR (infrared) spectroscopy. The emphasis has been on thorium compounds, but europium and uranium compounds were also studied. Megan and fellow summer student David Bao, under the supervision of Dave Wruck and Axel Brachmann of the Isotope Sciences Division, have taken the first Raman spectrum of one hydrate of thorium oxalate and have expanded on a published spectrum of another hydrate of thorium nitrate. Raman spectroscopy may one day be used for analysis of radioactive waste. If so, the availability of a database of peak assignments for possible waste components would aid in compound identification. 


\begin{tabular}{|c|c|c|c|c|c|c|c|c|c|c|c|c|c|}
\hline 90 & 91 & 92 & 93 & 94 & 95 & 96 & 97 & 98 & 99 & 100 & 101 & 102 & 103 \\
\hline Th & Pa & U & Np & Pu & Am & Cm & Bk & Cf & Es & Fm & Md & No & Lr \\
\hline
\end{tabular}

ASSSP

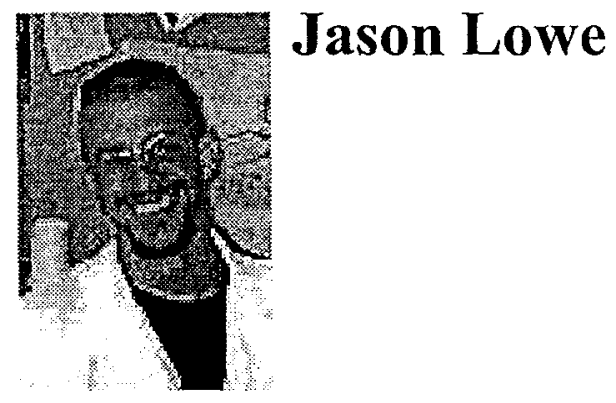

\section{Background}

Jason Lowe received a BA in chemistry and geology from the University of Rhode Island in May of 1998. He was awarded student of the year (1997) and held the office of undergraduate adviser to the Chemistry Department while maintaining a 3.46 GPA. Presently, Jason is in a master's degree program for organic synthesis at the University of Rhode Island and hopes to obtain his $\mathrm{PhD}$ in some aspect of chemistry following graduation. During the summer of 1997, Jason was selected to participate in the ACS Summer School in Nuclear and Radiochemistry in San Jose, California. Concurrently, he participated in the 1997 Pfizer Summer Fellowship Program, where he worked on a project involving natural products.

\section{Research Interests}

Natural products synthesis and other areas in the field of chemistry.

\section{Summer LLNL Project}

Metallic lead used in computer chips may contain significant amounts of $\mathrm{Pb}-210$. The problem with $\mathrm{Pb}-210$ is that it decays through $\mathrm{Bi}-210$ to $\mathrm{Po}-210$, an isotope (5.3 MeV alpha emitter) that induces "soft errors" in computer hard drives. Because there is no commercially available method to separate $\mathrm{Pb}-210$ from metallic lead, it is essential for the computer industry to know if the lead that is purchased for solder is of "low alpha" quality. Jason's research involves the isolation of Bi210 and Po-210 from lead samples. Once these values are known, it is possible to quantify the amount of $\mathrm{Pb}-210$ contained in the original sample, and thus, the suitability of the solder for use in computer chip manufacturing. Jason performed this research under the supervision of Brad Esser and Kevin Roberts of the Chemistry \& Materials Science Directorate, Isotope Sciences Division. 


\begin{tabular}{|c|c|c|c|c|c|c|c|c|c|c|c|c|c|c|}
\hline 104 & 105 & 106 & 107 & 108 & 109 & 110 & 111 & 112 & & & & & & \\
Rf & Ha & Sg & Ns & Hs & Mt & & & & $(113)$ & $(114)$ & $(115)$ & $(116$ & (117) & (118) \\
\hline
\end{tabular}

ASSSP

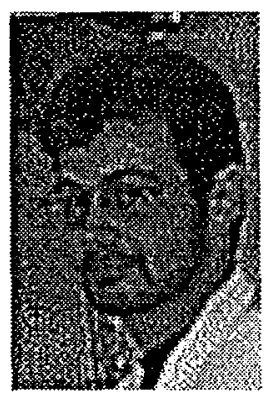

\section{David Schnepple}

\section{Background}

David is a senior at the University of Hawaii, Hilo, finishing his bachelor's degree in chemistry health sciences. He is a member of the Chemistry Society (student affiliates of the American Chemical Society). After graduation, David hopes to obtain a PhD in nuclear and/or organic chemistry. David was chosen for this inaugural Actinide Sciences Summer School Program due to his diverse scientific interests.

\section{Research Interests}

Electromedicine, nuclear chemistry, sonoluminescence; extraction of essential oils and the bioactivity of terpenoids, repair of mass spectrometers, and neurochemistry.

\section{Summer LLNL Project}

David's research project centered around plutonium chemistry, focusing on plutonium purification and separation methods as well as the production of specific isolated oxidation states. This research opportunity allowed him to work with plutonium in a glove box and to gain cxperience using sevcral spectroscopic techniques, such as alpha scintillation counting, direct alpha spectrometry using a solid-state detector, gamma spcctroscopy, and absorption spectroscopy of plutonium solutions. The primary objectivc was the preparation of pure plutonium in the +5 oxidation state. This was accomplished by first removing americium from the sample, before manipulating the oxidation state of the plutonium using a three-electrode cell. Products from this research will be used by other scientists to study the behavior of plutonium as it applies to nuclear storage and waste repositories (i.e., Yucca Mountain, WIPP). David's mentor is Kevin Roberts of the Chemistry \& Materials Science Directorate, Isotope Sciences Division. 


\begin{tabular}{|c|c|c|c|c|c|c|c|c|c|c|c|c|c|}
\hline 90 & 91 & 92 & 93 & 94 & 95 & 96 & 97 & 98 & 99 & 100 & 101 & 102 & 103 \\
Th & Pa & U & Np & Pu & Am & Cm & Bk & Cf & Es & Fm & Md & No & Lr \\
\hline
\end{tabular}

ASSSP

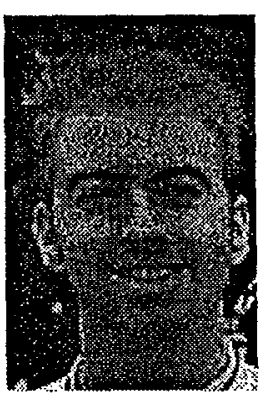

\section{Mark Sutton}

\section{Background}

Mark Sutton has a BSc (Hons) in Chemistry with emphasis on Analytical Chemistry, awarded in 1995 by Loughborough University of Technology, England. He is in the PhD program in the Environmental Radiochemistry Research Group at Loughborough University, headed by Dr. Peter Warwick. This PhD research sponsorship was awarded by British Nuclear Fuels plc (BNFL). On completion of his PhD in 1999, Mark hopes to return to the GTS-ITS at LLNL as a post-doctoral research associate performing research applicable to the Yucca Mountain Project. He is distinguished as the only foreign national student accepted into the GTS-ITS Actinide Sciences Summer School Program at LLNL.

\section{Research Interests}

Uranium solubility and speciation at high $\mathrm{pH}$, relevant to low-level nuclear waste disposal in theUnited Kingdom.

\section{Summer LLNL Project}

Mark is involved in both experimental and geochemical modeling investigations into the solubility of uranium at high $\mathrm{pH}$ through treated cement columns at room temperature. The work is part of a long-term assessment of the actinide source-term for nuclear waste disposal at the Yucca Mountain Site, Nevada. At high pH and in the presence of cementitious materials, uranium is expected to be removed from solution as hydrated oxides and uranate salts: an important factor in the retention of uranium inside the Yucca Mountain Site. This work is being done in collaboration with Cindy Palmer(Isotope Sciences Division) and Brian Viani (Geosciences \& Environmental Technologies) on research related to the Yucca Mountain Project. 


\begin{tabular}{|c|c|c|c|c|c|c|c|c|c|c|c|c|c|c|}
\hline 104 & 105 & 106 & 107 & 108 & 109 & 110 & 111 & 112 & & & & & & \\
Rf & $\mathrm{Ha}$ & $\mathrm{Sg}$ & $\mathrm{Ns}$ & $\mathrm{Hs}$ & $\mathrm{Mt}$ & & & & $(113)$ & $(114)$ & $(115)$ & $(116)$ & (117) & (118) \\
\hline
\end{tabular}
ASSSP 


\begin{tabular}{|l|l|l|l|l|l|l|l|l|l|l|l|l|l|}
\hline 90 & 91 & 92 & 93 & 94 & 95 & 96 & 97 & 98 & 99 & 100 & 101 & 102 & 103 \\
Th & Pa & U & Np & Pu & Am & Cm & Bk & Cf & Es & Fm & Md & No & Lr \\
\hline
\end{tabular}

PUBLICATIONS

\section{SECTION 5: PUBLICATIONS}

1. P. G. Allcn, D. K. Shuh, J. J. Bucher, N. M. Edelstein, T. Reich, M. A. Denecke, and H. Nitsche. Applications of Synchrotron Radiation to Chemical Issues in the Environmental Sciences, in Appl. of Synchrotron Radiation in Industrial, Chemical, and Materials Science, edited by K. D'Amico, L. Terininello, and D. K. Shuh, ACS Symposium Monograph; Plenum, New York, 169-186, 1996.

2. D. E. Morris, P. G. Allen, J. M. Berg, C. J. Chisolm-Brause, S. D. Conradson, R. J. Donohoe, N. J. Hess, J. A. Musgrave, and C. D. Tait . Speciation of Uranium in Fernald Soils by Molecular Spectroscopic Methods: Characterization of Untreated Soils, Environ. Sci \& Technol., 30, 2322-2331, 1996.

3. Polarized $x$-ray Absorption Spectroscopy of Uranyl: Comparison of Experiment and Theory. E. A. Hudson, P. G. Allen, L. J. Terminello, M. Denecke, T. Reich. Phys. Rev. B, 54, 1561996.

4. P.G. Allen, D. K. Veirs, S. D. Conradson, C. A. Smith, and S. F. Marsh. Characterization of Aqueous Pu (IV) Nitrate Complexes by Extended X-ray Absorption Fine Structure Spectroscopy, Inorganic Chemistry, 35, 2841-2845, 1996.

5. N. M. Edelstein, P. G. Allen, J. J. Bucher, D. K. Shuh, C. D. Sofield et al., The Oxidation State of Ce in the Sandwich Molecule Cerocene. J. Am. Chem. Soc. 118, 13115-13116, 1996.

6. P. G. Allen, D. K. Shuh, J. J. Bucher, N. M. Edelstein, C. E-A. Palmer, L. N. Marquez, E. A. Hudson, R. J. Silva, S. N. Nguyen. EXAFS Determinations of Uranium Structures: Schoepite and Other U(VI) Oxide Precipitates.. Radiochim. Acta, 75, 47-53, 1997.

7. P. G. Allen, D. K. Shuh, J. J. Bucher, N. M. Edelstein, C. E-A. Palmer, and L. N. Marquez.AXAFS Spectroscopic Studies of Uranium (VI) Oxide Precipitates Aqueous Chem. and Geochem. of Oxides and Oxyhydroxides, edited by J. A. Voigt et al. MRS Proc., Vol. 432, 139-143, 1996.

8. P. G. Allen, G. S. Siemering, D. K. Shuh, J. J. Bucher, N. M. Edelstein, C. A. Langton, S. B. Clark, T. Reich, and M. A. Denecke. Characterization of Technetium in Cement Waste Forms by X-ray Absorption Fine Structure Spectroscopy. Radiochim. Acta, 76, 77-86, 1997.

9. P. G. Allen, D. K. Shuh, J. J. Bucher, N. M. Edelstein, T. Reich, M. A. Denecke, and H. Nitsche. Chemical Speciation Studies of Radionuclides by XAFSXAFS-IX International Conference Proceeding, Grenoble, August, 1996. J. de Physique IV, 7, 789-792, 1997.

10. M. A. Denecke, T. Reich, S. Pompe, M. Bubner, P. G. Allen, D. K. Shuh, J. J. Bucher, and N. M. Edelstein. Differentiating between monodentate and bidentate carboxylate ligands coordinated to uranyl ions using EXAFS. XAFS-IX International Conference Proceeding, Grenoble, August, 1996. J. de Physique IV, 7, 637-638, 1997.

11. G. K. Marasinghe. M. Karabulut, C. S. Ray, D. E. Day, C. E. Booth, P. G. Allen, D. K. Shuh..Redox Characteristics and Structural Properties of Iron Phosphate Glasses: A Potential Host Matrix for Vitrifying High Level Nuclear Waste. Ceramic Transactions, 87, 261, 1998.

12. C. S. Ray, D. E. Day, M. G. Shumsky, W. B. Yelon, C. E. Booth, P. G. Allen, and D. K. Shuh. Structural Features of Iron Phosphate Glasses. G. K. Marasinghe. M. Karabulut, Journal of Noncrystalline Solids, V222, 144-152, 1997.

13. P. G. Allen, D. K. Shuh, J. J. Bucher, N. M. Edelstein, and T. Reich Investigation of Aquo and Chloro Complexes of $\mathrm{UO} 22+, \mathrm{NpO}+, \mathrm{Np} 4+$, and Pu3+ by X-ray Absorption Fine Structure Spectroscopy. Inorganic Chemistry, 36, 4676-4683, 1997. 


\begin{tabular}{|c|c|c|c|c|c|c|c|c|c|c|c|c|c|c|}
\hline 104 & 105 & 106 & 107 & 108 & 109 & 110 & 111 & 112 & (113) & $(114)$ & $(115)$ & $(116)$ & $(117)$ & $(118)$ \\
\hline Rf & $\mathrm{Ha}$ & $\mathrm{S}_{8}$ & $\mathrm{~N} 8$ & $\mathrm{Hs}$ & $\mathrm{Mt}$ & & & & &
\end{tabular}

\section{PUBLICATIONS}

14. L. Fabris, P. G. Allen, J. J. Bucher, N. M. Edelstein, D. A. Landis, N. W. Madden, and D. K. Shuh . A Fast Zero Dead-Time Single Channel Analyzer for Nuclear Spectroscopy Applications. Submitted to IEEE Conference April 1998.

15. L. Fabris, P. G. Allen, J. J. Bucher, N. M. Edelstein, D. A. Landis, N. W. Madden, and D. K. Shuh Fast Peak Detector Stretchers for Use in XAFS Applications. Sub. to IEEE Conference April 1998.

16. P.W. Durbin, B. Kullgren, J. Xu, K.N. Raymond, P.G. Allen, J.J. Bucher, N.M. Edelstein, and D.K. Shuh. Neptunium(237): Oxidation State In Vivo and Chelation by Multidentate Catecholate and Hydroxypyridinonate LigandsHealth Physics, 75, 34-50, 1998.

17. X. Feng, H. Li, J. G. Darab, M. J. Schweiger, J. D. Vienna, B. C. Bunker, P. G. Allen, D. K. Shuh, J. J. Bucher, N. M. Edelstein, R. C. Ewing, and L. M. Wang. Distribution and Solubility of Radionuclides in Waste Forms for Disposition of Pu and Spent Nuclear Fuels Int'l. Symp. On Waste Mgmt. Tech., American Ceramic Society National Meeting, Cincinnati, OH, May 1998.

18. M. A. Denecke, T. Reich, S. Pompe, M. Bubner, K. H. Heise, P. G. Allen, D. K. Shuh, J. J. Bucher, N. M. Edelstein. Determination of Structural Parameters of Uranyl Ions Complexed with Organic Acids Using EXAFS.. J. Alloys and Compounds, 271, 123-127, 1998.

19. W. W. Lukens, P. G. Allen, J. J. Bucher, N. M. Edelstein, E. A. Hudson, N. Kaltsoyannis, T. Reich, D. K. Shuh, and R. A. Andersen. Structures of Substituted Cyclopentadienyl Uranium (III) Dimers and Related Uranium Metallocenes Deduced by EXAFS, submitted June (1998).

20. . K. Marasinghe, M. Karabulut, C. S. Ray, D. E. Day, P. G. Allen, J. J. Bucher, N. M. Edelstein, Y. Badyl, M. L. Saboungi, M. Effects of Nuclear Waste Components on Selected Properties of Iron Phosphate GlassesGrimsditch, S. Shastri, and D. Heaffner, American Ceramic Society Proceedings, submitted June (1998).

21. C. E. Booth, P. G. Allen, D. K. Shuh. J. J. bucher, G. K. Marasinghe. M. Karabulut, C. S. Ray, D. E. Day Oxygen and Phosphorus Coordination Around Iron in Iron-Phosphate Glasses with UO2 or $\mathrm{Na} 2 \mathrm{O}$ and Crystalline Ferric Ferrous Pyrophophate, submitted to J. Mater. Research, Aug. 1998.

22. E. A. Hudson, L. J. Terminello, B. E. Vianni, M. Denecke, T. Reich, P. G. Allen, J. J. Bucher, and D. K. Shuh . The Structure of Uranium(VI) Sorption Complexes on Vermiculite and Hydrobiotite.. Submitted to Clay and Clay Minerals, June 1998.

23. S. Wasserman, P. G. Allen, N. M. Edelstein. EXAFS and Principal Component Analysis: A New Shell Game., submitted to J. of Synchrotron Rad. Sept., 1998.

24. Udeni R., Sherril D. Christian, Edwin E. Tucker, Richard W. Taylor and John F. Scamehorn "Removal of Uranyl Ions from Nuclear Waste by Ligand-Modified Polyelectrolyte Enhanced Ultrafiltration Using Carbonate Ligand," in preparation.

25. Ruthenium and Osmium, Li Chen; Geun-Bae Yi; Li-Sheng Wang; Udeni R. Dharmawardana; Amelia C. Dart; Masood A. Khan and George B. Richter-Addo. "Synthesis, Characterization, and Molecular Structure of DiethyInitrosamine Metalloporphyrin Complexes of Iron," Inorg. Chem., Submitted.

26. Udeni R. Dharmawardana; Sherril D. Christian; Edwin E. Tucker; Richard W. Taylor; John F. Scamehorn. "A Surface Tension Method to Determine Binding Constants of Inclusion Complexes of b-cyclodextrin With Surfactants," Langmuir, 2258, 9, 1993.

27. Udeni R. Dharmawardana; Sherril D. Christian; Richard W. Taylor; John F. Scamehorn. "An Equilibrium Model for the Ligand Modified Micellar Enhanced Ultrafiltration process Using a Water insoluble Ligand," Langmuir, 414, 8, 1992. 


\begin{tabular}{|c|c|c|c|c|c|c|c|c|c|c|c|c|c|}
\hline 90 & 91 & 92 & 93 & 94 & 95 & 96 & 97 & 98 & 99 & 100 & 101 & 102 & 103 \\
Th & Pa & U & Np & Pu & Am & Cm & Bk & Cf & Es & Fm & Md & No & Lr \\
\hline
\end{tabular}

PUBLICATIONS

28. G.F. Novak, I. Al Mahamid, K. Becraft, S. Carpenter, N.Hakem and T. Prussin, "Measurement and Thermodynamic Modelling of $\mathrm{Np}(\mathrm{V})$ Solubility in Aqueous $\mathrm{K} 2 \mathrm{CO} 3$ Solutions to High Concentrations", Journal of Solution Chemistry, Vol 26, No 7, (1997).

29. Al Mahamid, G.F. Novak, K. Becraft, S. Carpenter, N.Hakem, " Solubility of Np(V) in K-Cl-CO3 and Na-K-Cl-CO3 Solutions to High Concentrations: Measurements and Thermodynamic Model Predictions, Radiochimica Acta, 81, (1998).

30. N. Hakcm, I. Al Mahamid, J. Apps and G. Moridis, "Sorption of Cesium and Strontium on Savannah River Soil Impregnated with Colloidal Silica", Lawrence Berkeley National Laboratory Report, LBNL39498, UC-600 (1997).

31. C. S. Nash and B. E. Bursten"Spin-Orbit Coupling vs. the VSEPR Method: On the Possibility of a Nonplanar Structure for the Superheavy Noble-Gas Tetrafluoride [118]F4." Angewandte Chimie. (38) 151 (1999)

32. Clinton S. Nash and Bruce E. Bursten. "Spin-Orbit Effects, VSEPR Theory, and the Electronic Structures of Heavy and Superheavy Group IVA Hydrides and Group VIIIA Tetrafluorides. A Partial Role Reversal for Elements 114 and 118." J. Phys. Chem A. 103, 402-10, 1999.

33. Nash, C.S., "Spin-Orbit Effects on the Electronic Structure of Heavy and Superheavy Hydrogen Halides: Prediction of an Anomalously Strong Bond in H[117]." J. Phys. Chem. A., 103, 632-6, 1999

34. C.S. Nash, B. E. Bursten, and W. C. Ermler "Ab Initio Relativistic Effective Core Potentials with SpinOrbit Operators VII. Am-Element 118." Journal of Chemical Physics, 106, 5133-5142 (1997).

35. C. S. Nash and B. E. Bursten"Comparisons among transition metal, actinide, and transactinide complexes: The relativistic electronic structures of $\mathrm{Cr}(\mathrm{CO}) 6, \mathrm{~W}(\mathrm{CO}) 6, \mathrm{U}(\mathrm{CO}) 6$; and $\mathrm{Sg}(\mathrm{CO}) 6$." New J. Chem, 19, 669-675 (1995).

36. Clinton S. Nash and Bruce E. Bursten"Comparisons among Heavy and Superheavy Group VI Transition Metal Carbonyls: A Theoretical Investigation of $\mathrm{Mo}(\mathrm{CO}) 6, \mathrm{~W}(\mathrm{CO}) 6$, and $\mathrm{Sg}(\mathrm{CO}) 6 . "$ manuscript in preparation (preprint available upon request.

37. V.V. Romanovski, D.J. White, Jide Xu, D.C. Hoffman, and K.N. Raymond, "Plutonium(IV) and Plutonium(VI) Extraction by 1-hydroxy-6-N-octylcarboxamide-2(1H)-pyridinone," Accepted for publication in Solvent Extraction and Ion Exchange, 1999, V. 17, 1.

38. M.A. Afonin, V.V. Romanovski, and V.A. Scherbakov, "Oscillatory Extraction of Uranium," Solvent Extraction and Ion Exchange, 1998, V. 16, _ 5, pp. 1215-1231.

39. P. Zhao, V.V. Romanovski, D.W. Whisenhunt Jr., T. R. Mohs, Jide Xu, D.C. Hoffman, K.N. Raymond, "Extraction of Plutonium by Chelating Hydroxypyridinone and Catecholamide resins," Submitted to Solvent Extraction and Ion Exchange.

40. D.C. Hoffman, V.V. Romanovski, A.C. Veeck, P. Zhao. 1997. "Evaluation and Testing of Sequestering Agents for Removal of Actinides from Waste Streams." In Proc. of the Efficient Separation and Processing Cross-Cutting Program 1997 Technical Exchange Meeting, January 28-30, 1997, pp. 2.21-2.24, Gaithersburg, Maryland.

41. Vadim Romanovski, 1998. "Evaluation and Testing of Sequestering Agents for Removal of Actinides from Waste Streams." In Proc. of the Annual Technical Exchange Meeting of the Efficient Separation and Processing Cross-Cutting Program, March 17-19, 1998, pp. 91-96, Augusta, Georgia.

42. D.W. Whisenhunt Jr., V.V. Romanovski, A.C. Veeck, W.A. Andersen, K.N. Raymond, D.C. Hoffman, "Specific Sequestering Agents for the Actinides 30. Synthesis and Evaluation of Solid-Support Actinide Sequestering Agents," Manuscript in preparation. 


\begin{tabular}{|c|c|c|c|c|c|c|c|c|c|c|c|c|c|c|}
\hline 104 & 105 & 106 & 107 & 108 & 109 & 110 & 111 & 112 & $(113)$ & $(116)$ & $(115)$ & $(116)$ & $(117)$ & $(118)$ \\
Rf & $\mathrm{Ha}$ & $\mathrm{Sg}$ & $\mathrm{Ng}$ & $\mathrm{Hs}$ & $\mathrm{Mt}$ & & & & & \\
\hline
\end{tabular}

\section{PUBLICATIONS}

43. A.C. Veeck, D.J. White, D.W. Whisenhunt Jr., Jide Xu, V.V. Romanovski, D.C. Hoffman, K.N. Raymond, "Synthesis and Characterization of Hydroxypyridinone Liquid/Liquid Extractants for Pu(IV)," Submitted to Solvent Extraction and Ion Exchange.

44. "Evaluation and Testing of Sequestering Agents for Removal of Actinides from Waste Streams," Project Summary in the book "Decontamination and Decommissioning Focus Area, Quarterly Report 1997"

45. T.R. Mohs, J.Xu, K.N. Raymond, V.V. Romanovski, P. Zhao and D.C. Hoffman, "Ligands and Extractants for the Separation and Immobilization of Actinide Ions," 214th ACS National Meeting, Las Vegas, NV, September, 1997.

46. V.V. Romanovski, P. Zhao, D.C. Hoffman, D.W. Whisenhunt Jr., D. White, X. Jide, K.N. Raymond. 1997. "Pu sorption and extraction by the 1,2-hydroxypyridinone based agents." In Proc. of the Plutonium Futures - The Science, Topical Conference on Plutonium and Actinides, August 25-27, 1997, pp.247248, Santa Fe, New Mexico,USA.

47. P. Zhao, V.V. Romanovski, D.C. Hoffman, C.E.A. Palmer, D.W. Whisenhunt Jr., P.G. Allen, D.K. Shuh, J.J. Butcher, N.M. Edelstein, D. J. White, X. Jide, K.N. Raymond. 1997. "Spectroscopic Study of Chelation between $\mathrm{Pu}$ and Modified Siderophores." In Proc. of the Plutonium Futures - The Science, Topical Conference on Plutonium and Actinides, August 25-27, 1997, pp. 73-75, Santa Fe, New Mexico,USA.

48. T.R. Mohs, V.V. Romanovski, A.C. Veek, D.J. White, J.Xu, K.N. Raymond and D.C. Hoffman, "The Transition from Natural Complexing Agents to Actinide Specific Sequestering Agents," Oral Presentation, 213th ACS National Meeting, San Francisco, CA, April, 1997.

49. Pihong Zhao, Vadim V. Romanovski, Donald W. Whisenhunt Jr., Darleane C. Hoffman, Thomas R. Mohs, Jide Xu, Kenneth N. Raymond, "Extraction of Plutonium by Chelating Hydroxypyridinone and Catecholamide Resins." Accepted for Publication in Solvent Extraction and Ion Exchange.

50. Pihong Zhao, Silvio Rodriguez "Fluorescence Spectroscopic Studies on the Multicomponet System Coumarin 1/Fluorescein/Rhodamine B in Ethanol." J. Fluorescence 7(2), 121-130, 1997.

51. Pihong Zhao, Steven A. Steward, "Literature Review of Intrinsic Actinide Colloids Related to Spent Fuel Waste Package Release Rates." LLNL Report, UCRL-ID-126039, Jan. 1997.

52. David A. Wruck, Pihong Zhao, Cynthia E. A. Palmer, Robert J. Silva "Stability of Quotients of Neodymium Acetate Complexes from 20 to $70 \propto \mathrm{C}$ by Laser-Induced Photoacoustic Spectroscopy." J. Solution Chemistry 26(3), 267-275, 1997.

53. Pihong Zhao, Cynthia E. A. Palmer, Robert J. Silva "Formation and Stability of Plutonium(IV) Colloids in Sodium Chloride Solutions." Manuscript in preparation.

54. Brian E. Viani, Pihong Zhao, Pill C. Torretto and Sara L. Matzen "Models of Transport in the Near Field and Altered Zone." YMP Milestone Report (1998). 


\begin{tabular}{|c|c|c|c|c|c|c|c|c|c|c|c|c|c|}
\hline 90 & 91 & 92 & 93 & 94 & 95 & 96 & 97 & 98 & 99 & 100 & 101 & 102 & 103 \\
Th & Pa & U & Np & Pu & Am & Cm & Bk & Cf & Es & Fm & Md & No & Lr \\
\hline
\end{tabular}

PRESENTATIONS

\section{SECTION 6: PRESENTATIONS}

1. Poster-"The Effects of $\mathrm{Na} 2 \mathrm{O}, \mathrm{Al} 2 \mathrm{O} 3$, and $\mathrm{B} 2 \mathrm{O} 3$ on HFO-2 Solubility in Borosilicate Glass," L.L. Davis, L. Li, X. Feng, J.G. Darab, M. Qian, and H. Li; P.G. Allen, J.J. Bucher, I.M. Craig, N.M. Edelstein, and D.K. Shuh, poster at Materials Research Society Symposium QQ, Boston, Dec. 1998.

2. Poster- "Research Program to Investigate the Fundamental Chemistry of Technetium,". N.M. Edelstein, D.K. Shuh, P.G. Allen, J.J. Bucher, and C. Burns. DOE EMSP Scientific Workshop, Hyatt Regency O’Harc, Chicago, July 1998.

3. Poster- "An Alternative Host Matrix Based on Iron Phosphate Glasses for the Vitrification of Specialized Nuclear Waste Form,". G. K. Marasinghe. M. Karabulut, C. S. Ray, D. E. Day, M. G. Shumsky, W. B. Yelon, C. E. Booth, P. G. Allen, and D. K. Shuh. DOE EMSP Scientific Workshop, Hyatt Regency O'Hare, Chicago, July 1998.

4. Poster- "Extraction and Recovery of Mercury and Lead from Aqueous Waste Streams Using Redoxactive Layered Metal Chalcogenides," P. K. Dorhout, S. H. Strauss, A. E. Gash, L. M. Dysleski, C. J. Flashenreim, and P. G. Allen. DOE EMSP Scientific Workshop, Hyatt Regency O'Hare, Chicago, July 1998.

5. Poster-"Distribution and Solubility of Radionuclides and Neutron Absorbers in Waste Forms for Disposition of Pu and Spent Nuclear Fuels," X. Feng, H. Li, J. G. Darab, M. J. Schweiger, J. D. Vienna, B. C. Bunker, P. G. Allen, D. K. Shuh, J. J. Bucher, N. M. Edelstein, R. C. Ewing, and L. M. Wang. DOE EMSP Scientific Workshop, Hyatt Regency O'Hare, Chicago, July 1998.

6. Poster-"Speciation and Solubilites of Radionuclides in Waste Forms," D. K. Shuh, P. G. Allen, J. J. Bucher, I.M. Craig, N. M. Edelstein, X. Feng, J. D. Vienna, J. G. Darab, H. Li, J. Liu, B. C. Bunker, R. C. Ewing, and E. R. Vance, poster, XAFS-X, Chicago, IL, Aug. 1998.

7. Poster- "Coordination Chemistry of Trivalent Lanthanides and Actinides in Concentrated Chloride Solutions," P. G. Allen, J. J. Bucher, N. M. Edelstein, and D. K. Shuh, poster, XAFS-X, Chicago, IL, Aug. 1998.

8. Poster- "Speciation of Plutonium and Cerium in Wasteform Materials By XAFS," P. G. Allen, J. J. Bucher, N. M. Edelstein, D. K. Shuh, W. Bourcier, h. Shaw, R. Vankonynenburg, J. G. Darab, H. Li, M. J. Schweiger, J. D. Vienna. Actinides'97 International Conference. Baden-Baden, Germany, September 1997. Poster presentation. (also SSRL '97)

9. Poster-"Redox of Plutonium and Cerium in Vitrified Wastes," J. G. Darab, H. Li, M. J. Schweiger, J. D. Vienna, P. G. Allen, D. K. Shuh, J. J. Bucher, N. M. Edelstein. Plutonium Futures Conference, Santa Fe, NM. August 1997.

10. Poster-" Actinide and Fission Product Ion Speciation by XAS," P. G. Allen, J. J. Bucher, N. M. Edelstein, D. K. Shuh. SSRL 23rd Annual Users Conference, October, 1996. Poster presentation.

11. Invited-"Experimental Procedures and Safety Considerations for Transuranic Studies at the Stanford Synchrotron Radiation Laboratory," P. G. Allen, D. K. Shuh, J. J. Bucher, N. M. Edelstein, and T. Reich. Euro-Conference and NEA Workshop on Speciation, Techniques, and Facilities for Radioactive Materials at Synchrotron Light Sources, Grenoble France, Oct. 1998.

12. Invited- "Investigation of Aquo and Chloro Complexes of $\mathrm{UO} 22+, \mathrm{NpO} 2+, \mathrm{Np4+}$, and $\mathrm{Pu} 3+$ by $\mathrm{X}$-ray Absorption Fine Structure Spectroscopy," P. G. Allen, D. K. Shuh, J. J. Bucher, N. M. Edelstein, and T. Reich. Presentation given at FZR, Institute of Radiochemistry. Dresden, Germany, September 28, 1997. 


\begin{tabular}{|c|c|c|c|c|c|c|c|c|c|c|c|c|c|c|}
\hline 104 & 105 & 106 & 107 & 108 & 109 & 110 & 111 & 112 & $(113)$ & $(114)$ & $(115)$ & $(116)$ & (117) & (118) \\
\hline Rf & $\mathrm{Ha}$ & $\mathrm{Sg}_{\mathrm{g}}$ & $\mathrm{Ns}$ & $\mathrm{Hs}$ & $\mathrm{Mt}$ & & & & & &
\end{tabular}

\section{PRESENTATIONS}

13. Invited- "Chemical Speciation Studies of Radionuclides by XAFS," P. G. Allen, D. K. Shuh, J. J. Bucher, N. M. Edelstein. Presentation given at Forschungzentrum Rossendorf, Institute of Radiochemistry. Dresden, Germany, September 13, 1996.

14. "Applications of XAFS Spectroscopy to Speciation Problems in Environmental Radiochemistry," P. G. Allen, D. K. Shuh, J. J. Bucher, N. M. Edelstein, and T. Reich. Euro-Conference and NEA Workshop on Speciation, Techniques, and Facilities for Radioactive Materials at Synchrotron Light Sources, Grenoble France, Oct. 1998.

15. "Chloride Complexation of Aqueous Trivalent Actinide Ion," P. G. Allen, J. J. Bucher, N. M. Edelstein, and D. K. Shuh, ACS Meetings, Boston and San Francisco, Aug. 1998.

16. "X-ray Absorption Spectroscopy $\Lambda$ nalysis of Selenium Fate and Biotransformation in Microbial Cultures," M. Adamkiewicz, B. B. Buchanan, T. Leighton, P.G. Allen, J.J. Bucher, N.M. Edelstein, D.K. Shuh, I. Pickering, and R. Prince. American Society for Microbiology, Atlanta, May 1998.

17. "Recyclable Soft Heavy-metal Specific Ion Sorbants: Alkali Metal-Ion Intercalated Metal Chalcogenides." P. K. Dorhout, S. H. Strauss, A. E. Gash, L. M. Dysleski, C. J. Flashenreim, and P. G. Allen. ACS National Meeting, Dallas TX, April 1998.

18. "Solution Structures of Actinide Coordination Complexes by XAFS." P.G. Allen, J.J. Bucher, N.M. Edelstein, and D.K. Shun, Materials Research Society Symposium V, San Francisco, April 1998.

19. "An XAFS Investigation of the Formation of Actinide Aquo and Chloro Complexes." P. G. Allen, D. K. Shuh, J. J. Bucher, N. M. Edelstein, and T. Reich. American Chemical Society National Meeting, Las Vegas, NV, September 1997.

20. "X-ray Absorption Fine Structure Studies of Tc Speciation in Cements," P. G. Allen, D. K. Shuh, J. J. Bucher, and N. M. Edelstein. Workshop on Long-Lived Radionuclide Chemistry in Nuclear Waste Treatment. Villeneuve-les-Avignon, France, June 1997.

21. "Determination of Structural Parameters of Uranyl Ions Complexed with Organic Acids by EXAFS," M. A. Denecke, T. Reich, S. Pompe, M. Bubner, K. H. Heise, P. G. Allen, D. K. Shuh, J. J. Bucher, N. M. Edelstein. Actinides'97 International Conference. Baden-Baden, Germany, September 1997.

22. "X-ray Absorption Fine Structure of Actinides in Concentrated Electrolytes," P. G. Allen, D. K. Shuh, J. J. Bucher, N. M. Edelstein, T. Reich, M. A. Denecke, and H. Nitsche. Actinides'97 International Conference. Baden-Baden, Germany, September 1997. (also SSRL '97)

23. "Spectroscopic Study of Chelation Between Pu and Modified Siderophores," P. Zhao, V. V. Romanovski, D. C. Hoffman, C. E. A. Palmer, D. W. Whisenhunt Jr., P. G. Allen, D. K. Shuh, J. J. Bucher, N. M. Edelstein, D. J. White, J. Xu, and K. N. Raymond. Plutonium Futures Conference, Santa $\mathrm{Fe}, \mathrm{NM}$. August 1997.

24. "Application of Element and Species Specific X-ray Absorption Spectroscopy to Radionuclide Characterization," P. G. Allen, J. J. Bucher, N. M. Edelstein, D. K. Shuh. ACS Symposium on Separations for Ground Water and Surface Water Remediation, April, 1997.

25. "Chemical Speciation Studies of Radionuclides by XAFS," P. G. Allen, D. K. Shuh, J. J. Bucher, N. M. Edelstein, T. Reich, M. A. Denecke, and H. Nitsche. XAFS-IX International Conference on X-ray Absorption Spectroscopy. Grenoble, August, 1996.

26. "XAFS Structural Characterizations of Uranium (VI) Oxyhydroxides Precipitated from Sodium Sulfate Brines," P. G. Allen, D. K. Shuh, J. J. Bucher, and N. M. Edelstein. Materials Research Society Spring Meeting, San Francisco, April, 1996. 


\begin{tabular}{|c|c|c|c|c|c|c|c|c|c|c|c|c|c|}
\hline 90 & 91 & 92 & 93 & 94 & 95 & 96 & 97 & 98 & 99 & 100 & 101 & 102 & 103 \\
Th & $\mathrm{Pa}_{2}$ & $\mathrm{U}$ & $\mathrm{Np}$ & $\mathrm{Pu}$ & $\mathrm{Am}$ & $\mathrm{Cm}$ & $\mathrm{Bk}$ & $\mathrm{Cf}$ & $\mathrm{Es}$ & $\mathrm{Fm}$ & $\mathrm{Md}$ & $\mathrm{No}$ & $\mathrm{Lr}$ \\
\hline
\end{tabular}

PRESENTATIONS

27. Oral- "Removal of Uranyl Ions from Nuclear Waste by Ligand-Modified Polyelectrolyte Enhanced Ultrafiltration Using 1,2-Dihydroxy-3,5-benzenedisulfonic Acid Ligand," Udeni R. Dharmawardana, Sherril D. Christian, Edwin E. Tucker, Richard W. Taylor, John F. Scamehorn, Cindy E. A. Palmer and Darleane C. Hoffman, American Chemical Society Annual Meetings March 1999, Anheim California accepted.

28. Oral - "Selective Separation of Copper Ions from Waste Streams Using Iminoacetic Localized Polyamines", Udeni R. Dharmawardana Quarterly Progress Meeting of Institute of Applied Surfactant Research, University of Oklahoma, Norman, Oklahoma, 1991 December.

29. Poster-"Ligand-Modified Polyelectrolyte Enhanced Ultrafiltration: Use of Carbonate and 1,2-Dihydroxy3,5-benzenedisulfonic Acid to Remove UO2+ from Aqueous Solutions," Udeni R. Dharmawardana, Sherril D. Christian, Edwin E. Tucker, Richard W. Taylor, John F. Scamehorn, Poster Presentation Department of Energy, EMSP workshop, Chicago, Illinois, 1998.

30. Poster- " Radionuclides Diffusion through Savannah River Soil Impregnated or not with Colloidal Silica", 8- N.Hakem, G. Moridis, J. Apps , I. Al Mahamid and S. Borglin . 4th International Symposium on Environmental Geothechnology and Global Sustainable Development, Boston (Danvers), Massachusetts, (August 1998).

31. Oral- "The Theoretical Chemistry of the Transactinide Elements". Clinton Nash, delivered at The University of the Pacific, March 1999

32. Oral- "Spin-Orbit Effects, VSEPR Theory, and the Electronic Structures of Heavy and Superheavy Group IVA Hydrides and Group VIIIA Tetrafluorides: A Partial Role Reversal for Elements 114 and 118."delivered at Western Regional ACS Meeting, October 1998

33. Oral- "Einstein in the Periodic Table." Clinton Nash, delivered at Western Regional ACS Meeting, October, 1998.

34. Poster- . "Pu sorption and extraction by the 1,2-hydroxypyridinone based agents." V.V. Romanovski, P. Zhao, D.C. Hoffman, D.W. Whisenhunt Jr., D. White, X. Jide, K.N. Raymond. 1997 In Proc. of the Plutonium Futures - The Science, Topical Conference on Plutonium and Actinides, August 25-27, 1997, pp.247-248, Santa Fe, New Mexicu,USA.

35. Oral- "Evaluation and Testing of Sequestering Agents for Removal of Actinides from Waste Streams," the Annual Technical Exchange Meeting of the Efficient Separation and Processing Cross-Cutting Program, March 17-19, 1998, Augusta, Georgia.

36. Oral - "Evaluation and Testing of Sequestering Agents for Removal of Actinides from Waste Streams," the Efficient Separation and Processing Cross-Cutting Program 1997 Technical Exchange Meeting, January 28-30, 1997, Gaithersburg, Maryland.

37. Oral- "Pu Sorption and Extraction by the 1,2-Hydroxypyridinone based Agents." Vadim V. Romanovski, Pihong Zhao, Darleane C. Hoffman, Donald W. Whisenhunt Jr., David White, Jide Xu, Kenneth N. Raymond In Proc. of the Plutonium Futures-The Science, Topical Conference on Plutonium and Actinides, Santa Fe, NM, Aug. 25-27, 1997, pp247-248.

38. Oral- "Spcctroscopic Study of Chelation betwcen Pu and Modified Siderophores." Pihong Zhao, Vadim V. Romanovski, Darleane C. Hoffman, Cynthia E. A. Palmer, Donald W. Whisenhunt Jr., Patric G. Allen, David K. Shuh, Jerome J. Butcher, Norman M. Edelstain, Jide Xu, Kenncth N. Raymond. In Proc. of the Plutonium Futures-The Science, Topical Conference on Plutonium and Actinides, Santa Fe, NM, Aug. 25-27, 1997, pp73 75. 


\begin{tabular}{|c|c|c|c|c|c|c|c|c|c|c|c|c|c|c|}
\hline $\begin{array}{c}104 \\
\text { Rf }\end{array}$ & $\begin{array}{c}105 \\
\mathrm{Ha}\end{array}$ & 106 & $\begin{array}{c}107 \\
N_{s}\end{array}$ & $\begin{array}{c}108 \\
\mathrm{H}\end{array}$ & $\begin{array}{l}109 \\
\mathrm{Mt}\end{array}$ & 110 & 111 & 112 & (113) & (114) & (115) & (116) & (117) & (118) \\
\hline
\end{tabular}

\section{PRESENTATIONS}

39. Oral- "Ligands and Extractants for the Separation and Immobilization of Actinide Ions." Thomas R. Mohs, Jide Xu, Kenneth N. Raymond, Vadim V. Romanovski, Pihong Zhao, Darleane C. Hoffman ; 214th ACS National Meeting, Las Vegas, NV, Sep. 1997.

40. Oral- Zhao "Evaluation and Testing of Sequestering Agents for Removal of Actinides form Waste Streams." Darleane C. Hoffman, Vadim V. Romanovski, Allen C. Veeck, Pihong In Proc. of the Efficient Separation and Processing Cross-Cutting Program Technical Exchange Meeting, Richland, Washington, Jan. 28-30, 1997, pp2.21-2.24, PNNL-SA-28461, Pacific Northwest National Laboratory, (1997).

41. Oral- "Dissolution Testing and Modeling of Ceramic Waste Forms for Fissile Materials Disposition." William L. Bourcier, Pihong Zhao, Bradley K. Esser 215th ACS National Meeting, Dallas TX, March 1998.

42. Oral- "Dissolution Testing and Modeling of Titanate-Based Ceramic Waste Forms for Fissile Materials Disposition." William L. Bourcier, Pihong Zhao, Bradley K. Esser, ANS 3rd Topical Meeting on DOE Spent Nuclear Fuel and Fissile Materials Management, Charleston, SC, Sep. 8-11, 1998.

43. Oral- "Studies on Chelating Reactions between Plutonium and Siderophore-Based Resins." Pihong Zhao, Vadim V. Romanovski, Darleane C. Hoffman, Cynthia E. A. Palmer, Donald W. Whisenhunt Jr., Patric G. Allen, David K. Shuh, Jerom J. Bucher, Norman M. Edelstein, Thomas R. Mohs, David J. White, Jide Xu, Kenneth N. Raymond ; 34th ACS Western Regional Meeting, San Francisco, CA, Oct. 28-31,1998. 